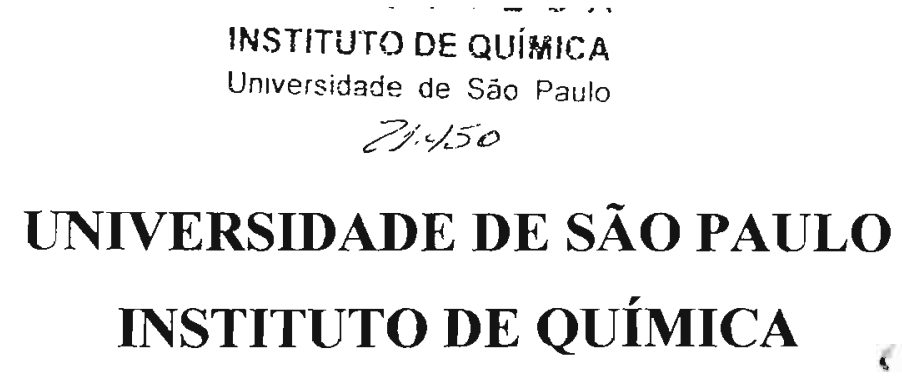

\title{
AVALIAÇÃO DE ELEMENTOS POTENCIALMENTE TóXICOS EM TINTAS
}

MARIA DA ROSA CAPRI

ORIENTADORA: PROF ${ }^{a}$. DRA. ELISABETH DE OLIVEIRA 


\section{"Avaliação de elementos potencialmente tóxicos em tintas"}

\section{MARIA DA ROSA CAPRI}

Tese de Doutorado submetida ao Instituto de Química da Universidade de São Paulo como parte dos requisitos necessários à obtenção do grau de Doutor em Química - Área: Química Analítica.

Aprovado(a) por:

\begin{tabular}{c}
$\begin{array}{c}\text { Profa. Dra. El.ISABETH DE OLIVEIRA } \\
\text { (Orientadora e Presidente) }\end{array}$ \\
\hline Prof. Dr. PEDRO VITORIANO DE OLIVEIRA \\
IQ - USP \\
\hline Profa. Dra. PÉROLA DE CASTRO VASCONCELLOS \\
IQ - USP \\
Profa. Dra. SOLANGE CADORE \\
IQ - UNICAMP \\
Prof. Dr. JOAQUIM DE ARAÚJO NÓBREGA \\
UFSCar \\
SÃO PAULO \\
O1 DE DEZEMBRO 2005
\end{tabular}


B BLIOTECA HMSTUTO DE QUIMICA Unversidata de São Paulo

\section{À minha família, ao Ângelo, meu marido, pelo amor, incentivo, apoio irrestrito e respeito.}




\section{Agradecimentos}

À Universidade de São Paulo, pela oportunidade que me foi concedida.

À minha orientadora, Profa.Dra. Elisabeth de Oliveira, pela orientação e amizade.

Ao Prof. Dr. Angelo Capri Neto, do Departamento de Engenharia de materiais da FAENQUIL, pelas sugestões, colaborações e incentivos.

Ao Prof. Dr. Pedro Vitoriano de Oliveira da USP pela amizade, sugestões e colaborações.

À Faculdade de Engenharia Química de Lorena (FAENQUIL): pelo afastamento parcial concedido para o desenvolvimento deste trabalho.

À minha familia que além do amor, contribuiu com a compreensão da minha ausência.

À Rosana Aparecida dos Santos Capri, Paulo Capri, Nilo Capri, Norma Uliana Capri e Amélia dos Santos, minha segunda família, pelo apoio irrestrito.

À todos os meus amigos que souberam me compreender, com sua paciência e carinho.

Aos amigos Roberto, Dari, Karen, Roseli, Kalil, Cíntia, Rita, Daniela e Sílvio pela amizade.

Aos pesquisadores, funcionários e amigos do Instituto de Química da USP oS quais sempre me deram apoio irrestrito.

Ao Diego da Rocha Ramos, meu orientando pela paciência, consideração e respeito.

Ao Marcos Antônio Jacó Batista por todo o apoio técnico e amizade.

À Tekno S.A. - Guaratinguetá, SP, pelo apoio técnico e utilização de seus laboratórios de pesquisa.

Ao Prof. Dr. Durval Rodrigues Jr, Msc Bento Ferreira e Prof. Dr. Paulo Atsushi Suzuki, do Departamento de Engenharia de Materiais da FAENQUIL, pelas análises de MEV - EDS e Difração de RX.

Ao Prof Dr. Hélcio José Izário Filho do Departamento de Engenharia Química da Faenquil, pela utilização de seu laboratório de análises. 
Ao Prof. Dr. Shigueo Watanabe e $D r^{2}$ Roseli Gennari pelas análises por ICPMS feitas no laboratório de análises, LACIFID (Laboratório de Cristais lônicos, Filmes Finos e Datação).

Aos pesquisadores, funcionários e alunos da FAENQUIL.

Aos amigos e colegas do Laboratório de Espectrometria de Emissão e Absorção Atômica - LEEAA e Laboratório de Preparo de Amostra - LAPA.

À Central Analítica da USP pelas análises de CHN e dedicação de seus funcionários. térmicas.;

Ao LATIG - Laboratório de Análise Térmica Ivo Giolito pelas análises

A ANACOM pelo empréstimo do forno de microondas e DMA utilizados no desenvolvimento desta tese;

Às entidades financiadoras FINEP, CNPq e FAPESP;

Aos amigos da secretaria de pós- graduação e secretaria de química analítica pela amizade, dedicação e paciência.;

À Profa. Kai L. Uemoto da Escola Politécnica - POLI/USP pela cooperação;

À Pró reitoria de Pós-Graduação da USP.

A todos os amigos e colaboradores que não foram nominalmente citados.

E, principalmente, a Deus que me acompanha em todos os momentos de vida.

A todos muito obrigada. 


\section{Resumo}

Neste trabalho são apresentados os resultados da determinação, por ICP OES, de elementos tóxicos e/ou potencialmente tóxicos ( $\mathrm{Al}, \mathrm{Cr}, \mathrm{Ni}, \mathrm{Cu}, \mathrm{Cd}, \mathrm{As}, \mathrm{Co}$ e $\mathrm{Pb}$ ) em tintas de acabamento imobiliário à base de água ou de solvente orgânico.

Foram desenvolvidas e comparadas método de digestão de amostras utilizando diferentes misturas ácidas em bornbas de decomposição, em forno de microondas (sistema com radiação focalizada e com cavidade) e método de cinzas. O Método de digestão utilizando forno de microondas com cavidade permitiu solubilização rápida $e$ eficiente de todos os tipos de tintas testados, em tempo inferior a 35 minutos. As método apresentaram valores aceitáveis para a maioria dos elementos nos testes de adição e recuperação dos analitos. Os resíduos resultantes da digestão foram avaliados por MEV-EDS e não apresentaram os elementos estudados, comprovando a eficiência da metodologia

Mercúrio foi determinado usando um Analisador Direto de Mercúrio (DMA) e apresentou valores entre $43,0 \pm 4,5$ e $188 \pm 9 \mu \mathrm{g} \mathrm{Kg}^{-1}$, valor considerado baixo quando comparado ao limite de $100 \mathrm{mg} \mathrm{Kg}^{-1}$, estabelecido na norma NRR 10004 para disposição de resíduos sólidos sem instalações especiais.

O estudo da migração dos elementos para o ambiente após a exposição da tinta a agentes "agressores" , como raios ultravioletas e umidade, foi realizado usando câmara do tipo "Weather-Ometer" (envelhecimento acelerado). A avaliação dos resultados foi feita por MEV EDS e ICP OES. As micrografias de MEV mostraram que houve mudança na morfologia do polímero que foi submetido ao intemperismo acelerado. Os resultados obtidos não foram conclusivos quanto à migração dos analitos em função da baixa razão entre as massas degradada e não degradada das amostras.

Uma proposta de metodologia para a avaliação por ICP OES das tintas e da disponibilidade de elementos tóxicos e potencialmente tóxicos, baseada na lixiviação de amostras secas em ambiente controlado é apresentada. São mostrados resultados de lixiviação de $\mathrm{Al}, \mathrm{Cr}, \mathrm{Ni}, \mathrm{Cu}, \mathrm{Cd}, \mathrm{As}$, Co e $\mathrm{Pb}$ com vários extratores e tempos diferentes de extração. Os resultados mostram que ocorre a migração de alguns elementos para as soluções estudadas e que, dos extratores avaliados, a chuva ácida apresentou maior potencial de lixiviação. 


\section{Abstract}

This work presents the results of the determination, using ICP OES, of the toxic and/or potentially toxic elements ( $\mathrm{Al}, \mathrm{Cr}, \mathrm{Ni}, \mathrm{Cu}, \mathrm{Cd}, \mathrm{As}, \mathrm{Co}$ and $\mathrm{Pb}$ ) in paints based in water or organic solvent.

Sample digestion method were developed and compared using different acid mixtures in decomposition pumps, in microwave oven (focused and with cavity) and ash method. The digestion method using microwave oven with cavity allowed fast and efficient solubilization of all tested types of paints, in inferior time to $35 \mathrm{~min}$. The methodologies showed acceptable values for the majority of the elements using addition and recovery tests. The residues resulting of the digestion were analyzed by SEM-EDS and did not present the studied elements, checking the efficiency of the method.

Mercury was determined using a Direct Mercury Analyzer (DMA) presenting values between $43.0 \pm 4.5$ and $188 \pm 9 \mu \mathrm{g} \cdot \mathrm{kg}^{-1}$, value considered low when compared to the limit of $100 \mathrm{mg} \cdot \mathrm{kg}^{-1}$, established in the norm NBR 10004 for disposition of solid residues without special installations.

The migration of the elements for the environment was studied after the exposition of the paints to aggressor agents, like ultraviolet radiation and humidity, using a Weather-Ometer type chamber (accelerated aging). The evaluation of the results was performed by SEM-EDS and ICP-OES. The SEM micrographs showed changes on the polymer morphologies submitted to accelerated aging. The obtained results were not conclusive on the migration of elements because of the low mass ratio between the degraded and non-degraded samples.

The proposed method for the evaluation by ICP-OES of paints and the disponibility of toxic and potentially toxic elements, based on the lixiviation of dry samples in controlled environment is described. Lixiviation results of $\mathrm{Al}, \mathrm{Cr}, \mathrm{Ni}, \mathrm{Cu}, \mathrm{Cd}$, As, $\mathrm{Co}$ and $\mathrm{Pb}$ using several different removal agents and extraction times are presented. The results show that happens the migration of some elements for the studied solutions and that, among all removal agents, the acid rain showed the highest lixiviation potential.

that, among all removal agents, the acid rain showed the highest lixiviation potential. 


\section{Índice}

Lista de tabelas

Lista de figuras

xvi

Lista de reduções

xvii

Resumo

Abstract

1 - Introdução

BIBLIOTECA

2 - Aspectos teóricos

2.1 - Componentes básicos de uma tinta

2.1.1- Pigmento

2.1.2 - Resina

2.1.3 - Aditivo

4

2.1.4 - Solvente

2.2 - Durabilidade do revestimento e intemperismo natural e acelerado

2.2.1 - Durabilidade do revestiı nento

2.2.2 - Intemperismo natural

2.2.3 - Intemperismo acelerado

2.3 - Toxicidade

6

2.4 - Forno de microondas

3.1 - Análise de tintas

3.2 - Degradação de filmes poliméricos

5.2 - Reagentes e soluções

5.3 - Instrumentação e material utilizado 
5.4.1 - Obtenção dos filmes secos 18

5.4 .2 - Digestão das amostras $\quad 18$

5.4.3 - Desenvolvimento do protocolo analítico 19

5.4.3.1 - Elaboração dos programas para controle instrumental $\quad 21$ e aquisição de dados do Espectrômetro Modula e CIROS da Spectro

5.4.3.2 - Determinação de mercúrio - programa de 23 aquecimento do ADM

5.5 - Estudo da migração de elementos potencialmente tóxicos presentes 25 em tintas para o ambiente

5.5.1 - Envelhecimento acelerado em câmaras de intempéries com 25 radiação UV

5.5.1.1 - Preparação das amostras

5.5.1.2 - Ensaios de envelhecimento acelerado - Câmara de $\quad 26$ intemperismo

5.5.2 - Envelhecimento acelerado sob ação de soluções extratoras - $\quad 27$ Testes de lixiviação

5.5.2.1 - Preparação das amostras $\quad 27$

5.5.2.2 - Ensaios de envelhecimento acelerado - Ação das 28 soluções extratores

6 - Resultados e discussões $\quad 29$

6.1 - Desenvolvimento dos Programas Analíticos e Eliminação das 29 interferências Espectrais

6.2 - Preparação da amostra 31

6.2.1 - Secagem das amostras 31

6.2.2 - Avaliação dos substratos 33

6.3 - Avaliação dos métodos de digestão de tinta à base de água 37

6.3.1 - Procedimento 1: $\mathrm{HNO}_{3} / \mathrm{HF}(3: 9, \mathrm{v} / \mathrm{v})$

6.3.2 - Procedimento 2: $\mathrm{HNO}_{3} / \mathrm{HF}(2: 6 \mathrm{v} / \mathrm{v})$

6.3.3 - Procedimento 3: $\mathrm{HNO}_{3} / \mathrm{HCl}$

6.4 - Definição das método de dissolução de tinta a base de solvente 50 orgânico

6.4.1 - Utilização de sistema de bombas de decomposição 50

6.4.1.1 - Procedimento 1: $\mathrm{HNO}_{3} / \mathrm{HCl}(1: 3 \mathrm{v} / \mathrm{v})$ 
6.4.1.2 - Procedimento 2: $\mathrm{HNO}_{3} / \mathrm{HCl}(3: 1 \mathrm{v} / \mathrm{v})$

6.4.1.3 - Procedimento 3: $\mathrm{HNO}_{3} / \mathrm{H}_{2} \mathrm{O}_{2}(1: 3 \mathrm{v} / \mathrm{v})$

6.4 .2 - Forno de microondas em sistema aberto 52

6.4.2.1 - Procedimento 1: $\mathrm{HNO}_{3} \quad 53$

6.4.2.2 - Procedimento 2: $\mathrm{HNO}_{3}$ e $\mathrm{H}_{2} \mathrm{O}_{2}$

6.4.2.3 - Procedimento 3: $\mathrm{HNO}_{3} / \mathrm{HCl}$ e $\mathrm{H}_{2} \mathrm{O}_{2}$

6.4.3 - Método de cinzas - Forno mufla com radiação microondas 54

6.4.4 - Forno de microondas - Sistema com cavidade 58

6.4.4.1 - Procedimento 1: $\mathrm{HNO}_{3} \quad 60$

6.4.4.2 - Procedimento 2: $\mathrm{HNO}_{3} / \mathrm{H}_{2} \mathrm{O}_{2} \quad 60$

6.4.4.3 - Procedimento 3: $\mathrm{HNO}_{3} / \mathrm{HCl} \quad 61$

6.4.4.4 - Procedimento 4: $\mathrm{HNO}_{3} / \mathrm{HCl}$ - Empregando filmes 64

secos de tinta

6.5 - Determinação de mercúrio 70

6.6 - Estudo da migração de elementos potencialmente tóxicos em tintas 72

6.6.1 - Intemperismo acelerado $\quad 72$

6.6.1.1 - Análise por Microscopia Eletrônica de Varredura 73

6.6.1.2 - Análise do filme envelhecido por Espectrometria de 75

Emissão Óptica

6.6 .2 - Exposição à ação de soluções extratoras - Testes de 77 lixiviação

7.0 - Conclusões

8.0 - Trabalhos futuros 95

9.0 - Referências Bibliográficas 96 
İndice de tabelas

Tabela 5.1. Parâmetros instrumentais utilizados na operação do espectrômetro de emissão ótica Spectroflame Modula (seqüencial), CIROS $^{C C D}$ (simultâneo) da Spectro Co e ICP MS Perkin Elmer ELAN 6100.

Tabela 5.2. Comprimentos de onda (nm)

Tabela 5.3. Programas analíticos e concentrações utilizadas na preparação da curva analítica - Espectrômetro Spectroflame Modula

Tabela 5.4. Programas analíticos e concentrações utilizadas na preparação da curva analítica - Espectrômetro CIROS $^{\mathrm{CCD}}$

Tabela 5.5. Programa analítico e concentrações utilizadas na preparação da curva analítica - Espectrômetro CIROS $^{\mathrm{CCD}}$

Tabela 5.6. Programa de aquecimento do DMA - 80

Tabela 6.1. Comprimentos de onda, limites de detecção e limites de quantificação de cada elemento em $\mathrm{mg} \mathrm{L}^{-1}$ do Espectrômetro Spectroflame Modula

Tabela 6.2. Comprimentos de onda, limites de detecção e limites de quantificação de cada elemento em $\mathrm{mg} \mathrm{L}^{-1}$ do Espectrômetro CIROS $^{\mathrm{CCD}}$

Tabela 6.3. Parâmetros das curvas analíticas ICP OES, Spectroflame Modula

Tabela 6.4. Parâmetros das curvas analíticas ICP OES, CIROS

Tabela 6.5. Procedimento empregado para a digestão das tintas à base de água, utilizando forno de microondas com cavidade Ethos

Tabela 6.6. Procedimento empregado para a digestão das tintas à base de água utilizando forno de microondas com cavidade Ethos

Tabela 6.7. Quantidades encontradas e desvios padrão dos elementos Al, $\mathrm{Cr}, \mathrm{Mn}, \mathrm{Co}, \mathrm{Ni}, \mathrm{Cu}, \mathrm{As}, \mathrm{Cd}$ e $\mathrm{Pb}$ em tinta à base de água da marca $\mathrm{C}$

Tabela 6.8. Valores de concentração e recuperação dos elementos adicionados e recuperados da tinta azul enriquecida 
Tabela 6.9. Valores de concentração e recuperação dos elementos adicionados e recuperados da tinta amarela enriquecida

Tabela 6.10. Valores de concentração e recuperação dos elementos adicionados e recuperados da tinta vermelha enriquecida

Tabela 6.11. Quantidade encontrada em \% e desvios padrão de $\mathrm{Pb}$, em 46 tinta à base de água de cor vermelha da marca $\mathrm{C}$

Tabela 6.12 Valores de concentração e recuperação de $\mathrm{Pb}$ adicionado e 46 recuperado na tinta vermelha enriquecida

Tabela 6.13. Procedimento empregado para a digestão das tintas à base de água utilizando forno de microondas com cavidade Ethos

Tabela 6.14. Quantidade encontrada e desvios padrão dos elementos $\mathrm{Al}$, 48 $\mathrm{Cr}, \mathrm{Mn}, \mathrm{Co}, \mathrm{Ni}, \mathrm{Cu}, \mathrm{As}, \mathrm{Cd}$ e $\mathrm{Pb}$, em tinta à base de água da marca $\mathrm{C}$

Tabela 6.15. Valores de concentração e recuperação dos elementos 48 adicionados e recuperados da tinta azul enriquecida

Tabela 6.16. Valores de concentração e recuperação dos elementos 49 adicionados e recuperados da tinta amarela enriquecida

Tabela 6.17. Valores de concentração e recuperação dos elementos 49 adicionados e recuperados da tinta látex vermelha enriquecida

Tabela 6.18. Procedimento empregado para a digestão de tinta azul a base de óleo da marca $A$ em forno de microondas com radiação focalizada

Tabela 6.19. Procedimento empregado para a digestão de tinta azul a base de óleo da marca $A$ em forno de microondas com radiação focalizada

Tabela 6.20. Procedimento empregado para a digestão de tinta azul a base de óleo da marca $A$ em forno de microondas com radiação focalizada

Tabela 6.21. Programa de aquecimento da mufla com radiação 56 microondas para a decomposição de amostras de tinta a base de óleo, cor azul da marca $A$

Tabela 6.22. Teores percentuais de Al, Cr, Mn, Co, Ni, Cu, As, Cd e Pb, em tinta azul da marca $A$, após digestão das cinzas pela mistura $\mathrm{HNO}_{3} / \mathrm{HCl}$ 
Tabela 6.23. Resultado do teste de recuperação dos elementos $\mathrm{Al}, \mathrm{Cr}, \mathrm{Mn}$,

$\mathrm{Co}, \mathrm{Ni}, \mathrm{Cu}, \mathrm{As}, \mathrm{Cd}$ e $\mathrm{Pb}$, em tinta azul da marca $\mathrm{A}$ após digestão das cinzas pela mistura $\mathrm{HNO}_{3} / \mathrm{HCl}$

Tabela 6.24. Resultado do teste de recuperação dos elementos $\mathrm{Al}, \mathrm{Cr}, \mathrm{Mn}$, 58

$\mathrm{Co}, \mathrm{Ni}, \mathrm{Cu}, \mathrm{As}, \mathrm{Se}, \mathrm{Cd}$ e $\mathrm{Pb}$, em solução branco, contendo $\mathrm{HNO}_{3}$ e $\mathrm{HCl}$ e água desionizada, enriquecida com os elementos de interesse. Método Cinzas

Tabela 6.25. Procedimento empregado na digestão de tinta à óleo de cor azul

Tabela 6.26. Teores percentuais em \% dos elementos $\mathrm{Al}, \mathrm{Cr}, \mathrm{Mn}, \mathrm{Co}, \mathrm{Ni}$, 62 $\mathrm{Cu}, \mathrm{As}, \mathrm{Cd}$ e $\mathrm{Pb}$, em tinta azul da marca $\mathrm{A}$ após digestão pela mistura $\mathrm{HNO}_{3}$ e $\mathrm{HCl}$ utilizando forno de microondas de alta pressão - ETHOS

Tabela 6.27. Resultado do teste de recuperação dos elementos $\mathrm{Al}, \mathrm{Cr}, \mathrm{Mn}$, $\mathrm{Co}, \mathrm{Ni}, \mathrm{Cu}, \mathrm{As}, \mathrm{Cd}$ e $\mathrm{Pb}$, da tinta a óleo azul após digestão pela mistura de $\mathrm{HNO}_{3}$ e $\mathrm{HCl}$

Tabela 6.28. Resultado do teste de recuperação dos elementos $\mathrm{Al}, \mathrm{Cr}, \mathrm{Mn}$, $\mathrm{Co}, \mathrm{Ni}, \mathrm{Cu}, \mathrm{As}, \mathrm{Cd}$ e $\mathrm{Pb}$, na solução branco composta por $\mathrm{HNO}_{3}$ e $\mathrm{HCl}$

Tabela 6.29. Procedimento empregado na digestão de tinta à óleo de cor 65 azul

Tabela 6.30. Teores percentuais dos elementos $\mathrm{Al}, \mathrm{Cr}, \mathrm{Mn}, \mathrm{Co}, \mathrm{Ni}, \mathrm{Cu}, \mathrm{As}$, $\mathrm{Cd}$ e $\mathrm{Pb}$, em tinta azul da marca $\mathrm{A}$ após digestão pela mistura $\mathrm{HNO}_{3} \mathrm{e}$ $\mathrm{HCl}$. Utilização de forno de microondas de alta pressão - ETHOS

Tabela 6.31. Quantidade encontrada (\%) dos elementos $\mathrm{Al}, \mathrm{Cr}, \mathrm{Mn}, \mathrm{Co}, \mathrm{Ni}$, 68 $\mathrm{Cu}, \mathrm{As}$, Se, Cd e $\mathrm{Pb}$, em tinta azul das marcas $\mathrm{A}, \mathrm{B}$ e $\mathrm{C}$ após solubilização pelo $\mathrm{HNO}_{3}$ e $\mathrm{HCl}$ composta por $\mathrm{HNO}_{3}$ e $\mathrm{HCl}$

Tabela 6.32. Valores de concentração e recuperação dos elementos adicionados e recuperados da tinta esmalte amarela, marca C enriquecida

Tabela 6.33. Valores de concentração e recuperação dos elementos adicionados e recuperados da tinta esmalte amarela marca D enriquecida

Tabela 6.34. Valores de concentração e recuperação dos elementos adicionados e recuperados da tinta óleo vermelha marca $B$ enriquecida 
Tabela 6.35. Concentração de mercúrio em tintas à base de água, média e desvio padrão $(n=3)$

Tabela 6.36. Concentração de mercúrio em tintas à base de solvente, média e desvio padrão $(n=3)$

Tabela 6.37. Valores médios do teor dos elementos estudados por Microscopia Eletrônica de Varredura e EDS em tinta esmalte de cor amarela da marca D antes e após a degradação

Tabela 6.38. Teores médios e desvios padrão radiação e determinação por ICP OES de tinta esmalte da marca $\mathrm{C}$ antes e após envelhecimento

Tabela 6.39. Quantidade encontrada em $\mathrm{mg} \mathrm{L}^{-1}$ de alumínio na tinta 78 esmalte após lixiviação com água desionizada, solução de $\mathrm{NaCl} 5 \%$ $(\mathrm{m} / \mathrm{v})$, solução sulfonítrica de $\mathrm{pH}=4$ e $\mathrm{HAc}$ de $\mathrm{pH}=5$, após troca de extrator a cada 7 dias

Tabela 6.40. Quantidade encontrada em $\mathrm{mg} \mathrm{L}^{-1}$ de crômio na tinta esmalte 78 após lixiviação com água desionizada, solução de $\mathrm{NaCl} 5 \%(\mathrm{~m} / \mathrm{v})$, solução sulfonitrica de $\mathrm{pH}=4$ e $\mathrm{HAc}$ de $\mathrm{pH}=5$, após troca de extrator a cada 7 dias

Tabela 6.41. Quantidade encontrada em $\mathrm{mg} \mathrm{L}^{-1}$ de manganês na tinta esmalte após lixiviação com água desionizada, solução de $\mathrm{NaCl} 5 \%$ $(\mathrm{m} / \mathrm{v})$, solução sulfonítrica de $\mathrm{pH}=4$ e $\mathrm{HAc}$ de $\mathrm{pH}=5$, após troca de extrator a cada 7 dias

Tabela 6.42. Quantidade encontrada em $\mathrm{mg} \mathrm{L}^{-1}$ de cobalto na tinta esmalte após lixiviação com água desionizada, solução de $\mathrm{NaCl} 5 \%(\mathrm{~m} / \mathrm{v})$, solução sulfonitrica de $\mathrm{pH}=4$ e $\mathrm{HAc}$ de $\mathrm{pH}=5$, após troca de extrator a cada 7 dias

Tabela 6.43. Quantidade encontrada em $\mathrm{mg} \mathrm{L}^{-1}$ de chumbo na tinta 79 esmalte após lixiviação com água desionizada, solução de $\mathrm{NaCl} 5 \%$ $(\mathrm{m} / \mathrm{v})$, solução sulfonítrica de $\mathrm{pH}=4$ e $\mathrm{HAc}$ de $\mathrm{pH}=5$, após troca de extrator a cada 7 dias

Tabela 6.44. Quantidade encontrada em $\mathrm{mg} \mathrm{L}^{-1}$ de aluminio na tinta látex após lixiviação com água desionizada, solução de $\mathrm{NaCl} 5 \%(\mathrm{~m} / \mathrm{v})$, solução sulfonítrica de $\mathrm{pH}=4$ e HAc de $\mathrm{pH}=5$, após troca de extrator a cada 7 dias 
Tabela 6.45. Quantidade encontrada em $\mathrm{mg} \mathrm{L}^{-1}$ de manganês na tinta látex 80 após lixiviação com água desionizada, solução de $\mathrm{NaCl} 5 \%(\mathrm{~m} / \mathrm{v})$, solução sulfonítrica de $\mathrm{pH}=4$ e $\mathrm{HAc}$ de $\mathrm{pH}=5$, após troca de extrator a cada 7 dias

Tabela 6.46. Quantidade encontrada em $\mathrm{mg} \mathrm{L}^{-1}$ de chumbo na tinta látex 80 após lixiviação com água desionizada, solução de $\mathrm{NaCl} 5 \%(\mathrm{~m} / \mathrm{v})$, solução sulfonitrica de $\mathrm{pH}=4$ e $\mathrm{HAc}$ de $\mathrm{pH}=5$, após troca de extrator a cada 7 dias

Tabela 6.47. Quantidade encontrada em $\mathrm{mg} \mathrm{L}^{-1}$ de alumínio na tinta esmalte após lixiviação com água desionizada, solução de $\mathrm{NaCl} 5 \%$ $(\mathrm{m} / \mathrm{v})$, solução sulfonítrica de $\mathrm{pH}=4$ e $\mathrm{HAc}$ de $\mathrm{pH}=5$

Tabela 6.48. Quantidade encontrada em $\mathrm{mg} \mathrm{L}^{-1}$ de crômio na tinta esmalte 82 após lixiviação com água desionizada, solução de $\mathrm{NaCl} 5 \%(\mathrm{~m} / \mathrm{v})$, solução sulfonítrica de $\mathrm{pH}=4$ e $\mathrm{HAc}$ de $\mathrm{pH}=5$

Tabela 6.49. Quantidade encontrada em $\mathrm{mg} \mathrm{L}^{-1}$ de manganês na tinta 82 esmalte após lixiviação com água desionizada, solução de $\mathrm{NaCl} 5 \%$ $(\mathrm{m} / \mathrm{v})$, solução sulfonítrica de $\mathrm{pH}=4$ e $\mathrm{HAc}$ de $\mathrm{pH}=5$

Tabela 6.50. Quantidade encontrada em $\mathrm{mg} \mathrm{L}^{-1}$ de cobalto na tinta esmalte 82 após lixiviação com água desionizada, solução de $\mathrm{NaCl} 5 \%(\mathrm{~m} / \mathrm{v})$, solução sulfonítrica de $\mathrm{pH}=4$ e $\mathrm{HAc}$ de $\mathrm{pH}=5$

Tabela 6.51. Quantidade encontrada em $\mathrm{mg} \mathrm{L}^{-1}$ de chumbo na tinta 83 esmalte após lixiviação com água desionizada, solução de $\mathrm{NaCl} 5 \%$ $(\mathrm{m} / \mathrm{v})$, solução sulfonítrica de $\mathrm{pH}=4$ e $\mathrm{HAc}$ de $\mathrm{pH}=5$

Tabela 6.52. Quantidade encontrada em $\mathrm{mg} \mathrm{L}^{-1}$ de Ni, Cu, As e Cd na tinta 83 esmalte após lixiviação com água desionizada, solução de $\mathrm{NaCl} 5 \%$ $(\mathrm{m} / \mathrm{v})$, solução sulfonítrica de $\mathrm{pH}=4$ e HAc de $\mathrm{pH}=5$ após a troca do extrator em 7, 14, 21 e 28 dias)

Tabela 6.53. Quantidade encontrada em $\mathrm{mg} \mathrm{L}^{-1}$ de alumínio na tinta látex 83 após lixiviação com água desionizada, solução de $\mathrm{NaCl} 5 \%(\mathrm{~m} / \mathrm{v})$, solução sulfonítrica de $\mathrm{pH}=4$ e HAc de $\mathrm{pH}=5$

Tabela 6.54. Quantidade encontrada em $\mathrm{mg} \mathrm{L}^{-1}$ de manganês na tinta látex após lixiviação com água desionizada, solução de $\mathrm{NaCl} 5 \%(\mathrm{~m} / \mathrm{v})$, solução sulfonitrica de $\mathrm{pH}=4$ e $\mathrm{HAc}$ de $\mathrm{pH}=5$ 
Tabela 6.55. Quantidade encontrada em $\mathrm{mg} \mathrm{L}^{-1}$ de chumbo na tinta látex após lixiviação com água desionizada, solução de $\mathrm{NaCl} 5 \%(\mathrm{~m} / \mathrm{v})$, solução sulfonitrica de $\mathrm{pH}=4$ e HAc de $\mathrm{pH}=5$

Tabela 6.56. Quantidade encontrada em $\mathrm{mg} \mathrm{L}^{-1}$ de $\mathrm{Cr}$, Co, Ni, Cu, As e Cd 84 na tinta látex após lixiviação com água desionizada, solução de $\mathrm{NaCl}$ $5 \%(\mathrm{~m} / \mathrm{v})$, solução sulfonítrica de $\mathrm{pH}=4$ e $\mathrm{HAc}$ de $\mathrm{pH}=5$ após a troca do extrator em 7, 14, 21 e 28 dias)

Tabela 6.57. Avaliação da reprodutibilidade na tinta esmalte após lixiviação 91 com solução sulfonítrica de $\mathrm{pH}=4$ (chuva ácida) 


\section{Índice de figuras}

Figura 5.1. Procedimento de digestão das amostras e determinação dos analitos

Figura 5.2. Esquema do analisador direto de mercúrio

Figura 5.3. Fluxograma do procedimento utilizado para a avaliação da

migração dos elementos de interesse em câmara de intemperismo acelerado.

Figura 5.4.Fotografia do frasco pintado.

Figura 6.1. (a)llustração do aplicador tipo "Wire-Cator", (b) detalhe do aplicador

Figura 6.2. Pelicula de filme pintada em placa de acrílico 33

Figura 6.3. (a) e (b): Mostram a má formação do filme, causada pela polimerização da camada externa da tinta antes da secagem completa

Figura 6.4. (a), (b) e (c): Mostram o filme formado sendo facilmente 34 retirado com o auxílio de uma espátula

Figura 6.5. Mostra o comprometimento do substrato após aquecimento 35 superior a $60^{\circ} \mathrm{C}$

Figura 6.6. (a) e (b): Mostram o filme formado sob o celofane, dando 35 ênfase as pequenas lascas que são removidas por uma espátula

Figura 6.7. Mostra o filme sendo retirado do celofane usando-se a quina da 36 uma bancada

Figura 6.8. (a) e (b) :Mostram a película de tinta sendo facilmente 36 removida da placa de PE com auxílio de uma espátula

Figura 6.9. Representação dos valores de \% recuperação das tintas azul, 43 amarela e vermelha da marca $C$

Figura 6.10. Espectro do resíduo da tinta azul, obtido por MEV-EDS

Figura 6.11. Espectro do resíduo da tinta amarela, obtido por MEV-EDS

Figura 6.12. Espectro do residuo da tinta vermelha, obtido por MEV-EDS

Figura 6.13. Sistema de Bombas de Decomposição (1- Bloco de aço inox;

2- camisa de alumínio; 3- cadinho de TEFLON®; 4- mola; 5termostato) 
Figura 6.14. Representação gráfica do programa de aquecimento do forno de microondas com cavidade

Figura 6.15. Espectro do residuo da tinta esmalte azul, obtido por MEVEDS

Figura 6.16. Fotografias de parte de placas de Polietileno cobertas com tinta, comparando a regiões protegidas durante os testes de intemperismo (a) com as regiões expostas (b)

Figura 6.17. Micrografia do filme da tinta esmalte amarela antes da exposição aos raios ultravioleta (200x)

Figura 6.18. Micrografia aumentada: (a) 100x e (b) 200x

Figura 6.19. Micrografias de um filme de tinta à base de água: (a) antes do envelhecimento e (b) após envelhecimento (200x)

Figura. 6.20. Representação esquemática do processo de degradação da superficie do revestimento. a) sem exposição; b) pouco tempo de exposição, perda de resina; c) perda de partículas de pigmento; d) perda do revestimento de resina, exposição e perda de pigmento

Figura 6.21. Concentração de Al em função do tempo de exposição das soluções extratoras em tinta esmalte

Figura 6.22. Concentração de $\mathrm{Cr}$ em função do tempo de exposição das soluções extratoras em tinta esmalte

Figura 6.23. Concentração de Mn em função do tempo de exposição das soluções extratoras em tinta esmalte

Figura 6.24. Concentração de Co em função do tempo de exposição das 86 soluções extratoras em tinta esmalte

Figura 6.25. Conceritração de $\mathrm{Pb}$ em função do tempo de exposição das 86 soluções extratoras em tinta esmalte

Figura 6.26. Variação da concentração de Al nos diferentes extratores em tinta esmalte após 28 dias com troca de extrator a cada $7 \mathrm{em}$ comparação a 28 dias ininterruptos

Figura 6.27. Avaliação do equilíbrio da extração de $\mathrm{Cr}$ nos diferentes extratores em tinta esmalte

Figura 6.28. Avaliação do equilíbrio da extração de $\mathrm{Mn}$ nos diferentes extratores em tinta esmalte 
Figura 6.29. Avaliação do equilíbrio da extração de Co nos diferentes

88 extratores em tinta esmalte

Figura 6.30. Avaliação do equilíbrio da extração de $\mathrm{Pb}$ nos diferentes 88 extratores em tinta esmalte

Figura 6.31. Concentração de Al em função do tempo de exposição das 89 soluções extratoras em tinta látex

Figura 6.32. Concentração de $\mathrm{Mn}$ em função do tempo de exposição das 89 soluções extratoras em tinta látex

Figura 6.33. Concentração de $\mathrm{Pb}$ em função do tempo de exposição das 89 soluções extratoras em tinta látex

Figura 6.34. Concentração de Al em função do tempo de exposição das 90 soluções extratoras em tinta látex

Figura 6.35. Concentração de Mn em função do tempo de exposição das 90 soluções extratoras em tinta látex

Figura 6.36. Concentração de $\mathrm{Pb}$ em função do tempo de exposição das 90 soluções extratoras em tinta látex 


\section{Lista de Reduções}

ABRAFATI Associação Brasileira dos Fabricantes de Tintas

FUNASA Fundação Nacional de Saúde

ASTM American Society for Testing and Materials

$\mathrm{pH} \quad$ Potencial hidrogeniônico

ABNT Associação Brasileira de Normas Técnicas

NBR Norma Brasileira Regulamentadora

ICP OES Inductively Coupled Plasma Optical Emission Spectrometry

COVs - Compostos Orgânicos Voláteis

LOD Limite de deteç̧ão

LOQ Limite de Quantificação

UV Radiação ultravioleta

AAS Atomic Absorption Spectrometry

EPA Environmental Protection Agency

NCCA National Coil Coaters Association

MEV-EDS Microscópio Eletrônico de Varredura - Espectrômetro de Energia

Dispersiva

PE Polietileno

TEFLON@ Politetrafluoroetileno marca registrada da Dupont

PTFE Politetrafluoroetileno

ICP-MS Inductively Coupled Plasma Mass Spectrometry

WO Weather-Ometer

UVA Absorvedores de radiação UV 


\section{Introdução}

Tinta é definida como um líquido viscoso e constituída de um ou mais pigmentos dispersos em uma resina que, ao sofrer um processo de cura após ser aplicada na forma de película fina, forma um filme que adere ao substrato [FAZENDA, 1995].

Segundo a ABRAFATI (Associação Brasileira dos Fabricantes de Tintas) o Brasil ocupa a $5^{\text {a }}$ posição no mercado mundial de tintas [ABRAFATI, http//www.abrafati.com.br, 2005]. Em 2004 foram produzidos no Brasil aproximadamente 913 milhões de litros de tintas, sendo que a produção de tintas imobiliárias foi de 701 milhões de litros e a capacidade de produção é de aproximadamente 1,1 bilhão de litros.

Os componentes básicos da tinta são pigmentos, resinas, aditivos e solventes. Estes componentes (principalmente o pigmento e o aditivo) podem conter compostos inorgânicos constituídos por elementos potencialmente tóxicos como $\mathrm{Al}$, $\mathrm{Cr}, \mathrm{Mn}, \mathrm{Co}, \mathrm{Ni}, \mathrm{Cu}, \mathrm{As}, \mathrm{Cd}$ e $\mathrm{Pb}$. Embora exista, por exigência de órgãos ambientais, uma grande tendência à eliminação destes elementos devido à sua toxicidade, eles ainda podem ser encontrados na composição deste produto. O Brasil não possui regulamentação em relação a estes elementos nas tintas, necessitando recorrer a normas internacionais. Em relação ao chumbo, existe o projeto de lei $n^{\circ} 4509$, de 2001 que "Proíbe a utilização do chumbo na fabricação de tinta de parede" [FUNASA, 2001].

A tinta que contém metais pesados em sua composição pode oferecer grande risco às crianças uma vez que estas normalmente levam objetos à boca $e$, conseqüentemente, podem ingerir estes metais presentes nas tintas usadas na pintura de brinquedos, materiais escolares etc [SALDÍVAR, 2002; WONG, 1999]. Aos pintores, o risco é oferecido quando eles entram em contato diretamente com a tinta ou quando paredes pintadas são raspadas e/ou lixadas para repintura e, nestes casos, os elementos tóxicos entram no organismo via trato digestivo.

Os elementos tóxicos não trariam danos ao meio ambiente $e$, consequentemente. à saúde se eles permanecessem indefinidamente imobilizados nas tintas. Embora o uso de biocidas proteja as tintas da degradação por fungos, elas podem, em pequena escala, ser degradadas por estes organismos. Além disso. 
a perda destes elementos ou seus compostos pode ocorrer por meio da lixiviação da tinta de fachadas causada pelas intempéries e agentes climáticos, restos de tinta que são descartados, particulados que são provenientes da preparação da parede para repintura e pedaços de tinta provenientes de paredes que sofreram defeitos na aplicação ou devido à má qualidade do material. A tinta pode sofrer degradação por foto-oxidação e hidrólise causada pela exposição à luz solar, ao ar, à umidade e à alta temperatura [WICKS et al. 1999]. Outra grande fonte de contaminação ambiental é o entulho de demolição das construções.

O problema ambiental tem sido muito discutido nas últimas décadas. $O$ International Council for Building, Research Studies and Documentation (CIB, sigla original do Francês, "Conseil International du Bâtiment") o colocou entre suas prioridades de pesquisa e desenvolvimento sustentável. A European Construction Industry Federation possui agenda especifica sobre este tema e em uma pesquisa da Civil Engineering Research Foundation (CERF), uma entidade dedicada à promoção da modernização da construção civil nos EUA, a "questão ambiental" foi considerada como a $2^{\mathrm{a}}$ tendência mais importante para o futuro. Mesmo no Brasil, há sinais de que o impacto ambiental já começa a ser sentido na engenharia civil [JOHN, 2000].

Existe grande preocupação da substituição dos metais pesados nas tintas [MEIER et al., 1999], mas o custo financeiro é alto e as empresas continuam usando estes metais na sua composição, tornando fundamental o controle de qualidade do produto oferecido no mercado brasileiro. Como não existe lei que regula o teor destes metais nas tintas, caberá ao consumidor fazer exigências na qualidade do produto e aos pesquisadores fornecerem subsídios para esta avaliação e, para isto, um método de análise deve ser investigado. A análise deverá compreender a digestão da amostra, a determinação dos analitos de interesse e a mobilidade destes metais da tinta para o meio ambiente. Esta é uma tarefa analítica complicada em função deste produto conter compostos orgânicos e inorgânicos, o que torna as etapas de preparação e digestão da amostra complexas e demoradas.

Este trabalho relata o desenvolvimento de método visando a determinação de elementos tóxicos elou potencialmente tóxicos em tintas de acabamento imobiliário e avaliação de suas mobilidades, ou seja, a migração destes elementos para o ambiente após a exposição da tinta a agentes "agressores", como raios ultravioleta e soluções extratoras com diferentes $\mathrm{pH}$ 's. 


\section{Aspectos teóricos}

Neste item são abordados os temas sobre componentes básicos das tintas, durabilidade do revestimento e intemperismo natural e acelerado, toxicidade e forno de microondas.

\subsection{Componentes básicos de uma tinta}

Tinta é definida como um líquido viscoso e constituída de um ou mais pigmentos dispersos em uma resina que, ao sofrer um processo de cura após ser aplicada na forma de película fina, forma um filme que adere ao substrato [FAZENDA,1995]. Tanto a eficiência quanto a capacidade de proteção da tinta dependem da resina usada na sua formulação [VALET,1997].

Normalmente as tintas de revestimento são classificadas como: imobiliárias/arquitetônicas, tintas para automóveis e veículos automotores (tintas originais e para repintura) e tintas industriais [ABRAFATI, 2005].

Os componentes básicos da tinta são: pigmentos, solventes, aditivos e resinas [FAZENDA, 1995; LAMBOURNE,1987].

\subsubsection{Pigmento}

É definido como partícula sólida fina, insolúvel no veículo, usada na preparação da tinta. Os pigmentos podem ser coloridos (conferem cor), não coloridos e anticorrosivos (conferem proteção às superfícies metálicas). Eles podem ser orgânicos, inorgânicos e metálicos. Os pigmentos inorgânicos são mais estáveis que os orgânicos, o que Ihes conferem maior resistência a raios ultravioleta. Suas cores são menos brilhantes, porém apresentam maior resistência química. Os pigmentos mais importantes são: dióxido de titânio, pigmento de chumbo (principais, $\mathrm{Pb}_{3} \mathrm{O}_{4}$ e $\mathrm{PbCrO}_{4}$ ), alumínio (tintas metalizadas e marteladas), sulfato de bário, óxido de antimônio, sulfeto de cádmio, óxido de ferro e zinco, que é usado em superfícies de aço (anticorrosivas). Devido à legislação governamental, alguns países têm 
substituído pigmentos inorgânicos tóxicos por outros menos agressivos [LAMBOURNE, 1987; TEVES, 2001].

\subsubsection{Resina}

É a parte não volátil da tinta, que serve para aglomerar as partículas de pigmentos e também é a maior responsável pela formação do filme. As propriedades físico-químicas da tinta dependem basicamente da natureza das resinas.

As resinas mais comuns são: alquídica, acrílica, vinílica, epóxi, poliéster, que são usadas isoladas ou combinadas entre si.

\subsubsection{Aditivo}

Proporciona características especiais às tintas ou proporcionam melhorias às suas propriedades. Os aditivos mais comuns são: secantes (soluções de sais metálicos como cobalto, manganês, chumbo, zinco, cálcio, ferro etc.), dispersantes (lecitina de soja, naftenato de zinco, resinato de zinco etc), antiespumantes (álcool octílico, álcool caprílico e palmitato de etila e silicones), plastificantes (dietillftalato, fosfato de tricresila etc).

\subsubsection{Solvente}

É um líquido volátil, em geral de baixo ponto de ebulição, utilizado para dissolver a resina, conferir viscosidade adequada à aplicação e retardar ou acelerar a secagem. Os solventes mais comuns são: cetonas, esteres, álcoois e hidrocarbonetos.

\subsection{Durabilidade do revestimento e intemperismo natural e acelerado}

\subsubsection{Durabilidade do revestimento}

Durabilidade é a capacidade que uma tinta possui em resistir à degradação ao ser exposta a condições adversas [LAMBOURNE,1987]. Como a durabilidade 
está relacionada às condições ambientais, o monitoramento do desempenho da pintura simulando as condições de uso é um constante tema de pesquisas.

O processo de degradação inclui alterações de propriedades e características estéticas, como perda de propriedades mecânicas, resistência química, adesão, redução de brilho, descoloração, calcinação, trincas, manchas d'água e outras. A velocidade com que ocorre a degradação dependerá do local e tempo de exposição, composição do revestimento e do substrato [WICKS et al.,1999].

\subsubsection{Intemperismo natural}

A degradação é caracterizada pela ação de agentes naturais (intemperismo) como, exposição à luz solar, ar, umidade e temperatura. Neste caso é necessário muitas vezes à exposição do material por longo período de tempo para que uma degradação significativa seja observada. Este teste consiste em se colocar os corpos de prova (painéis pintados), em painéis devidamente preparados para este fim, em ângulos de $45^{\circ}$, e proceder a análises regulares. Todo painel deve estar com a face a ser testada voltada para o norte, a fim de receber os raios solares durante a maior parte do dia. São testes demorados, podendo variar de 3 meses até anos [ASTM D 1014].

\subsubsection{Intemperismo acelerado}

Estes testes são feitos em laboratório, buscando reproduzir o aspecto sinérgico da atmosfera correlacionando-o às condições naturais. Neste caso, por meio de equipamento é simulada a condição natural de forma mais agressiva e, desta forma, ocorrerá a degradação acelerada do revestimento [BIGGS et al., 2001].

Um teste de envelhecimento acelerado regularmente utilizado é o uso de câmara de intemperismo "Weather-Ometer". Nesta câmara a fonte de radiação UV é obtida por um eletrodo de carbono. A intensidade da radiação obtida por eletrodo de carbono é superior à luz solar. Para determinados materiais, como os polímeros usados nas tintas, a degradação é acentuada porque eles absorvem a radiação UV de baixos comprimentos de onda [BATISTA, 2004]. 


\subsection{Toxicidade}

Toxicidade é a propriedade dos agentes tóxicos de promoverem efeitos nocivos às estruturas biológicas por meio de interações físico-químicas [TEVES, 2001].

A tinta é constantemente citada em artigos como grande fonte de contaminação e poluição ambiental [PIMENTA, VITAL, 1994; SUTTON et al., 1995, DAVIS, BURNS, 1999; MIELKE et al., 2001; AHMED, ALAM, 2001; JABEEN et al., 2001].

Elementos tóxicos e/ou potencialmente tóxicos (metais pesados) encontramse presentes no solo, na água e no ar. Sua presença pode ser de fonte natural ou antrópica. Problemas relacionados à saúde e ambientais são constantemente discutidos a nível mundial e em todos os segmentos da sociedade devido à toxicidade destes elementos. Os principais elementos potencialmente tóxicos são: Mercúrio, Chumbo, Arsênio, Cádmio, Niquel e Alumínio [TEIXEIRA, COUTINHO, 2004].

Dados da literatura classificam o chumbo como um dos elementos mais investigados por pesquisadores. O chumbo é um dos contaminantes mais comuns, no ambiente e reconhecido pela Organização Mundial da Saúde como um dos elementos químicos que oferece maior risco para a saúde humana [MOREIRA, MOREIRA, 2004; VANZ et al., 2003].

Em artigos sobre avaliação ambiental, o chumbo normaimente é citado como um dos elementos mais agressivos ao meio ambiente. Após a proibição de sua utilização na gasolina, a tinta tem sido constantemente citada como fonte contaminante [BRAUN et al., 2002; MARTIN et al., 1996; TONG, LAMB, 2000]. Em países em que a utilização deste elemento é proibida, a atenção se volta às edificações antigas que foram pintadas com tintas a base de chumbo. Uma imobiliária de Boston, por exemplo, foi obrigada a retirar a tinta das paredes de 10.400 apartamentos por apresentarem chumbo em sua composição [News Link Environmental - http://www.caprep.com, 2004].

Envenenamento por chumbo seguido de morte de alguns animais foi constatado no sul do Brasil. A contaminação foi proveniente da tinta que vazou de latas enferrujadas abandonadas no ambiente destes animais [TRAVERSO et al., 2004]. Este elemento também tem sido identificado em uma enorme variedade de 
ambientes (ar, água de superfície, lençóis d'água, chorume, solo, sedimento, peixes e animais de caça) coletados nos perigosos depósitos de lixo, onde freqüentemente é o metal mais encontrado [MOREIRA, MOREIRA, 2004].

Chumbo é um elemento não essencial. É uma substância tóxica cumulativa e afeta o sistema nervoso. Uma intoxicação crônica por este metal pode levar a uma doença denominada saturnismo, que ocorre na maioria das vezes em trabalhadores expostos ao metal, causando danos neurológicos [CETESB, 1996; ORGANIZAÇÃO MUNDIAL DE SAÚDE,1998]. Em adultos causa hipertensão e anemia. No organismo os ions $\mathrm{Pb}^{2+}$ podem depositar-se nos ossos, pois possuem tamanho similar aos íns cálcio. A toxicidade do $\mathrm{Pb}$ está relacionada à quantidade presente nos tecidos macios, e não à quantidade que se encontra no sangue ou nos ossos, porém, o exame referente a toxicidade geralmente é feito no sangue [BAIRD, 2002; MOREIRA, MOREIRA, 2004].

Alumínio é um elemento não essencial. Seus aspectos tóxicos não são bem definidos, uma vez que este elemento é pouco absorvido pelo intestino. Acredita-se que no organismo humano a presença de compostos de Al possa diminuir a absorção de outros elementos como $\mathrm{Fe}$ e $\mathrm{Ca}$ (BAIRD, 2002).

Crômio trivalente apresenta baixa toxicidade enquanto na forma hexavalente é extremamente tóxico para animais e vegetais, podendo ser carcinogênico [CETESB, 1996; JORDÃO et al., 1999]. O crômio absorvido por via cutânea permanece por longo período retido na junção dermo-epidérmica e o absorvido por via respiratória é influenciado pela eficiência dos mecanismos broncociliar [TEVES, 2001].

Manganês é elemento essencial para todos os organismos vivos, participando de reações enzimáticas [YABE, 1995]. Existe grande margem entre a quantidade recomendada em relação às tóxicas, porém envenenamento crônico provoca desordem psíquica, caracterizada por irritabilidade, dificuldade de caminhar, distúrbios da fala e comportamento compulsivo.

Cobalto é elemento essencial e desempenha importante papel na nutrição animal. Porém em niveis tóxicos, os sais de Co produzem superprodução de eritrócitos, hiperplasia da medula óssea e aumento do fluxo sangüíneo, podendo levar a uma anemia se houver ingestão elevada por causar a baixa absorção de ferro. Pode provocar vômitos e diarréia [PEDRO,1998]. 
Níquel é um elemento não essencial que em doses elevadas pode causar dermatites e afetar nervos cardíacos e respiratórios [MERCK, 1976]. Em níveis elevados pode apresentar efeitos carcinogênicos [MOORE et al., 1993].

Cobre é um elemento essencial amplamente distribuido nos tecidos biológicos, agindo em alguns processos enzimáticos. Por via oral, é considerado pouco tóxico. Em doses elevadas torna-se tóxico, levando a sintomas hemolíticos, lesões no fígado e cérebro [YABE, 1995].

Cádmio é um metal não essencial de elevado potencial tóxico para plantas e animais. Em humanos e animais, há fortes evidências de que o rim é o principal alvo da toxicidade do cádmio, após exposição por tempo prolongado. É cumulativo porque não é rapidamente eliminado, permanecendo por décadas no organismo [BAIRD, 2002].

Arsênio é um elemento que se for ingerido em quantidade de traço é considerado essencial, porém este elemento é mais conhecido por sua ação tóxica. É carcinogênico para os seres humanos. Por inalação causa câncer de pulmão e a ingestão causa câncer de pele e fígado [BAIRD, 2002; CHIRENJE et al., 2003].

Mercúrio é um elemento tóxico de efeito cumulativo. Principalmente na forma orgânica causa danos irreparáveis ao sistema nervoso, pois esta espécie entra imediatamente na corrente sangüínea. A espécie encontrada nas tintas é orgânica (acetato de fenilmercúrico) [TEVES, 2001]. 


\subsection{Forno de microondas}

Por volta dos anos 70 , começou-se a utilizar o aquecimento por microondas para aumentar a velocidade do processo de digestão de amostras e favorecer reações químicas [KINGSTON, 1988; BURGUERA, BURGUERA, 1998].

Microondas são ondas eletromagnéticas, com freqüências compreendidas entre 300 e $300.000 \mathrm{Mhz}$ e comprimento de onda entre 0,1 a $100 \mathrm{~cm}$. São emitidas por um dispositivo eletrônico, denominado magnetron. Este dispositivo fica na cavidade do forno transforma energia elétrica em campo eletromagnético.

As microondas consistem em uma forma de energia eletromagnética, não ionizante, que provoca a movimentação das moléculas a qual pode ocorrer por migração de íons ou rotação de dipolos, sem causar mudanças na estrutura molecular. Devido a esse mecanismo de "stress" induzido, ocorre o aquecimento, pela interação entre a radiação microondas e as moléculas da amostra. Para que haja aquecimento é necessário a presença de moléculas polares e ions em solução [ARRUDA, SANTELLI 1997].

Existem dois tipos de sistemas de aquecimento por microondas: sistema com cavidade que utiliza frascos fechados, onde a energia de microondas é dispersa através da cavidade, e sistema focalizado com frasco aberto à pressão atmosférica, onde a energia é focalizada no frasco de digestão que contém a amostra. Devido à influência dos dipolos das moléculas na absorção das microondas, é necessário conduzir a digestão das amostras em presença de um ácido ou misturas de ácidos [ARRUDA, SANTELLI 1997].

Sua utilização tem se revelado bastante conveniente no que diz respeito à diminuição do tempo de digestão da amostra, menor consumo de reagentes e níveis menores de contaminação. Portanto, procedimentos usualmente demorados em sistemas convencionais podem ser substituídos por aquecimento por microondas diminuindo o tempo de digestão da amostra. Desse modo, processos convencionais de aquecimento que poderiam levar várias horas são realizados em poucos min, produzindo o mesmo efeito [AGAZZI, PIROLA, 2000]. 


\section{Revisão bibliográfica}

\subsection{Análise de tintas}

Para a aplicação de um método para controle de processos e / ou controle de qualidade na indústria, procura-se empregar, preferencialmente, método analítico único ou que atenda a maioria das matrizes, visando principalmente aumentar a produtividade, minimizar resíduos e diminuir custos tanto na produção quanto no controle de qualidade.

Normas referentes à análise de tintas tratam em sua maioria sobre o tempo de secagem, granulometria, consistência da tinta, teor de substâncias voláteis e aderência [NBR 3, 1987]. A NBR 9944 (1987) trata da determinação do teor de pigmentos, ou seja, da quantidade de pigmento que não foi emulsionado à água. $A$ norma MB 61 trata da determinação dos pigmentos em tintas, absorção em óleo, comparação de cor e determinação de um determinado pigmento (por exemplo, cromato de chumbo ou azul da Prússia). Métodos de determinação de alguns elementos como chumbo, antimônio e bário foram listados por Watson (1994).

O que é observado nas normas técnicas encontradas para a determinação de metais em tintas é que não existe um método único, que vise a obtenção máxima de informações, ou seja, determinação de um grande número de analitos por meio de um único procedimento. Isso se deve à complexidade deste tipo de matriz. Esse fato tem levado à investigação de método alternativos por vários autores.

Paudyn et al. (1993), empregaram digestão assistida por microondas à amostras de tinta visando a determinação de elementos de interesse por ICP OES. Os resultados obtidos foram comparados aos obtidos da análise por ativação por neutrons, que foi o método utilizado como referência. Uma amostra de tinta certificada contendo chumbo também foi avaliada. Os resultados das determinações de $\mathrm{Pb}, \mathrm{Ba}, \mathrm{Zn}, \mathrm{Ca}, \mathrm{Ti}, \mathrm{S}, \mathrm{Mg}, \mathrm{Al}, \mathrm{Cu}, \mathrm{Sb}, \mathrm{Mn}$ por ativação neutrônica foram comparados com os obtidos por ICP OES após digestão usando a mistura $\mathrm{HNO}_{3} / \mathrm{HF}$, obtendo-se boa concordância entre eles. Quando se utilizou a mistura $\mathrm{HNO}_{3} / \mathrm{HCl}$ (água régia) os resultados apresentaram diferenças significativas para os elementos $\mathrm{Ba}, \mathrm{Ti}, \mathrm{Al}, \mathrm{Sb}$ e $\mathrm{Mn}$. 
Digestão ácida usando forno de microondas foi utilizada como procedimento comparativo para a avaliação da técnica de ablação por laser. No procedimento de digestão, a tinta foi inicialmente calcinada em bico de bunsen, as cinzas e uma mistura ácida de $5 \mathrm{~mL}$ de $\mathrm{HNO}_{3}$ e $2 \mathrm{~mL}$ de $\mathrm{HF}$, ambos concentrados, foram colocadas nas bombas de digestão do forno $e$ irradiadas por 2 min a aproximadamente $600 \mathrm{~W}$. Após o resfriamento com auxilio de $20 \mathrm{~mL}$ de água a solução foi quantitativamente transferida para um béquer de Teflon e seu volume reduzido a $1 \mathrm{~mL}$ em uma chapa de aquecimento a uma temperatura de $120^{\circ} \mathrm{C}$. A solução resultante foi filtrada, seu volume acertado a $100 \mathrm{~mL}$ e os analitos determinados por ICP OES [KENNETH e CHAN, 1997].

Wong (1981) propõe método para a determinação de traços de cério em tintas amarelas usadas na pintura de asfalto usando o método de cinzas e posterior determinação dos elementos de interesse por ICP OES. Neste caso, 10,0 g de tinta foram secas em chapas de aquecimento, em seguida, a amostra seca foi calcinada a $450{ }^{\circ} \mathrm{C}$ em mufla por $6 \mathrm{~h}$ visando destruir a matéria orgânica. As cinzas foram retomadas em uma mistura de $10 \mathrm{~mL}$ de $\mathrm{HNO}_{3}, 10 \mathrm{~mL}$ de $\mathrm{HCl}$ e algumas gotas de $\mathrm{H}_{2} \mathrm{O}_{2}$. A solução resultante foi diluída a $100 \mathrm{~mL}$ e uma aliquota de $10 \mathrm{~mL}$ da solução foi novamente diluída a $100 \mathrm{~mL}$ e foi usada para a determinação de cério na amostra. Segundo o autor o método estabelecido é simples e rápido para a determinação de traços de cério em amostras de tintas usando ICP OES.

Davis e Burns (1999), apresentaram um estudo para identificar e quantificar categorias de estruturas pintadas como fontes possiveis de contaminação de chumbo. No desenvolvimento deste estudo foi feita a determinação de chumbo das tintas coletadas das superfícies pintadas de 18 edificações. Para a digestão da amostra foi utilizado o procedimento ASTM D335-85a e a determinação do chumbo foi feita por AAS. Estes resultados foram comparados com os obtidos após lixiviação usando água da chuva sintética. A relação entre o teor de chumbo da tinta e a concentração do lixiviado apresentam alguma correlação, ou seja, quanto maior o teor de chumbo total, maior foi a concentração de chumbo na água da chuva sintética.

Korn et al. (2002), compararam quatro procedimentos de digestão de $\mathrm{TiO}_{2}$ (componente básico de tintas) usando as misturas $\left(\mathrm{NH}_{4}\right)_{2} \mathrm{SO}_{4} / \mathrm{H}_{2} \mathrm{SO}_{4}, \mathrm{HF} / \mathrm{H}_{2} \mathrm{SO}_{4}$, $\mathrm{H}_{3} \mathrm{PO}_{4}$ e $\mathrm{HCl} / \mathrm{HNO}_{3} / \mathrm{HF}$ sob aquecimento. A determinação dos analitos ( $\mathrm{Al}, \mathrm{Cd}, \mathrm{Cr}$, $\mathrm{Fe}, \mathrm{Mn}, \mathrm{P}, \mathrm{Zn}$ e $\mathrm{Zr}$ ) foi feita usando um ICP OES com configuração radial e axial. Os 
métodos de digestão propostos foram comparados. A mistura $\left(\mathrm{NH}_{4}\right)_{2} \mathrm{SO}_{4} / \mathrm{H}_{2} \mathrm{SO}_{4}$ digeriu completamente a amostra à uma temperatura de $250{ }^{\circ} \mathrm{C}$ em $30 \mathrm{~min}$, a mistura $\mathrm{HF} / \mathrm{H}_{2} \mathrm{SO}_{4}$ foi aquecida à uma temperatura de $200{ }^{\circ} \mathrm{C}$ e consumiu um tempo elevado para a digestão (aproximadamente $4 \mathrm{~h}$ ), a utilização de $\mathrm{H}_{3} \mathrm{PO}_{4}$ a uma temperatura de $250{ }^{\circ} \mathrm{C}$ por 15 min não foi muito viável devido a viscosidade da solução resultante interferir no transporte da mesma, necessitando de grande diluição da amostra e, finalmente, a mistura ácida $\mathrm{HCl} / \mathrm{HNO}_{3} / \mathrm{HF}$ foi eficiente na digestão da amostra e consumiu tempo de 20 min utilizando aquecimento com radiação microondas.

Hee e Boyle (1988), apresentaram um estudo para a otimização de método para a análise simultânea de $\mathrm{Ag}, \mathrm{Al}, \mathrm{Ba}, \mathrm{Ca}, \mathrm{Cd}, \mathrm{Co}, \mathrm{Cr}, \mathrm{Cu}, \mathrm{Fe}, \mathrm{K}, \mathrm{Li}, \mathrm{Mg}, \mathrm{Mn}, \mathrm{Na}$, $\mathrm{P}, \mathrm{Pb}, \mathrm{S}, \mathrm{Sb}, \mathrm{Si}, \mathrm{Sr}$, Ti e $\mathrm{Zn}$ em tinta por ICP OES. Neste estudo foram apresentadas várias composições ácidas de diferentes concentrações empregadas na digestão das amostras. Foi feita a comparação entre os métodos utilizando bombas de decomposição e digestão assistida por microondas. Dos elementos avaliados, $\mathrm{Ag} \mathrm{e}$ $\mathrm{Sb}$ apresentam resultados discordantes entre si. Também estudaram a digestão em chapa de aquecimento para a determinação de $\mathrm{Ag}, \mathrm{Al}, \mathrm{Ba}, \mathrm{Cr}, \mathrm{Cu}, \mathrm{Fe}, \mathrm{Mg}, \mathrm{Mn}, \mathrm{Pb}$, $\mathrm{Sr}, \mathrm{Ti}$ e $\mathrm{Zn}$. Foram comparadas diferentes misturas ácidas, concluindo que a digestão depende da mistura ácida empregada.

Pimenta e Vital (1994), usaram a absorção atômica para a determinação de chumbo, cádmio e zinco em amostras de cabelo de pintores profissionais e indivíduos que não trabalhavam no setor. Neste estudo também foi feita análise de tintas usando $\mathrm{HCl}$ e $\mathrm{HNO}_{3}$ para a digestão da amostra, uma adaptação da norma técnica ISO $n^{\circ} 6713$. Mesmo sendo o chumbo um elemento bastante tóxico e banido na comunidade Européia e USA, nas tintas analisadas naquele ano, foi encontrado alto teor em algumas cores e marcas variando de 0,004 à $9,04 \%(\mathrm{~m} / \mathrm{m})$. O teor de cádmio não excedeu a $0,004 \%(\mathrm{~m} / \mathrm{m})$, zinco não excedeu a $0,84 \%(\mathrm{~m} / \mathrm{m})$ e não foi detectado em algumas amostras.

Métodos de análise de tintas por Fluorescência de Raios X (FRX) têm sido desenvolvidos, principalmente, para aplicações em objetos de arte e antigüidades, por ser uma técnica multielementar, não destrutiva e que, em princípio, não exige preparação de amostras [CECHAK, 2004]. Entretanto, problemas referentes a interferências interelementares provenientes da tinta elou do substrato, levam à necessidade de múltiplas medições e correções manuais para a obtenção de 
resultados consistentes. A fim de evitar esses problemas, Afshari et.al. (1997), desenvolveram um equipamento de fluorescência portátil dedicado à determinação de chumbo em tintas com correções automáticas das interferências. Técnicas de quimiometria e métodos matemáticos têm sido usados para desenvolver protocolos analíticos para identificar e classificar amostras de tintas [HALL, 2003; BUENO, 2005].

Em um amplo estudo de avaliação da qualidade de tintas acrílicas usadas para a pintura de pisos também foi feita a análise química qualitativa (metais) do material. A técnica de Fluorescência Rajos $X$ foi empregada na tinta na forma de filmes secos e os seguintes elementos foram encontrados na amostra: Si, Fe, Mg, $\mathrm{Ca}, \mathrm{Al}, \mathrm{Na}, \mathrm{Ke} \mathrm{Ti}$ [NASCIMENTO et al.,2004].

\subsection{Degradação de filmes poliméricos}

A degradação de filmes poliméricos vem sendo avaliada e várias técnicas de análise têm sido empregadas [YANG et al., 2002; BATISTA, 2004]. Este estudo é fundamental para avaliar alterações na morfologia, variação de brilho e dureza dos filmes de revestimentos.

Yang et al. (2001, 2002, 2003), estudaram as alterações na superfície de revestimento poliuretano. Nestes estudos foram avaliadas as degradações ocorridas em diferentes condições e tempo de exposição do material. Os meios de degradação utilizados foram câmaras de UV e névoa salina, e as técnicas de caracterização foram MFA (Microscopia de Força Atômica) e MEV (Microscopia Eletrônica de Varredura). A degradação preferencial na superfície do revestimento foi observada usando MFA. Neste caso, foi observada alteração de brilho. Imagens das degradações em função do tempo são apresentadas e discutidas.

Usando a técnica de MFA, Biggs et al. (2001) verificaram alterações na estrutura do filme de poliéster que foi submetido à ação de intemperismo natural e artificial (Câmara de UV). As alterações estão associadas à redução do brilho, cor e morfologia de filme. Devido à perda de material polimérico, partículas do pigmento poderiam ficar expostas e, conseqüentemente, ocorrer erosão do pigmento.

A cristalização do material polimérico em polietileno após intemperismo acelerado foi observada por Gulmine et al. (2003). Portanto, observa-se que pode 
ocorrer a degradação polimérica das tintas e conseqüente exposição dos pigmentos de modo que estes compostos ficam mais susceptiveis a ação de intemperismo natural, facilitando a migração de componentes tóxicos para o meio ambiente.

Wernstahl (1996), relaciona a perda de brilho de um sistema acrílico/melamina à perda de reticulação após um estudo de degradação.

A absorção de água de um revestimento acrílico/melamina, causada devido ao aumento da umidade relativa e temperatura, facilitou a hidrólise resultando na formação de determinada quantidade de formaldeído na amostra. Os radicais HCO • e $\mathrm{H} \bullet$ produzidos do formaldeído na presença de radiação UV reagem com o oxigênio produzindo peróxido no filme e, com isto, promovem a degradação polimérica resultando em "crateras" na superfície da amostra [Nguyen et al].

Segundo, Edge et al. o aumento de umidade aliado a temperatura colabora com a degradação do material. Neste caso, estudou a mudança na estrutura de poli tereftalato de etileno (PET), causada pela hidrólise do material. 


\section{Objetivos}

Os objetivos deste trabalho foram desenvolver métodos adequados para a determinação de $\mathrm{Al}, \mathrm{Cr}, \mathrm{Mn}, \mathrm{Co}, \mathrm{Ni}, \mathrm{Cu}, \mathrm{As}, \mathrm{Cd}$ e $\mathrm{Pb}$ em tintas à base de água e solvente orgânico, por ICP OES e desenvolver método para avaliar a migração e, conseqüentemente, a disponibilidade destes elementos presentes nas tintas para o ambiente. 


\section{Materiais e métodos}

\subsection{Amostras}

Foram utilizadas tintas à base de água e à base de solvente orgânico nas cores azul, vermelha e amarela de diferentes marcas adquiridas no mercado de São Paulo. Em todo o desenvolvimento deste projeto foram utilizadas amostras reais.

\subsection{Reagentes e soluções}

Utilizou-se em todas as etapas do desenvolvimento deste trabalho, água destilada e desionizada em coluna de troca iônica (Permution) e água com elevado grau de pureza $\left(18,2 \mathrm{M} \Omega \mathrm{cm}^{-1}\right)$ purificada em um sistema de ultrapurificação Milli $Q^{\circledR}$ (Millipore, Bedford, MA, EUA).

Os ácidos, $\mathrm{HNO}_{3}(65 \% \mathrm{~m} / \mathrm{m}$, Merck), $\mathrm{HCl}(37 \% \mathrm{~m} / \mathrm{m}$, Merck), $\mathrm{HF}(48 \% \mathrm{~m} / \mathrm{m}$, Nuclear e Merck), $\mathrm{H}_{2} \mathrm{SO}_{4}\left(98 \% \mathrm{~m} / \mathrm{m}\right.$, Merck) e $\mathrm{CH}_{3} \mathrm{COOH}(99,8 \%$, Merck) utilizados para a digestão das amostras, testes de lixiviação, preparação dos brancos e das soluções de calibração foram de grau P.A. $\mathrm{O} \mathrm{H}_{2} \mathrm{O}_{2}(30 \%(\mathrm{~m} / \mathrm{m})$ Merck) também foi utilizado na preparação das amostras.

As soluções de $\mathrm{Al}, \mathrm{Cd}, \mathrm{Cr}, \mathrm{Cu}, \mathrm{Mn}, \mathrm{Co}, \mathrm{Pb}, \mathrm{As}$ e $\mathrm{Ni}$ foram preparadas a partir de soluções estoque de $1000 \mathrm{mg} \mathrm{L}^{-1}$ (Tritisol Merck).

A partir de diluições sucessivas das soluções citadas, foram obtidas as soluções usadas nas curvas analíticas. O teor de ácido das soluções multielementares usadas nas curvas analíticas foram os mesmos usados na digestão das amostras.

Soluções-tampão de $\mathrm{pH}=4$ e pH $=8$ da Merck foram utilizadas na calibração do medidor de $\mathrm{pH}$. 


\subsection{Instrumentação e material utilizado}

- Espectrômetros de Emissão Ótica com Plasma Indutivamente Acoplado (ICP OES) modelos Spectroflame Modula seqüencial (radial) e CIROS ${ }^{C C D}$ simultâneo (axial) ambos da Spectro Co, Germany;

- Espectrômetro de Massas com Plasma Induzido Acoplado (ICP MS). Elan 6100, da Perkin-Elmer, EUA;

- Forno de microondas com vaso fechado ETHOS 1600, Milestone, Sorisole, Itália, equipado com 5 frascos de Teflon $\circledast$, pressão máxima de operação 110 atm;

- Forno de microondas focalizado modelo 350 da Spex equipado com tubos de vidro borossilicato com capacidade de $250 \mathrm{~mL}$;

- Microscópio Eletrônico de Varredura da Marca LEO, Modelo LEO 1450VP - com EDS (Energy - Dispersive Spectrometer), Oxford INKA ENERGY;

- Forno mufla com microondas da Milestone;

- Câmara de intemperismo acelerado do tipo "Weather-Ometer" marca Atlas, modelo XW-WR;

- Analisador Direto de Mercúrio, ADM-80 da Milestone;

- Balança analítica, Mettler, AG 245;

- Pipetas graduadas de $10 \mathrm{~mL}$;

- Micropipetas 100-1000 $\mu \mathrm{L}$ e 100-2500 $\mu \mathrm{L}$, marca Eppendorf;

- Frascos de polietileno com capacidade de $15 \mathrm{~mL}$ e $50 \mathrm{~mL}$, marca Sarstedt;

- Placas de polietileno de alta densidade;

- Aplicador de tinta tipo "Wire-Cator", Byk Gardener;

- Espátula de porcelana;

- Balões volumétricos de vidro e de polietileno de 25 e $50 \mathrm{~mL}$;

- Papel de filtração (Whatman);

- Medidor de pH digital portátil (pH Metter.Unity Instrumentos).

Todo material que foi utilizado para preparar e armazenar soluções foi previamente lavado com detergente, enxaguado com água destilada e desionizada. A descontaminação foi feita deixando-se os frascos e vidrarias imersas em solução $10 \% \mathrm{v} / \mathrm{v}$ de ácido nítrico, Merck, $65 \%(\mathrm{v} / \mathrm{v})$ por, no mínimo, $24 \mathrm{~h}$ visando a dessorção de possíveis íons metálicos adsorvidos na superfície destes recipientes. 
Antes de ser usado, todo material foi enxaguado com água ultrapura. As placas de polietileno de alta densidade usadas como substratos na secagem das tintas sofreram o mesmo procedimento de limpeza citado.

\subsection{Método de tratamento da amostra}

\subsubsection{Obtenção dos filmes secos}

Visando a homogeneidade da amostra, a lata de tinta foi agitada manualmente por 1 min e em seguida, com o auxílio de uma espátula de porcelana, fez-se a agitação da tinta por meio de movimentos circulares e contínuos por $5 \mathrm{~min}$. Esta é uma adaptação da norma da ABNT, NBR 5839 (1984), que trata da coleta de amostras de tintas e vernizes. Este procedimento foi usado em todas as etapas do desenvolvimento do projeto.

As tintas foram aplicadas sobre placas de polietileno de alta densidade medindo 65×233 mm, utilizando um aplicador de filme do tipo "Wire-Cator" (Byk Gardener). Em seguida, foram secas em estufa a $50^{\circ} \mathrm{C}$ por 5 dias. Os filmes secos de tinta foram destacados com auxílio de espátulas e acondicionados em frascos de polietileno.

Outros substratos também foram testados, como acrílico, celofane e vidro e os resultados são apresentados e discutidos.

\subsubsection{Digestão das amostras}

Os métodos usados no estudo de digestão das amostras de tintas à base de água e à base de solvente orgânico serão apresentadas e discutidas no capítulo Resultados e Discussão para facilitar a compreensão e tornar a leitura mais dinâmica. O procedimento geral está apresentado na Figura 5.1. 


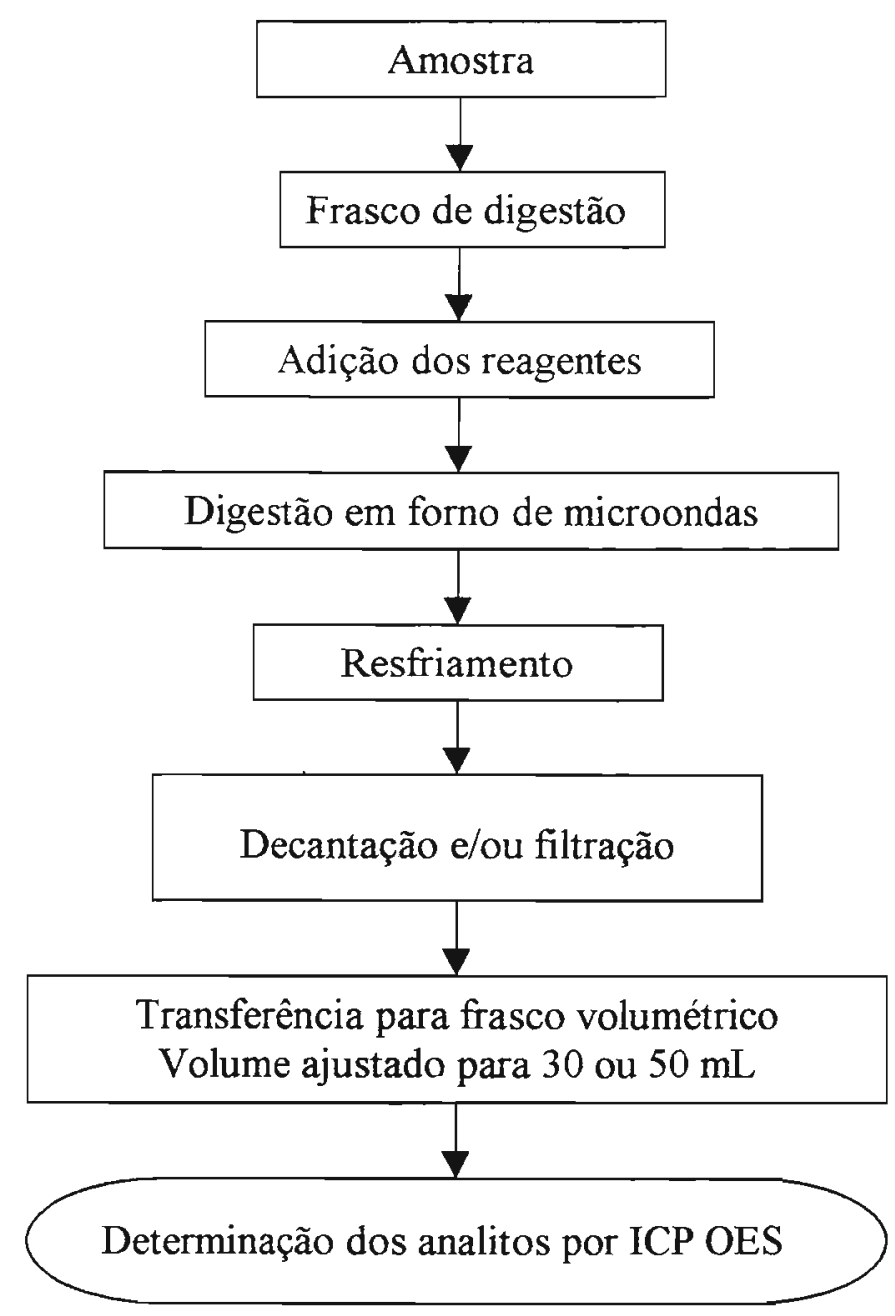

Figura 5.1. Procedimento de digestão das amostras e determinação dos analitos

\subsubsection{Desenvolvimento do protocolo analítico}

As tintas à base de água que foram digeridas em meio fluorídrico tiveram seus analitos determinados usando o Espectrômetro de emissão ótica com plasma indutivamente acoplado (ICP OES), modelo Spectroflame Modula da Spectro Co, seqüencial, instalado no Laboratório de Absorção e Emissão Atômica do Instituto de Química da USP o qual usa a posição axial da tocha. Este equipamento foi utilizado devido ao canal central da tocha ser feito de material resistente a HF.

O equipamento seqüencial é composto por uma ótica no vácuo, com $1 \mathrm{~m}$ de distância focal, e uma ótica ao ar com grade de difração holográfica de 2400 linhas $/ \mathrm{mm}$. O gerador de rádio freqüência de $27,12 \mathrm{MHz}$ permite um ajuste de 
potência entre 750 e $1700 \mathrm{~W}$, dependendo da matriz analítica a ser estudada. O sistema de introdução da amostra é equipado com nebulizador de fluxo cruzado (Crossflow). A amostra é bombeada para a tocha através de uma bomba peristáltica acoplada ao equipamento e seu fluxo é controlado pelo programa do equipamento

Foi utilizado um espectrômetro de massas quadrupolar com fonte de plasma induzido de argônio, com um nebulizador de fluxo cruzado acoplado à uma câmara de nebulização, para a determinação de chumbo em tinta à base de água de cor vermelha após a digestão com mistura ácida contendo HF. Este equipamento possui tocha e nebulizador resistentes a HF.

Quando não foi usado HF na digestão, utilizou-se o Espectrômetro de Emissão Ótica com Plasma Indutivamente Acoplado (ICP OES) simultâneo CIROS $^{\mathrm{CCD}}$ da Spectro Co para a determinação dos metais, $\mathrm{Al}, \mathrm{Cd}, \mathrm{Cr}, \mathrm{Cu}, \mathrm{Mn}, \mathrm{Co}, \mathrm{Pb}$ e $\mathrm{Ni}$ presentes nas tintas à base de água que foram solubizadas em meio nítrico e clorídrico, tintas à base de solvente orgânico e as soluções resultantes dos testes de lixiviação. Este instrumento, instalado no Laboratório de Absorção e Emissão Atômica do Instituto de Química da USP, usa a posição axial da tocha e detector de estado sólido. O equipamento é composto por uma ótica em nitrogênio, com $1 \mathrm{~m}$ de distância focal, um arranjo de CCDs no círculo de Rowland e uma grade de difração holográfica de 2400 linhas $/ \mathrm{mm}$. O gerador de rádio freqüência de $27,12 \mathrm{MHz}$ permite um ajuste de potência entre 750 e $1700 \mathrm{~W}$, dependendo da matriz analítica a ser estudada. O sistema de introdução da amostra é equipado com nebulizador de fluxo cruzado (Crossflow). A amostra é bombeada para a tocha, através de uma bomba peristáltica acoplada ao equipamento e seu fluxo é controlado pelo programa do equipamento. A tocha é de quartzo.

As condições de operação dos Espectrômetros de emissão ótica (ICP OES) e de massas com plasma (ICP MS) estão apresentadas na Tabela 5.1. 
Tabela 5.1. Parâmetros instrumentais utilizados na operação do espectrômetro de emissão ótica Spectroflame Modula (seqüencial), $\operatorname{CIROS}^{\mathrm{CCD}}$ (simultâneo) da Spectro Co e ICP MS Perkin Elmer ELAN 6100.

\begin{tabular}{|c|c|c|c|}
\hline Parámetros & $\begin{array}{l}\text { TCPOES } \\
\text { Spectrofiame Modula }\end{array}$ & $\begin{array}{l}\text { ICP OES } \\
\text { CIROS }^{\text {COD }}\end{array}$ & $\begin{array}{l}\text { ICPMS } \\
\text { Peikin EImer }\end{array}$ \\
\hline Potência & $1,2 \mathrm{KW}$ & $1,4 \mathrm{KW}$ & $1,0 \mathrm{KW}$ \\
\hline Gerador RF & & & $40 \mathrm{MHz}$ \\
\hline $\begin{array}{l}\text { Fluxo de gás Ar } \\
\text { refrigerante: }\end{array}$ & $12 \mathrm{~L} \mathrm{~min} \min ^{-1}$ & $12\left\llcorner\min ^{-1}\right.$ & 12 L. $\min ^{-1}$ \\
\hline Fluxo de gás Ar auxiliar: & $1,2 \mathrm{~L} \min ^{-1}$ & $1,0 \mathrm{~mL} \mathrm{~min}^{-1}$ & $1,0 \mathrm{~mL} \mathrm{~min}^{-1}$ \\
\hline Fluxo de gás Ar de arraste: & $1,0 \mathrm{~mL} \mathrm{~min}^{-1}$ & $1,0 \mathrm{~mL} \mathrm{~min}^{-1}$ & $0,86 \mathrm{~mL} / \mathrm{min}$ \\
\hline Altura de observação acima & $12 \mathrm{~mm}$ & & - \\
\hline da bobina de cobre: & Tocha posição radial & Tocha posição axial & Tocha posição axial \\
\hline $\begin{array}{c}\text { Vazão de Introdução da } \\
\text { Amostra: }\end{array}$ & $1,5 \mathrm{~mL} / \mathrm{min}$ & $1,5 \mathrm{~mL} / \mathrm{min}$ & $1,4 \mathrm{~mL} / \mathrm{min}$ \\
\hline Tempo de integração & $5 s$ & $3 s$ & $55 \mathrm{~s}$ \\
\hline Pressão do nebulizador & 26 psi (cross-flow) & 26 psi (cross-flow) & (cross flow) \\
\hline
\end{tabular}

\subsubsection{Elaboração dos programas para controle instrumental e aquisição de dados do Espectrômetro Modula e CIROS da Spectro}

Os comprimentos de ondas escolhidos foram selecionados pelo critério de sensibilidade da linha livre de superposições espectrais, originadas por outros elementos presentes na amostra. Os equipamentos utilizados contêm uma biblioteca de linhas espectrais que nos permite fazer uma escolha criteriosa dos comprimentos de ondas. Quando necessário a literatura também foi consultada [BOUMANS, 1984] e foram feitas varreduras em torno de cada linha usando soluções de concentração de $10 \mathrm{mg} \mathrm{L}^{-1}$ dos elementos de interesse e de elementos que estão presentes em algumas tintas mas que não fazem parte deste estudo, como Ti, Si, $\mathrm{Fe}, \mathrm{Ba}$ e $\mathrm{Zn}$.

$\mathrm{Na}$ Tabela 5.2 são apresentados os comprimentos de ondas para cada elemento. A emissão de fundo ("background") foi corrigida em 1 ou 2 pontos fora do pico máximo de emissão do analito. $O$ refinamento das linhas selecionadas foi feito com soluçōes monoelementares de $10 \mathrm{mg} \mathrm{L}^{-1}$. 
Tabela 5.2. Comprimentos de onda (nm)

\begin{tabular}{|c|c|c|c|}
\hline 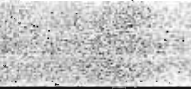 & Spectroflame Modula & 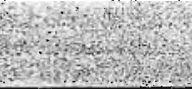 & CIROS $^{O C D}$ \\
\hline Elemento & Linha de emissão $(\lambda)(\mathrm{nm})$ & Elemento & Linha de emissão $(\lambda)(\mathrm{nm})$ \\
\hline $\mathrm{Al}(\mathrm{I})$ & 396,152 & $\mathrm{Al}(\mathrm{II})$ & 167,078 \\
\hline $\mathrm{Cr}(I I)$ & 283,563 & $\mathrm{Cr}(\mathrm{II})$ & 205,552 \\
\hline $\operatorname{Mn}(I I)$ & 257,610 & $\mathrm{Mn}(11)$ & 257,610 \\
\hline Co (II) & 228,616 & Co (II) & 228,615 \\
\hline $\mathrm{Ni}$ (II) & 231,604 & $\mathrm{Ni}(\mathrm{II})$ & 221,648 \\
\hline $\mathrm{Cu}(\mathrm{I})$ & 327,396 & $\mathrm{Cu}$ (II) & 219,226 \\
\hline As ( ) & 188,979 & As (1) & 193,759 \\
\hline $\mathrm{Cd}(\mathrm{II})$ & 214,438 & $\mathrm{Cd}(\mathrm{II})$ & 214,438 \\
\hline $\mathrm{Pb}(\mathrm{II})$ & 182,200 & $\mathrm{~Pb}(\mathrm{II})$ & 168,215 \\
\hline
\end{tabular}

Foi feita análise semiquantitativa das amostras a fim de se obter uma estimativa dos teores dos elementos de interesse. Para este fim foram feitas varreduras em torno de cada linha de emissão selecionada usando soluçōes sintéticas de concentrações conhecidas e soluções obtidas da digestão das amostras de tintas. $O$ equipamento, por meio do programa de controle, permite a comparação das alturas dos picos de emissão provenientes de cada solução e estima a concentração de cada elemento na amostra, pois a concentração do analito é proporcional à intensidade de radiação emitida por ele. Este procedimento nos dá informações necessárias para a otimização da tarefa analítica, ou seja, definir as concentrações das soluções que serão utilizadas na obtenção da curva analítica.

Utilizou-se o método de curva analítica na determinação dos elementos de interesse por meio de soluções padrão multielementares. As faixas de concentração e os programas utilizados são apresentados nas Tabelas 5.3, 5.4 e 5.5 . 
Tabela 5.3. Programas analíticos e concentrações utilizadas na preparação da curva analítica - Espectrômetro Spectroflame Modula.

\begin{tabular}{|l|l|l|}
\hline IDENTIFICACÁOO & ELEMENTOS & CONCENTRACAOO $\left(\mathrm{mg} \mathrm{L}^{-1}\right)$ \\
\hline Programa A & $\mathrm{Al}$ & Branco $-10-25-30-50$ \\
\hline Programa B & $\mathrm{Cr}, \mathrm{Mn}, \mathrm{Co}, \mathrm{Ni}, \mathrm{Cu}, \mathrm{Cd}$ e Pb & Branco -0,2 - 0,5-1,0-2,0 \\
\hline
\end{tabular}

Tabela 5.4. Programas analíticos e concentrações utilizadas na preparação da curva analítica - Espectrômetro CIROS $^{\mathrm{CCD}}$.

\begin{tabular}{|c|c|c|}
\hline IDENTIFICAÇÄO & ELEMENTOS & CONCENTRACAAO $\left(\mathrm{lng}^{-3}\right)$ \\
\hline Programa A & $\mathrm{Pb}$ & Branco $-1,0-2,5-5,0-7,5-10,0$ \\
\hline Programa B & $\mathrm{Cr}, \mathrm{Mn}, \mathrm{Co}, \mathrm{Ni}, \mathrm{Cu}, \mathrm{Cd}$ e $\mathrm{Al}$ & Branco $-0,2-0,5-1,0-2,0$ \\
\hline
\end{tabular}

Tabela 5.5. Programa analítico e concentrações utilizadas na preparação da curva analítica - Espectrômetro CIROS ${ }^{\mathrm{CCD}}$.

\begin{tabular}{|l|l|l|}
\hline IDENTIFICACÁAO & ELEMENTOS & CONCENTRAGAO (mg L I) \\
\hline Programa & $\mathrm{Pb}, \mathrm{Cr}, \mathrm{Mn}, \mathrm{Co}, \mathrm{Ni}, \mathrm{Cu}, \mathrm{Cd}$ e Al & Branco $-0,5-1,0-5,0-10,0-20,0$ \\
\hline
\end{tabular}

\subsubsection{Determinação de mercúrio - programa de aquecimento do ADM}

$\mathrm{Na}$ determinação de $\mathrm{Hg}$ feita pelo Analisador Direto de Mercúrio (ADM-80), a amostra sólida ou líquida é seca e decomposta termicamente em um forno que atinge temperaturas de 120 a $900^{\circ} \mathrm{C}$ em um fluxo de oxigênio. Os gases provenientes da combustão são direcionados a uma coluna catalítica, onde sofrem decomposição $e$ as espécies de mercúrio existentes são reduzidas a mercúrio metálico. $\mathrm{O}$ vapor de mercúrio é amalgamado no forno amalgamador e após um novo ciclo de aquecimento $\circ \mathrm{Hg}$ é dessorvido e arrastado novamente pelo fluxo de oxigênio para a quantificação que é realizada por um espectrômetro de absorção atômica a 254nm [EPA / 600/R-04/012, 2004]. Na Figura 5.2 é mostrado um esquema do equipamento. 
Este tipo de análise não requer pré-tratamento da amostra, os resultados são obtidos 5 min após a introdução da amostra, há menor geração de resíduo, menos erros sistemáticos e menos exposição do técnico devido à volatilização do $\mathrm{Hg}$ durante a manipulação da amostra. É um método totalmente livre de efeitos de matriz e permite calibração com padrões sintéticos, além de atingir o limite de detecção de 0,02 $\mathrm{ng}$ de $\mathrm{Hg}$.

Especificações técnicas do equipamento: espectrofotômetro de canal único com fluxo seqüencial através da célula óptica, lâmpada de vapor de mercúrio de baixa pressão, $\lambda 253,65 \mathrm{~nm}$, fotodetector UV a base de silício, limite de deteç̧ão $0,02 \mathrm{ng} \mathrm{Hg}$, faixa linear (I) $-0-35 \mathrm{ng} \mathrm{Hg}$ e faixa linear (II) $-35-600 \mathrm{ng} \mathrm{Hg}$, repetibilidade $<1,5 \%$, completamente auto programável (40 amostras), curva analítica de calibração com soluções aquosas ou amostras sólidas, volume máximo para líquidos $500 \mu \mathrm{L}$ e para sólidos $500 \mathrm{mg}$, gás carregador $\mathrm{O}_{2}\left(160 \mathrm{ml} \mathrm{min}^{-1}\right)$.

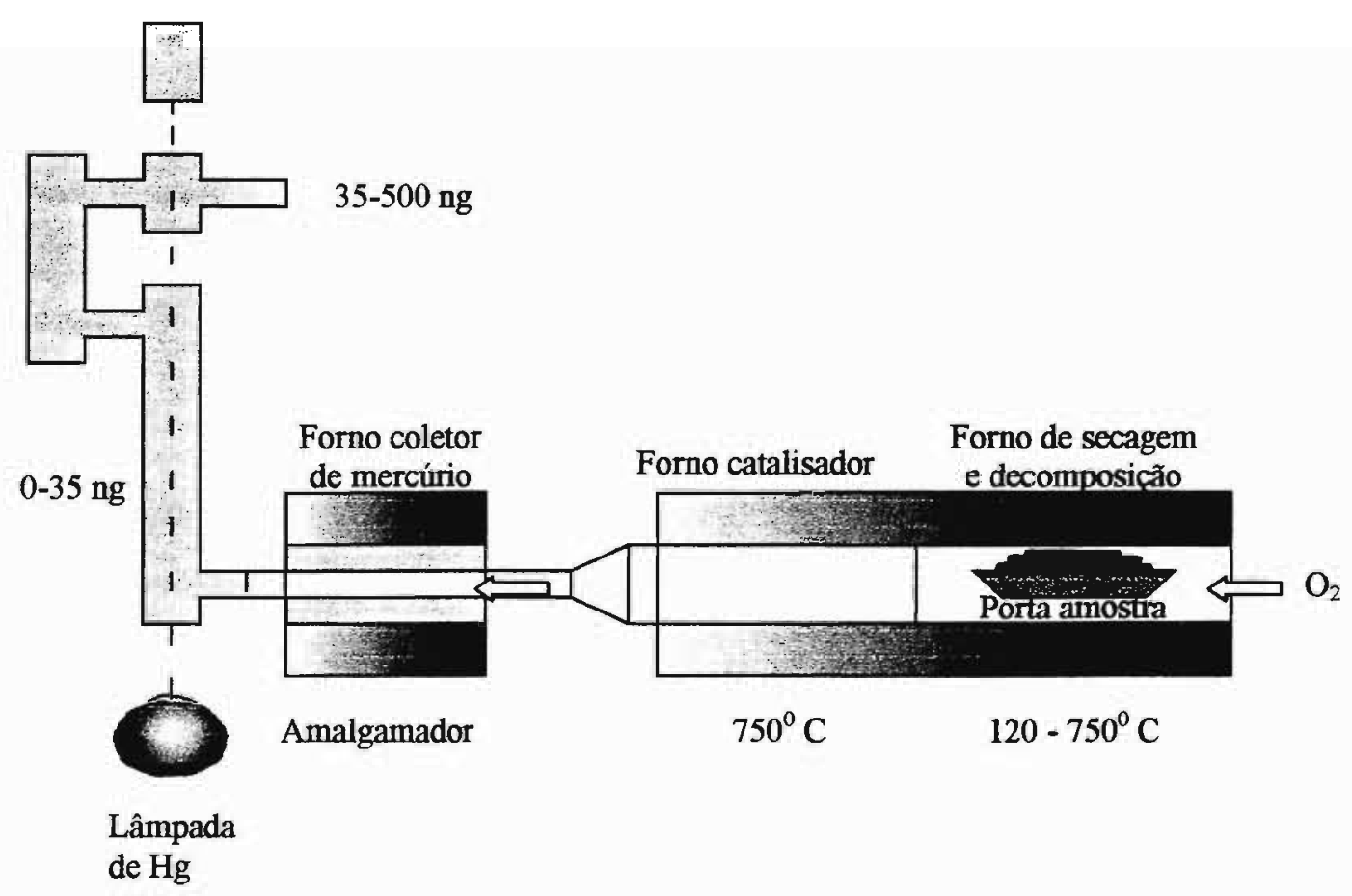

Figura 5.2. Esquema do analisador direto de mercúrio.

A calibração do equipamento foi efetuada usando solução aquosa de referência de $\mathrm{Hg}$ adequadamente diluída na faixa de concentração de branco a 300 $\mu \mathrm{g} \mathrm{Kg}{ }^{-1}$ (solução estoque $\mathrm{Hg} 1000 \mathrm{mg} \mathrm{L}^{-1}$ preparada a partir de $\mathrm{Hg}$ destilado em meio de ácido nítrico $2 \%(\mathrm{v} / \mathrm{v})$ ), o limite de detecção obtido foi de $0,118 \mu \mathrm{g} \mathrm{Kg}^{-1}$. 
Uma massa de $20 \mathrm{mg}$ de amostras secas de tintas látex das cores: branca, marfim, azul, vermelho e tinta a base solvente das cores marfim, azul, amarela e vermelha de diferentes marcas foram colocadas nos porta amostras (barca) de níquel com capacidade de $500 \mu \mathrm{L}$, e submetidas ao programa de aquecimento apresentado na Tabela 5.6. A pressão do oxigênio foi 65 psi e a vazão de fluxo de gás foi de $160 \mathrm{~mL} \mathrm{~min}^{-1}$.

Tabela 5.6. Programa de aquecimento do ADM- 80

\begin{tabular}{c|c|c|c|c|c|}
\hline $\begin{array}{c}\text { Massa } \\
\text { (mg) }\end{array}$ & $\begin{array}{c}\text { Temperatura } \\
\text { de secagem }\end{array}$ & $\begin{array}{c}\text { Tempo de } \\
\text { secagem (s) }\end{array}$ & $\begin{array}{c}\text { Temperatura de } \\
\text { decomposiçăo }\end{array}$ & $\begin{array}{c}\text { Tempo de } \\
\text { decomposiçáo(s) }\end{array}$ & $\begin{array}{c}\text { Tempo de } \\
\text { purga(s) }\end{array}$ \\
\hline 20,0 & $300^{\circ} \mathrm{C}$ & 60 & $850^{\circ} \mathrm{C}$ & 180 & 60 \\
\hline
\end{tabular}

\subsection{Estudo da migração de elementos potencialmente tóxicos presentes em tintas para 0 ambiente}

Neste estudo visou-se obter informações sobre a migração para o ambiente dos elementos potencialmente tóxicos presentes nas tintas em duas situações:

1- após a exposição das tintas em câmaras de intempéries com radiação ultra violeta (UV);

2- após a exposição à ação de soluções extratoras como água desionizada, chuva ácida (solução sulfonítrica de $\mathrm{pH} 4$ ), solução ácida de $\mathrm{pH}$ igual a 5 e solução salina, simulando condiçōes ambientais.

\subsubsection{Envelhecimento acelerado em câmaras de intempéries com radiação UV}

\subsubsection{Preparação das amostras}

As tintas foram aplicadas sobre placas de vidro e/ou polietileno de alta densidade, medindo 65×233mm, utilizando um Aplicador de tinta tipo "Wire-Cator", formando camadas com espessura de $38 \mu \mathrm{m}$, secas em estufa por 5 dias a uma temperatura de $50^{\circ} \mathrm{C}$ 


\subsubsection{Ensaios de envelhecimento acelerado - Câmara de intemperismo}

Os ensaios de degradação foram realizados conforme norma técnica da NCCA (National Coil Coaters Association) Boletim Técnico III-7, de acordo com o seguinte método: os painéis contendo o filme seco de tinta foram colocados em uma câmara de intemperismo acelerado do tipo "Weather-Ometer", marca Atlas, modelo $X W-W R$, usando um eletrodo de carbono como fonte de radiação UV. Os painéis foram submetidos a 150 ciclos de teste. Cada ciclo correspondendo a $2 \mathrm{~h}$ de teste, sendo: $1 \mathrm{~h}$ com radiação UV, sem filtro de luz, a $66 \pm 3^{\circ} \mathrm{C}$, com umidade relativa de $50 \%$ e, $1 \mathrm{~h}$ a sem radiação UV, a $29 \pm 1^{\circ} \mathrm{C}$, com umidade relativa de $100 \%$.

A água utilizada no equipamento foi desionizada, com pH de 7,3 a 7,5. Neste teste, as amostras foram colocadas em um carrossel que giravam ao redor da fonte de radiação ultravioleta em intervalos predeterminados. Essas eram borrifadas com água e/ou expostas à umidade e temperatura pré-definidas.

Após a degradação dos filmes, as amostras foram retiradas da câmara de "Weather-Ometer" e secas em estufa a $50^{\circ} \mathrm{C}$ por $5 \mathrm{~h}$, para remoção da umidade residual presente no filme, proveniente dos ciclos úmidos de degradação. Os filmes secos de tinta foram removidos com auxilio de uma espátula de plástico e submetidos à análise por MEV-EDS e ICP OES. A Figura 5.3 apresenta o fluxograma do procedimento desenvolvido.

A análise por MEV-EDS foi feita no Departamento de Engenharia de Materiais - Faculdade de Engenharia Química de Lorena (FAENQUIL), usando um microscópio Marca LEO, Modelo LEO 1450VP - com EDS (Energy - Dispersive Spectrometer), Oxford INCA ENERGY.

A técnica de microscopia eletrônica consiste de um feixe de elétrons que é impulsionado sobre o material a ser analisado. Do choque dos elétrons com o material, a energia é transferida e o que se observa é o resultado da interação desses elétrons com o material sendo o sinal gerado capturado por um sistema de detecçảo e de processamento [LEAL, 2000] 


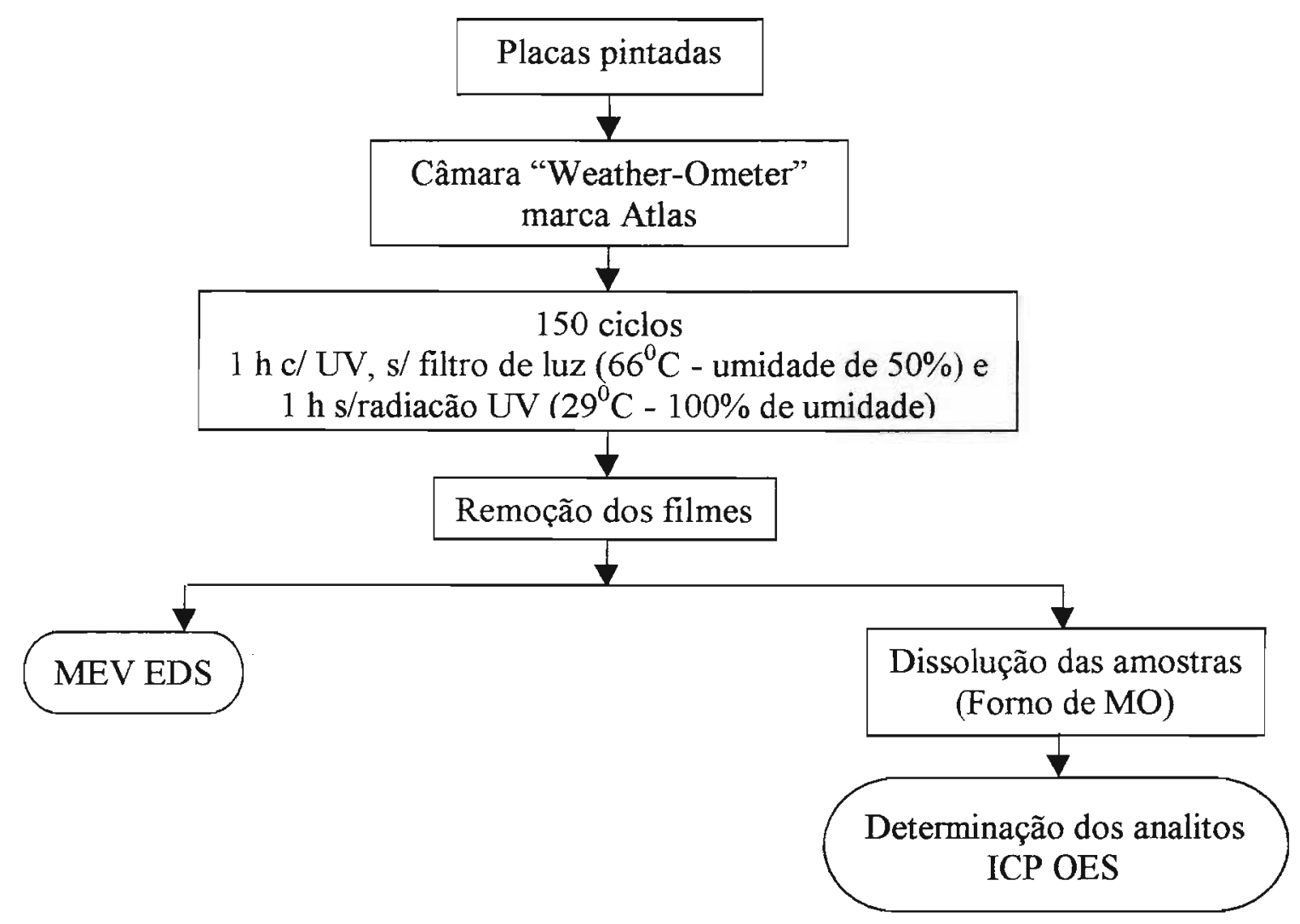

Figura 5.3. Fluxograma do procedimento utilizado para a avaliação da migração dos elementos de interesse em câmara de intemperismo acelerado.

\subsubsection{Envelhecimento acelerado sob ação de soluções extratoras - Testes de lixiviação}

\subsubsection{Preparação das amostras}

Frascos de polietileno de $50 \mathrm{~mL}$ da marca Sarstedt (Figura 5.4) foram utilizados como corpos de prova, que tiveram suas paredes pintadas com as amostras de tintas à base de solvente orgânico (tinta esmalte amarela) e à base de água (tinta látex vermelha). Os frascos foram levados a estufa por 5 a 7 dias à temperatura de $50^{\circ} \mathrm{C}$. Após $24 \mathrm{~h}$ os frascos foram inspecionados para a verificação de possíveis falhas ocorridas na cobertura da parede. Quando houve necessidade, os frascos foram novamente pintados. Após o período de exposição, detalhado no capítulo Resultados e Discussões, os analitos foram determinados por ICP OES. 
Os testes de lixiviação foram realizados com água desionizada, solução salina $(\mathrm{NaCl} 5 \% \mathrm{~m} / \mathrm{v}$ ), solução sulfonítrica de $\mathrm{pH}=4$ (chuva ácida) e solução de ácido acético de $\mathrm{pH} 5$.

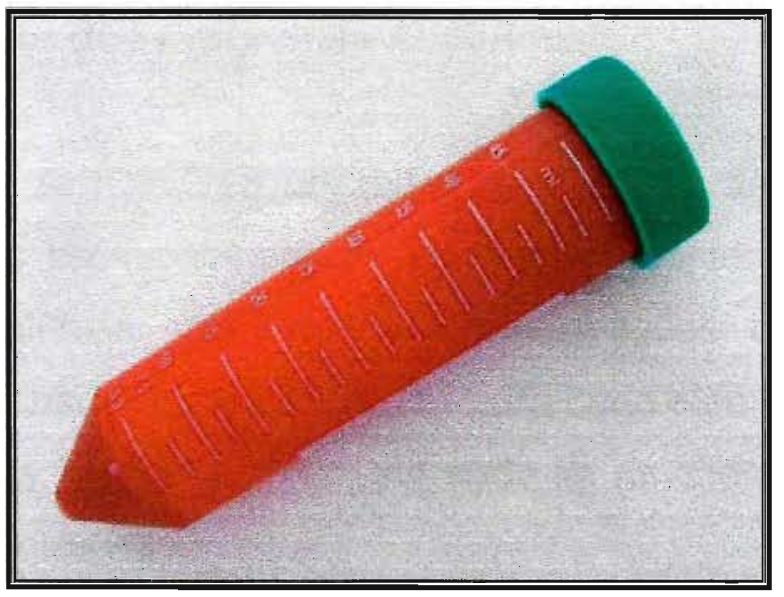

Figura 5.4.Fotografia do frasco pintado.

\subsubsection{Ensaios de envelhecimento acelerado - Ação das soluções extratoras}

Após a secagem dos corpos de prova das amostras, $50 \mathrm{~mL}$ das seguintes soluções extratoras foram colocadas nos frascos pintados com tinta esmalte amarela e látex vermelha: água desionizada, solução de ácido acético em $\mathrm{pH} 5$, solução simulando $\mathrm{pH}$ de chuva ácida, ou seja, solução sulfonítrica de $\mathrm{pH} 4$, obtida pela mistura de $0,4 \mathrm{~mL}$ de $\mathrm{HNO}_{3}$ e $0,4 \mathrm{~mL} \mathrm{H}_{2} \mathrm{SO}_{4}$, ambos $0,1 \mathrm{~mol} \mathrm{~L}^{-1}$, diluídas a 1 litro, e solução de $\mathrm{NaCl} 5 \%(\mathrm{~m} / \mathrm{v})$.

Um conjunto de frascos em duplicata contendo as soluções extratoras foi agitado por 5 min e deixado em repouso por 7 (sete) dias, novamente agitado e as soluções analisadas por ICP OES. Estas soluções foram substituídas por novas (usando os mesmos frascos) e deixadas por mais 7 dias em repouso, agitadas e os analitos determinados. Este procedimento foi refeito cada 7 dias até completar 28 dias.

Paralelamente, outros conjuntos de frascos contendo as soluções extratoras, em duplicatas, foram agitados por 5 min e deixados em repouso por 14 (quatorze), 21 (vinte e um) e 28 (vinte e oito) dias. Após cada período, os frascos foram agitados por 5 min e os analitos de interesse determinados por ICP OES. 


\section{Resultados e Discussão}

\subsection{Desenvolvimento dos Programas Analíticos}

Os aparelhos de ICP OES utilizados realizam as determinações a partir de programas analíticos pré-estabelecidos, onde são definidos os vários parâmetros instrumentais e analíticos, incluindo as concentrações das soluções da curva analítica. Foram obtidas as curvas analíticas para cada elemento a partir de soluções de referência em dois programas, considerando-se as diferenças de concentrações dos elementos presentes na amostra.

As curvas analíticas são representadas pela equação da reta obtida por meio da regressão linear, sendo a concentração de cada analito dada pela equação abaixo.

$$
C=A_{0}+A_{1} \cdot I_{R}
$$

Onde, $\mathrm{C}=$ Concentração do elemento

$A_{0}=$ Coeficiente linear;

$A_{1}=$ Coeficiente angular;

$I_{R}=$ Intensidade relativa da emissão do analito.

O limite de detecção instrumental é definido como a concentração do analito que fornece uma resposta igual a três vezes o valor do desvio padrão do branco dividido pelo coeficiente angular da curva analítica de calibração [LEITE, 1996], com base em 11 leituras. O limite de quantificação ou determinação é igual a 3,3 vezes o limite de detecção instrumental [CARRÉ et al., 1997]. As Tabelas 6.1 e 6.2 mostram as linhas de emissão que forann selecionadas, limites de detecção instrumentais e limites de quantificação para cada elemento, obtidos nos espectrômetros Spectroflame Modula e CIROS $^{\mathrm{CCD}}$, respectivamente. As Tabelas 6.3 e 6.4 mostram os coeficientes de correlação e faixas de concentração relativos às curvas analíticas obtidas. Estes valores foram obtidos através de rotinas de determinação incorporadas ao programa de controle do equipamento. 
Tabela 6.1. Comprimentos de onda, limites de deteç̧ão e limites de quantificação de cada elemento em $\mathrm{mg} \mathrm{L}^{-1}$ do Espectrômetro Spectroflame Modula.

\begin{tabular}{|c|c|c|c|}
\hline Elemento & $\begin{array}{l}\text { Linha de emissao ( }) \\
\text { (nm) }\end{array}$ & $\begin{array}{l}\text { Limito de deteccäo } \\
\text { instrumental ( } \mathrm{mg} \mathrm{L}^{-} \text {) }\end{array}$ & $\begin{array}{l}\text { Limite de } \\
\text { quantificacáo }\left(\mathrm{mg} \mathrm{L}^{-1}\right)\end{array}$ \\
\hline $\mathrm{Al}$ & 396,152 & 0,0099 & 0,0327 \\
\hline $\mathrm{Cr}$ & 283,563 & 0,0138 & 0,0455 \\
\hline $\mathrm{Mn}$ & 257,610 & 0,0075 & 0,0248 \\
\hline Co & 228,616 & 0,0035 & 0,0116 \\
\hline $\mathrm{Ni}$ & 231,604 & 0,0055 & 0,0182 \\
\hline $\mathrm{Cu}$ & 327,396 & 0,0069 & 0,0228 \\
\hline As & 188,979 & 0,0162 & 0,0535 \\
\hline $\mathrm{Cd}$ & 214,438 & 0,0015 & 0,0050 \\
\hline $\mathrm{Pb}$ & 182,200 & 0,0147 & 0,0485 \\
\hline
\end{tabular}

(*) Limite de detecção instrumental - Valor mínimo detectado, LOD $=3$ vezes o desvio padrão do branco expresso em concentraçăo.

$(*)$ Limite de quantificação - Valor mínimo quantificado $L O Q=3,3$ vezes $O L O D$.

Tabela 6.2. Comprimentos de onda, limites de detecção e limites de quantificação de cada elemento em $\mathrm{mg} \mathrm{L}^{-1}$ do Espectrômetro CIROS ${ }^{\mathrm{CCD}}$.

\begin{tabular}{|c|c|c|c|}
\hline Etemento & $\begin{array}{c}\text { Linha da emissajo (9) } \\
\text { (nm) }\end{array}$ & 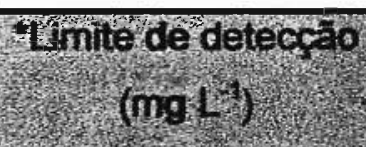 & $\begin{array}{l}\text { Wimite de quantificacáo } \\
\left(\operatorname{lng}^{-1}\right)\end{array}$ \\
\hline $\mathrm{Al}$ & 167,078 & 0,0029 & 0,00957 \\
\hline $\mathrm{Cr}$ & 205,552 & 0,0005 & 0,00165 \\
\hline $\mathrm{Mn}$ & 257,610 & 0,0006 & 0,00198 \\
\hline Co & 228,615 & 0,0006 & 0,00198 \\
\hline $\mathrm{Ni}$ & 221,648 & 0,0006 & 0,00198 \\
\hline $\mathrm{Cu}$ & 219,226 & 0,0075 & 0,02475 \\
\hline As & 193,759 & 0,0093 & 0,03069 \\
\hline $\mathrm{Cd}$ & 214,438 & 0,0005 & 0,00165 \\
\hline $\mathrm{Pb}$ & 168,215 & 0,0032 & 0,01056 \\
\hline
\end{tabular}


Tabela 6.3. Parâmetros das curvas analíticas ICP OES, Spectroflame Modula

\begin{tabular}{|c|c|c|}
\hline Elemento & $\begin{array}{c}\text { Coeficiente de } \\
\text { correlagab }\end{array}$ & $\begin{array}{c}\text { Faixas de concentracáo } \\
\text { (mg L } \text { ) }\end{array}$ \\
\hline $\mathrm{Al}$ & 0,9997 & $0,010-60,00$ \\
\hline $\mathrm{Cr}$ & 0,9998 & $0,012-2,400$ \\
\hline $\mathrm{Mn}$ & 0,9997 & $0,007-2,400$ \\
\hline $\mathrm{Co}$ & 0,9998 & $0,004-2,400$ \\
\hline $\mathrm{Ni}$ & 0,9997 & $0,005-2,400$ \\
\hline $\mathrm{Cu}$ & 0,9999 & $0,007-2,400$ \\
\hline $\mathrm{As}$ & 0,9993 & $0,016-2,400$ \\
\hline $\mathrm{Cd}$ & 0,9999 & $0,0015-2,400$ \\
\hline $\mathrm{Pb}$ & 0,9998 & $0,015-2,400$ \\
\hline
\end{tabular}

Tabela 6.4. Parâmetros das curvas analíticas ICP OES, CIROS

\begin{tabular}{|c|c|c|}
\hline Elomenio & $\begin{array}{l}\text { Coericiente de } \\
\text { correlagao }\end{array}$ & $\begin{array}{c}\text { Faixas de concentragáo } \\
\text { (mg L') }\end{array}$ \\
\hline $\mathrm{Al}$ & 1,0000 & $0,0029-2,400$ \\
\hline $\mathrm{Cr}$ & 1,0000 & $0,0006-2,400$ \\
\hline $\mathrm{Mn}$ & 1,0000 & $0,0003-2,400$ \\
\hline Co & 1,0000 & $0,0006-2,400$ \\
\hline $\mathrm{Ni}$ & 1,0000 & $0,0006-2,4000$ \\
\hline $\mathrm{Cu}$ & 1,0000 & $0,008-2,400$ \\
\hline As & 0,9999 & $0,0093-2,400$ \\
\hline $\mathrm{Cd}$ & 1,0000 & $0,0005-2,400$ \\
\hline $\mathrm{Pb}$ & 1,0000 & $0,0032-2,400$ \\
\hline
\end{tabular}

A escolha dos comprimentos de onda de linhas sem interferência espectral ou efeito de matriz foi feita com base em informações do programa do equipamento, onde são listadas as interferências espectrais, e com base nos espectros obtidos experimentalmente de padrões simples, padrões multi-elementares e soluções de amostras. 


\subsection{Preparação da amostra}

\subsubsection{Secagem das amostras}

As tintas se classificam, de acordo com o mecanismo da secagem, em termoplásticas ou lacas, bases de água e termofixas.

As tintas termoplásticas (vinilicas, acrilicas etc) são constituídas de polímeros dissolvidos em solventes que, ao evaporarem, reconstituem o polímero. Na secagem ocorre somente um fenômeno físico.

Nas tintas emulsionadas (látex, PVA etc) os componentes das tintas são emulsionados em água, que funciona como solvente. Ao ser aplicada à tinta, quebrase a emulsão, evapora-se o solvente e o filme se forma por coalescência das partículas.

Tintas termofixas (tintas catalisadas, tintas de estufas etc) são formuladas com veículos convertiveis, ou seja, veículos que sofrem reação química. O filme sofre secagem não só por evaporação do solvente, mas também por um processo químico, ou cura do filme, que não pode ser dissolvido pelo solvente [FAZENDA, 1995].

Os filmes secos de tinta foram utilizados no método de digestão de amostra e avaliação da mobilidade dos metais de interesse. Portanto os substratos precisariam apresentar características como: ser de fácil manipulação, baixa interação com a tinta, não apresentar metais em sua composição, suportar emprego de calor, aderir à tinta uniformemente e, após a obtenção do filme, ser de fácil remoção. Na avaliação da mobilidade, a tinta teria que permanecer no substrato durante a ação de intemperismo e ser facilmente removivel após o procedimento.

A tinta foi aplicada com auxílio de um extensor de aço inoxidável tipo "WireCator". As Figuras 6.1 a e b apresentam a ilustração do aplicador. As amostras foram secas em estufa a $50^{\circ} \mathrm{C}$ por 5 a 7 dias. 


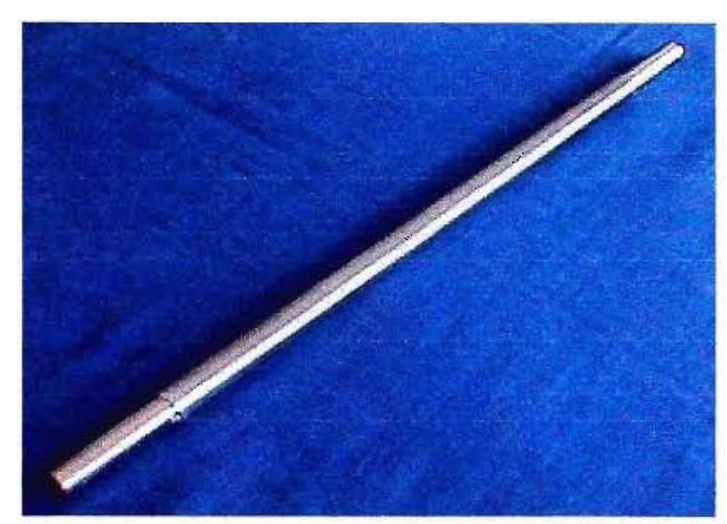

(a)

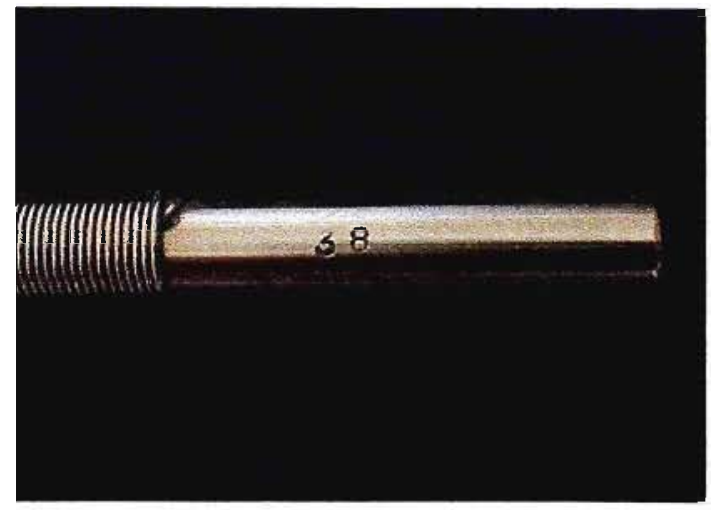

(b)

Figura 6.1. (a)llustração do aplicador tipo "Wire-Cator", (b) detalhe do aplicador.

\subsubsection{Avaliação dos substratos}

A placa de vidro é um substrato adequado para a utilização na câmara de intemperismo, porém a película de tinta formada é de difícil remoção para algumas tintas, havendo a necessidade do uso de solventes orgânicos. Se a utilização for somente para digestão da tinta, então ela pode ser aplicada ao substrato e, antes que o filme seque completamente, deve ser retirado da placa e colocado em outro recipiente para continuar a secagem.

Placas de acrílico (Figura 6.2) possibilitam a uniformidade da película, porém para a maioria das tintas é difícil retirar o filme formado.

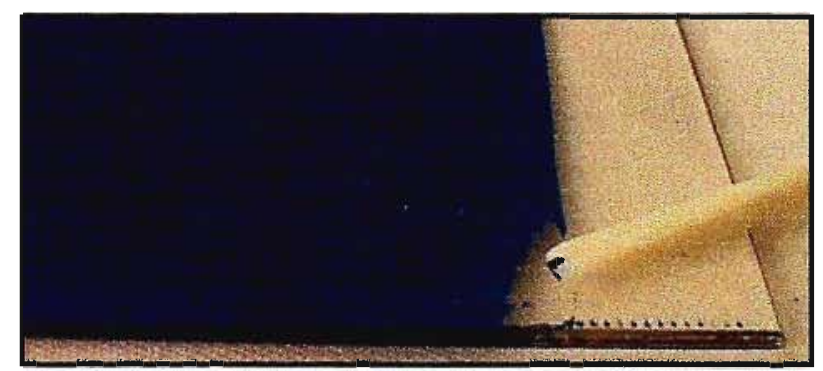

Figura 6.2. Película de filme pintada em placa de acrílico.

Embalagens de polietileno de baixa densidade usadas para congelamento de alimento apresentam vantagens por serem de fácil obtenção e livres de metais pesados, porém dependendo da tinta, podem ocorrer reações do solvente orgânico com o polímero do substrato e comprometer a formação do filme, formando poças e polimerização da camada superficial, dificultando a secagem da tinta (Figura 6.3). 


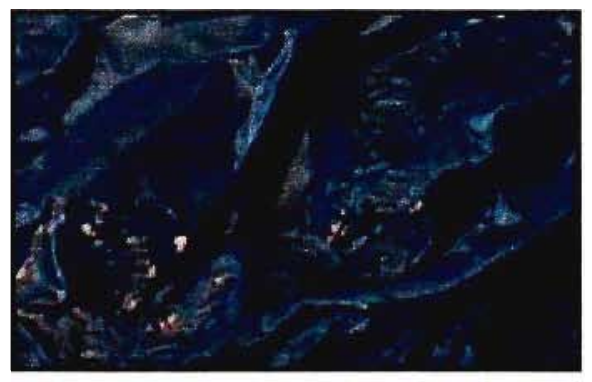

(a)

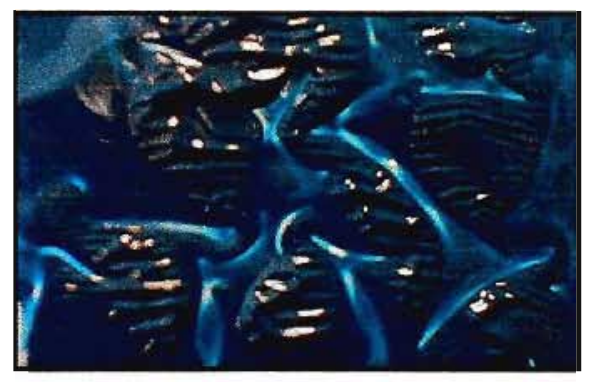

(b)

Figura 6.3. (a) e (b): Mostram a má formação do filme, causada pela polimerização da camada externa da tinta antes da secagem completa.

Para algumas tintas, a aplicação em pequenas áreas da embalagem de polietileno possibilita uma boa formação do filme e o mesmo sai facilmente do substrato, como pode ser observado na Figura 6.4. Porém para o desenvolvimento de métodos em que grande número de replicatas é necessário, a utilização deste substrato não foi viável, pois o tempo requerido para a aplicação de uma massa representativa da amostra seria grande.

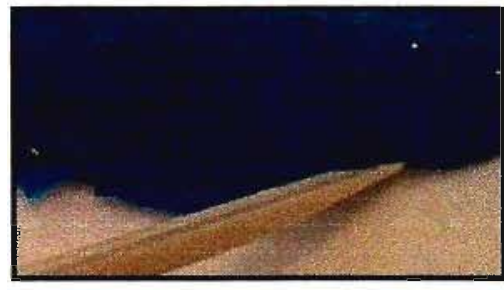

(a)

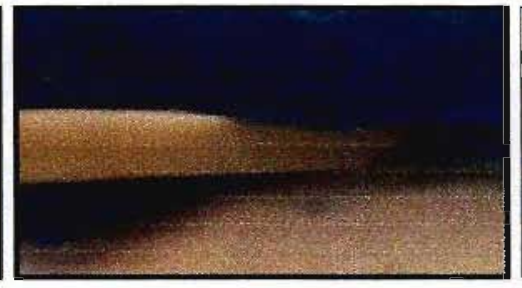

(b)

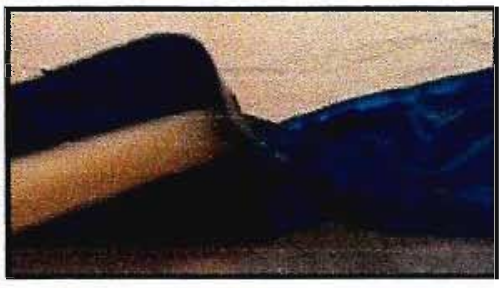

(c)

Figura 6.4. (a), (b) e (c): Mostram o filme formado sendo facilmente retirado com o auxílio de uma espátula.

Temperaturas acima de $60^{\circ} \mathrm{C}$ comprometeram o substrato e, conseqüentemente, a amostra, como observado na Figura 6.5. 


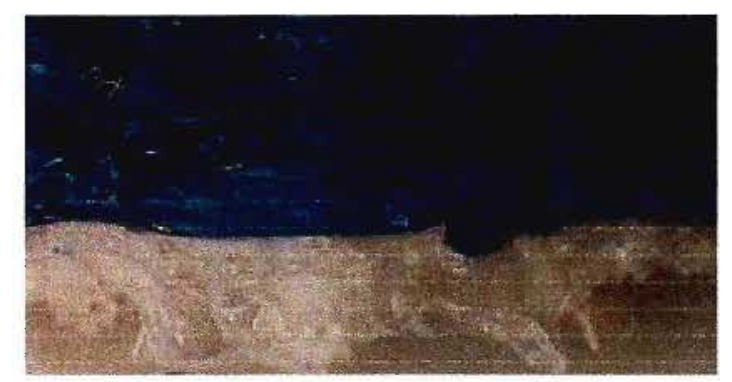

Figura 6.5. Mostra o comprometimento do substrato após aquecimento superior a $60^{\circ} \mathrm{C}$.

O celofane é um material de uso culinário e, portanto, livre de metais pesados, facilmente encontrados, de fácil manuseio, descartável e permite a formação de um filme perfeito, porém, para tintas que formam filmes muito elásticos, não foi possível se retirar o filme. Em contrapartida, para tintas que produzem filmes menos elásticos a remoção é possível, mas neste caso, existe a dificuldade de se retirar o filme com o auxílio de uma espátula (Figura 6.6). Neste caso, a parte de trás do celofane pode ser raspada contra a quina da bancada para facilitar a remoção do filme (Figura 6.7).

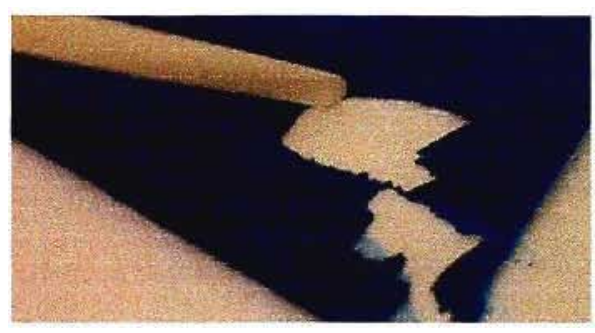

(a)

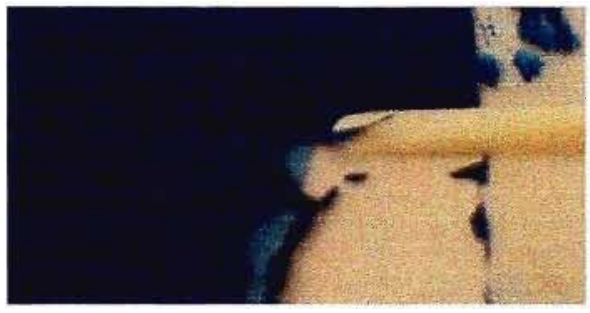

(b)

Figura 6.6. (a) e (b): Mostram o filme formado sob o celofane, dando ênfase as pequenas lascas que são removidas por uma espátula. 


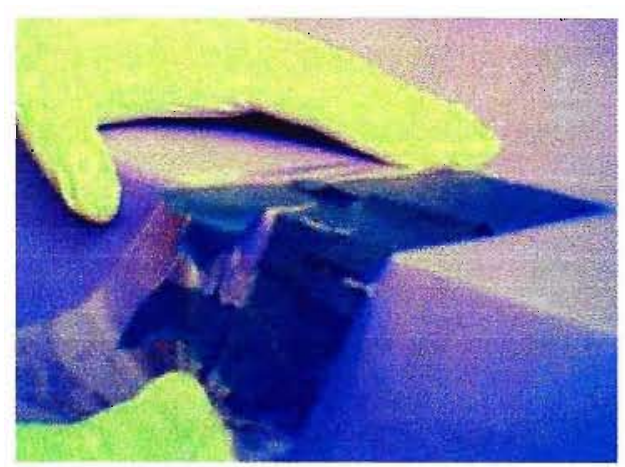

B IBLIOTECA INSTITUTO DE QUIMICA Unversidade de São Paulo

Figura 6.7. Mostra o filme sendo retirado do celofane usando-se a quina da uma bancada.

Para os testes de avaliação da mobilidade, a tinta teria que permanecer no substrato durante o procedimento de intemperismo e, após o procedimento, ser facilmente removível. Os testes foram feitos em câmara de intemperismo com radiação UV e câmara de névoa salina. Placas de polietileno $(\mathrm{PE})$ de alta densidade de $1 \mathrm{~mm}$ de espessura foram usadas neste estudo apresentando as vantagens de ser de fácil manipulação, baixa interação com a tinta, não apresentar metais em sua composição, suportar o emprego de calor, aderir à tinta uniformemente e, após a obtenção do filme, ser fácil a remoção da película formada.

Tintas látex e tintas brilhantes à base de solvente saem facilmente com o auxílio de uma espátula, como pode ser observado na Figura 6.8, enquanto as acetinadas à base de solvente saem mais facilmente ao passarmos o verso da placa por uma quina de bancada, como exemplificado na Figura 6.7.

As placas podem ser encontradas no comércio medindo $2 \times 1 \mathrm{~m}$ a um custo baixo, cerca de R $\$ 27,00$ (US $\$ 12,30$ ).

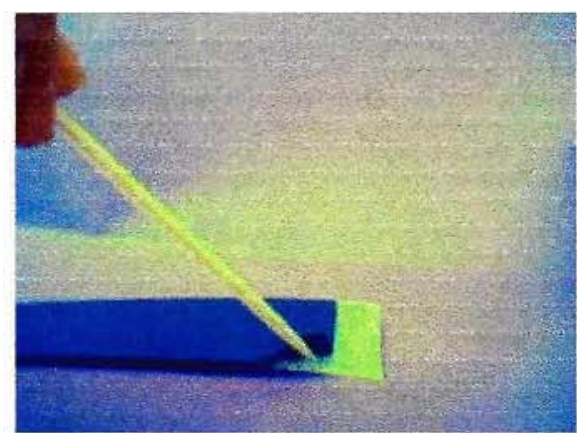

(a)

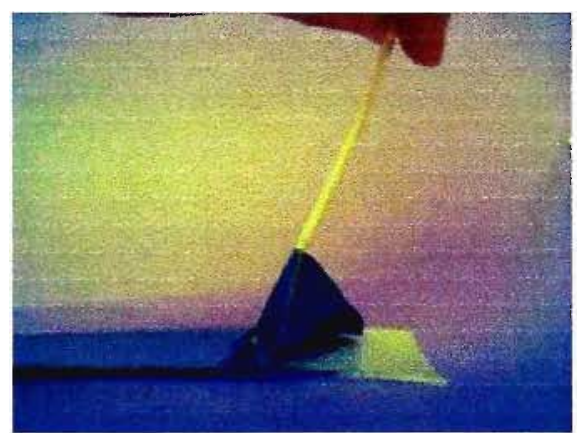

(b)

Figura 6.8. (a) e (b) :Mostram a película de tinta sendo facilmente removida da placa de PE com auxilio de uma espátula. 
Placas de Teflon $\otimes$ foram testadas e se prestam bem à formação e retirada dos filmes, porém, além se serem relativamente caras apresentam a desvantagem de não poderem ser submetidas à câmara de intempéries porque o filme poderia soltar devido à ação mecânica causada pela água usada na câmara.

O substrato que apresentou maior vantagem para a maioria das tintas, visando a uniformidade, retirada do filme e uso na câmara de intemperismo foi a placa de polietileno de alta densidade.

\subsection{Avaliação dos métodos de digestão de tinta à base de água}

Tintas à base de água apresentam em sua composição alto teor de $\mathrm{TiO}_{2}$ que é utilizado como pigmento para a cor branca e para dar opacidade às tintas coloridas. Alem disso confere maior poder de cobertura, não é tóxico e não escurece quando em contato com $\mathrm{H}_{2} \mathrm{~S}$. É usado em substituição ao carbonato de chumbo, sulfato de bário e sulfato de cálcio [LEE, 1996].

$\mathrm{O} \mathrm{H}_{2} \mathrm{SO}_{4}$ é utilizado na digestão de $\mathrm{TiO}_{2}$. Embora seja um desidratante, tenha o poder de oxidar um grande número de metais e apresentar a vantagem de destruir a matéria orgânica, pode precipitar o chumbo na forma de $\mathrm{PbSO}_{4}$, que é um elemento de interesse na análise de tintas. Alem disso é um ácido de alta densidade causando problemas na introdução da amostra através dos sistemas pneumáticos de nebulização. Este ácido combinado com $\mathrm{HNO}_{3}$ e $\mathrm{H}_{2} \mathrm{O}_{2}$ fez parte do início deste estudo e foi abandonado por não apresentar resultados satisfatórios.

$\mathrm{O}$ ácido nítrico, embora seja um agente oxidante muito poderoso, não dissolve alguns compostos como óxidos de $\mathrm{Al}, \mathrm{Ti}, \mathrm{Ta} \mathrm{Th}, \mathrm{Zr}$ e Hf e, portanto, a ele deve ser adicionado um agente complexante para contribuir na digestão de alguns destes compostos.

Devido à presença do $\mathrm{TiO}_{2}$, neste estudo utilizou-se $\mathrm{HF}$ que é um excelente complexante formando fluoretos estáveis e fluorocomplexos com vários elementos. Ele reage com os elementos que formam óxidos refratários, solubilizando-os. Uma vez que o íon fluoreto reage com o óxido de silício, que faz parte da composição do quartzo, existe a necessidade de se usar uma tocha resistente a HF. Outro inconveniente é que alguns elementos podem formar fluoretos insolúveis como $\mathrm{CaF}_{2}, \mathrm{MgF}_{2}$. NaALF $4, \mathrm{MgAlF}_{5}$. Nestes casos, dependendo da necessidade de 
avaliação de um determinado analito, o ion fluoreto pode ser eliminado da solução com a adição de ácido bórico. A equação química abaixo ilustra a reação do ácido bórico com o ácido fluorídrico [KRUG, 2004].

$$
\begin{gathered}
\mathrm{H}_{3} \mathrm{BO}_{3}+3 \mathrm{HF} \leftrightarrow \mathrm{HBF}_{3}(\mathrm{OH})+2 \mathrm{H}_{2} \mathrm{O} \\
\mathrm{HBF}_{3}(\mathrm{OH})+\mathrm{HF} \leftrightarrow \mathrm{HBF}_{4}+\mathrm{H}_{2} \mathrm{O}
\end{gathered}
$$

Visando a digestão total da amostra para tornar possível a determinação dos elementos de interesse, foram realizados testes utilizando misturas ácidas. Para este fim, usou-se na digestão das tintas à base de água (látex) nas cores vermelha, amarela e azul, um forno de microondas com cavidade. Nestes estudos foram digeridas 5 amostras simultaneamente.

\subsubsection{Procedimento $1: \mathrm{HNO}_{3} / \mathrm{HF}(3: 9, \mathrm{v} / \mathrm{v})$}

No procedimento de digestão das amostras foram empregadas massas de aproximadamente $0,2 \mathrm{~g}$ de amostra seca, pesadas em balança analítica. A estas amostras foram adicionados $3,0 \mathrm{~mL}$ de $\mathrm{HNO}_{3}(65 \% \mathrm{~m} / \mathrm{m})$ necessários para decomposição da matéria orgânica devido ao seu poder oxidante e $9,00 \mathrm{~mL}$ de HF $(40 \% \mathrm{~m} / \mathrm{m})$, necessário devido à presença do $\mathrm{TiO}_{2}$. $\mathrm{O}$ método empregado foi uma adaptação do método EPA 3052 da Agência de Proteção Ambiental dos EUA que foi desenvolvido para a digestão total de uma grande variedade de matrizes incluindo solos, sedimentos, lodos, óleos, efluentes oleosos e matrizes biológicas e botânicas [Kingston e Walter, 1995].

$\mathrm{Na}$ primeira etapa do programa fez-se uma rampa de aquecimento até se atingir a temperatura de $80{ }^{\circ} \mathrm{C}$. Esta temperatura foi mantida por 2 min (isoterma) seguida por outra rampa até atingir $120^{\circ} \mathrm{C}$. Esta temperatura foi mantida por 2 min e prosseguiu-se o aquecimento com outra rampa, mais demorada, até atingir $200{ }^{\circ} \mathrm{C}$, que foi mantida por $10 \mathrm{~min}$. Em seguida o sistema foi resfriado por $30 \mathrm{~min}$. 0 procedimento é apresentado na Tabela 6.5. 
Tabela 6.5. Procedimento empregado para a digestão das tintas à base de água, utilizando forno de microondas com cavidade Ethos.

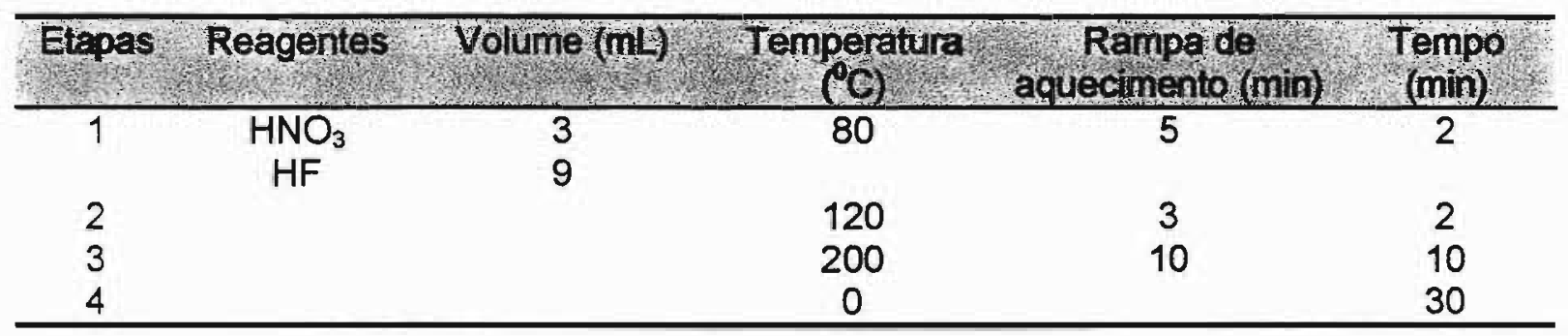

As soluções resultantes apresentaram coloração clara, restando pequena quantidade de resíduo branco. Se uma solução resultante de uma digestão apresenta-se limpida ou levemente amarelada, assume-se que a oxidação da matéria orgânica foi completa [MATUSIEWICZ et al., 1989]. Visando diminuir o tempo de análise, diminuiu-se o tempo da terceira etapa, mas restou muito $\mathrm{TiO}_{2}$ sem digerir. Testou-se novo método, alterando-se a proporção dos ácidos, visando diminuir a quantidade de reagente e a pressão do sistema.

\subsubsection{Procedimento $2: \mathrm{HNO}_{3} / \mathrm{HF} / 2: 6 \mathrm{v} / \mathrm{v}$ )}

Neste procedimento foram usados uma massa de $0,2 \mathrm{~g}$ de amostra, $6 \mathrm{~mL}$ de $\mathrm{HF}, 2 \mathrm{~mL}$ de $\mathrm{HNO}_{3}$ e as condições mostradas na Tabela 6.6.

Tabela 6.6. Procedimento empregado para a digestão das tintas à base de água utilizando forno de microondas com cavidade Ethos.

\begin{tabular}{cccccc}
\hline Etapas & Reagentes & Volume (mL) & $\begin{array}{c}\text { Temperatura } \\
\text { (O) }\end{array}$ & $\begin{array}{c}\text { Rampa de } \\
\text { aquecimanto (min) }\end{array}$ & $\begin{array}{c}\text { Tempo } \\
\text { (min) }\end{array}$ \\
\hline 1 & $\mathrm{HNO}_{3}$ & 2 & 80 & 5 & 2 \\
2 & $\mathrm{HF}$ & 6 & & & 2 \\
3 & & & 120 & 10 & 10 \\
4 & & & 0 & & 30 \\
\hline
\end{tabular}

Após o resfriamento os frascos foram abertos, a solução foi transferida para um frasco volumétrico e o volume ajustado com água desionizada para $30 \mathrm{~mL}$. Após ficar em repouso e o resíduo decantar, os analitos foram determinados por ICP OES e os residuos analisados por MEV EDS. 
Na Tabela 6.7 são apresentados os valores das médias das concentrações dos elementos em \% e os desvios-padrão na determinação de $\mathrm{Al}, \mathrm{Cr}, \mathrm{Mn}, \mathrm{Co}, \mathrm{Ni}$, $\mathrm{Cu}, \mathrm{As}, \mathrm{Cd}$ e $\mathrm{Pb}$ em tinta à base de água da marca $\mathrm{C}$, após a digestão utilizando 6 $\mathrm{mL}$ de $\mathrm{HF}$ e $2 \mathrm{~mL}$ de $\mathrm{HNO}_{3}$ (procedimento 2).

Usou-se a mesma curva analítica para todas as cores de tinta analisadas. Quando necessário, as amostras foram diluídas. As soluções padrão usadas na obtenção das curvas analíticas foram preparadas de acordo com a mistura ácida empregada na digestão da amostra.

Nesse estudo, os valores das concentraçōes dos elementos nas provas em branco foram todos inferiores aos limites de detecção.

A possibilidade de efeito de matriz e espectral causada pela alta concentração de Ti foi investigada e não foram detectados problemas.

Com exceção do $\mathrm{Al}$, foram observados baixos teores para todos os elementos nas três tintas avaliadas. A tinta amarela apresenta um teor maior de Co em relação às demais tintas e a tinta azul apresenta um conteúdo maior de $\mathrm{Cu}$.

Embora não exista legislação brasileira que limite os teores destes elementos nas tintas, para $\circ \mathrm{Pb}$ pode ser feita uma comparação com o valor aceitável nos Estados Unidos da América, que é 0,06\% [PIMENTA, VITAL, 1994]. Nas três tintas os valores de $\mathrm{Pb}$ estão abaixo deste valor.

Tabela 6.7. Quantidades encontradas e desvios padrão dos elementos $\mathrm{Al}, \mathrm{Cr}, \mathrm{Mn}$, $\mathrm{Co}, \mathrm{Ni}, \mathrm{Cu}, \mathrm{As}, \mathrm{Cde} \mathrm{Pb}$ em tinta à base de água da marca $\mathrm{C}$.

\begin{tabular}{cccc}
\hline Eementos & $\begin{array}{c}\text { Azui profundo }(n=3) \\
\%(\mathrm{~m} / \mathrm{m})\end{array}$ & $\begin{array}{c}\text { Amarelo canário }(\mathrm{n}=3) \\
\%(\mathrm{~m} / \mathrm{m})\end{array}$ & $\begin{array}{c}\text { Vermelho cardinal }(\mathrm{n}=6) \\
\%(\mathrm{~m} / \mathrm{m})\end{array}$ \\
\hline $\mathrm{Al}$ & $23 \pm 6$ & $6,1 \pm 0,6$ & $25,0 \pm 0,6$ \\
$\mathrm{Cr}$ & $0,014 \pm 0,003$ & $0,004 \pm 0,001$ & $0,042 \pm 0,001$ \\
$\mathrm{Mn}$ & $0,009 \pm 0,001$ & $0,0058 \pm 0,0001$ & $0,025 \pm 0,001$ \\
$\mathrm{Co}$ & $0,078 \pm 0,007$ & $0,209 \pm 0,003$ & $0,004 \pm 0,001$ \\
$\mathrm{Ni}$ & $0,004 \pm 0,001$ & $0,003 \pm 0,001$ & $0,008 \pm 0,001$ \\
$\mathrm{Cu}$ & $0,78 \pm 0,06$ & $0,0170 \pm 0,0001$ & $0,008 \pm 0,001$ \\
$\mathrm{As}$ & $0,004 \pm 0,002$ & $0,006 \pm 0,001$ & $0,008 \pm 0,002$ \\
$\mathrm{Cd}$ & $<0,00002$ & $<0,00002$ & $<0,00002$ \\
$\mathrm{~Pb}$ & $<0,0002$ & $<0,0002$ & $0,039 \pm 0,003$ \\
\hline
\end{tabular}


Como não existe material de referência certificado para todos os elementos avaliados, realizou-se um estudo para comprovar a exatidão do método de preparo da amostra e da determinação dos analitos por ICP OES. Neste estudo, as amostras são enriquecidas sinteticamente com quantidades conhecidas dos elementos de interesse, passam pelo mesmo procedimento de digestão da amostra e determinação dos analitos e seus resultados são comparados com os resultados das amostras que não foram enriquecidas.

As soluções usadas nos testes de recuperação foram feitas a partir das soluções analíticas de referência.

Nas Tabelas $6.8,6.9$ e 6.10 e na Figura 6.9 pode ser observado os resultados dos testes de recuperação referentes às cores azul profundo, amarela e vermelha da marca $\mathrm{C}$ e foram calculados com base nos valores de concentrações esperados $\mathrm{e}$ efetivamente encontrados nas soluções de análise $\left(\mathrm{mg} \mathrm{L}^{-1}\right)$. Não foram feitos testes de adição e recuperação para alumínio.

A limpeza dos vasos de digestão do forno microondas, antes e depois da utilização, foi feita usando-se a mesma mistura ácida e o mesmo programa de digestão das amostras. Estas soluções foram analisadas posteriormente e a quantidade encontrada dos elementos de interesse foi a mesma encontrada na solução do branco, abaixo do limite de detecção, garantindo que não há perda de amostra por aderência nas paredes dos frascos. 
Tabela 6.8. Valores de concentração e recuperação dos elementos adicionados e recuperados da tinta azul enriquecida.

\begin{tabular}{ccccc}
\hline Elemento & $\begin{array}{c}\text { Quantidade } \\
\text { adicionada } \\
\left(\mathrm{mg} \mathrm{L}^{-1}\right)\end{array}$ & $\begin{array}{c}\text { Quantidade } \\
\text { esperada } \\
\left(\mathrm{mg} \mathrm{L}^{-1}\right)\end{array}$ & $\begin{array}{c}\text { Quantidade } \\
\text { encontrada } \\
\left(\mathrm{mg} \mathrm{L}^{-1}\right)\end{array}$ & $\begin{array}{c}\text { Recuperaçáo } \\
(\%)\end{array}$ \\
\hline $\mathrm{Cr}$ & 0,500 & 0,59 & $0,69 \pm 0,05$ & 117 \\
$\mathrm{Mn}$ & 0,500 & 0,56 & $0,67 \pm 0,02$ & 119 \\
$\mathrm{Co}$ & 0,500 & 1,03 & $1,06 \pm 0,02$ & 103 \\
$\mathrm{Ni}$ & 0,500 & 0,53 & $0,73 \pm 0,04$ & 138 \\
$\mathrm{Cu}$ & 0,500 & 5,73 & $5,6 \pm 0,2$ & 97 \\
$\mathrm{As}$ & 0,500 & 0,527 & $0,632 \pm 0,005$ & 120 \\
$\mathrm{Cd}$ & 0,500 & 0,50 & $0,60 \pm 0,02$ & 119 \\
$\mathrm{~Pb}$ & 0,500 & 0,50 & $0,23 \pm 0,01$ & 47 \\
\hline
\end{tabular}

Tabela 6.9. Valores de concentração e recuperação dos elementos adicionados e recuperados da tinta amarela enriquecida.

\begin{tabular}{|c|c|c|c|c|}
\hline Elemento & $\begin{array}{l}\text { Quantidade } \\
\text { adicionada } \\
\left(m g L^{-1}\right)\end{array}$ & $\begin{array}{l}\text { Quantidade } \\
\text { esperada } \\
\left(m g L^{-1}\right)\end{array}$ & $\begin{array}{c}\text { Quantidade } \\
\text { encontrada } \\
\left(\mathrm{mg} \mathrm{L}^{-1}\right)\end{array}$ & $\begin{array}{c}\text { Recuperaçáo } \\
(\%)\end{array}$ \\
\hline $\mathrm{Cr}$ & 0,500 & 0,53 & $0,29 \pm 0,03$ & 56 \\
\hline $\mathrm{Mn}$ & 0,500 & 0,542 & $0,433 \pm 0,004$ & 80 \\
\hline Co & 0,500 & 1,92 & $1,80 \pm 0,03$ & 94 \\
\hline $\mathrm{Ni}$ & 0,500 & 0,524 & $0,471 \pm 0,007$ & 90 \\
\hline $\mathrm{Cu}$ & 0,500 & 0,62 & $0,59 \pm 0,01$ & 95 \\
\hline As & 0,500 & 0,54 & $0,53 \pm 0,03$ & 98 \\
\hline $\mathrm{Cd}$ & 0,500 & 0,50 & $0,47 \pm 0,02$ & 94 \\
\hline $\mathrm{Pb}$ & 0,500 & 0,50 & $0,21 \pm 0,01$ & 42 \\
\hline
\end{tabular}

$n=3$ 
Tabela 6.10. Valores de concentração e recuperação dos elementos adicionados e recuperados da tinta vermelha enriquecida.

\begin{tabular}{|c|c|c|c|c|c|}
\hline Elemento & $\begin{array}{l}\text { Quantidade } \\
\text { acicioniada } \\
(\%(\mathrm{~m} / \mathrm{m}))\end{array}$ & $\begin{array}{l}\text { Quantidade } \\
\text { esperada } \\
(\%(\mathrm{mim})\end{array}$ & $\begin{array}{l}\text { Quantidade } \\
\text { encontrada } \\
(\%(n / m))\end{array}$ & $\begin{array}{c}\text { Recuperagão } \\
(\%)\end{array}$ & Replicatas \\
\hline $\mathrm{Cr}$ & 0,500 & 0,805 & $0,947 \pm 0,005$ & 118 & $n=3$ \\
\hline $\mathrm{Mn}$ & 0,500 & 0,679 & $0,803 \pm 0,002$ & 118 & $n=3$ \\
\hline Co & 0,500 & 1,01 & $1,01 \pm 0,05$ & 112 & $n=9$ \\
\hline $\mathrm{Ni}$ & 0,500 & 0,53 & $0,65 \pm 0,02$ & 122 & $n=3$ \\
\hline $\mathrm{Cu}$ & 0,500 & 0,56 & $0,57 \pm 0,03$ & 101 & $n=9$ \\
\hline As & 0,500 & 0,55 & $0,60 \pm 0,04$ & 109 & $n=9$ \\
\hline $\mathrm{Cd}$ & 0,500 & 0,500 & $0,541 \pm 0,001$ & 108 & $n=3$ \\
\hline $\mathrm{Pb}$ & 0,500 & 0,781 & $0,886 \pm 0,003$ & 113 & $n=3$ \\
\hline
\end{tabular}

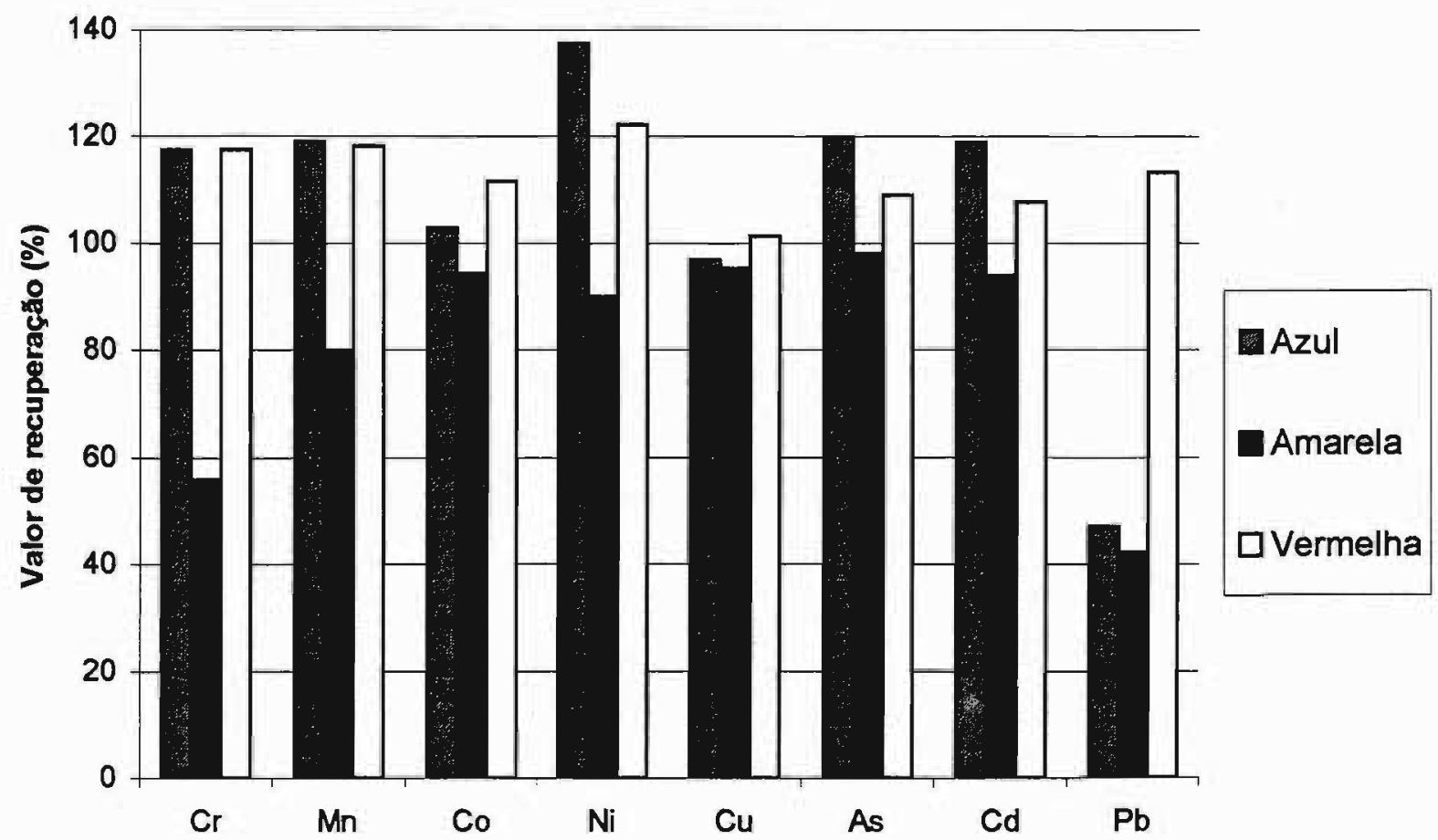

Figura 6.9. Representação dos valores de recuperação (\%) das tintas azul, amarela e vermelha da marca $C$. 
Nas amostras de tinta de cor azul observaram-se porcentagens de recuperação entre 80 a 120\% para $\mathrm{Cr}, \mathrm{Mn}$, Co, Cu, As e Cd, maior que 120\% para Ni e menor porcentagem de recuperação para $\mathrm{Pb}(47 \%)$.

Nas amostras de tinta de cor amarela observaram-se porcentagens de recuperação entre 80 a 120\% para $\mathrm{Mn}$, Co, Cu, As e Cd e menor que $80 \%$ de recuperação para $\mathrm{Cr}(56 \%)$ e $\mathrm{Pb}(42 \%)$.

Nas amostras de tinta de cor vermelha observaram-se porcentagens de recuperação entre 80 a $120 \%$ para $\mathrm{Mn}$, Co, Cu, Cr, As, Cd e $\mathrm{Pb}$ e maior que $100 \%$ de recuperação para $\mathrm{Ni}$.

No caso específico do chumbo a baixa recuperação está relacionada a interferência causada pela cauda de uma linha de Si $(182,246 \mathrm{~nm})$ próxima à de chumbo $(182,200 \mathrm{~nm})$. Este problema não pôde ser corrigido por meio de parâmetros instrumentais para as amostras contendo pequenas quantidades de chumbo. Não foi possivel a utilização de outra linha disponível no programa do equipamento, uma vez que todas apresentaram interferência espectral. Em função destes resultados a determinação do chumbo foi feita por ICP MS.

Nos espectros dos resíduos obtidos após a digestão das tintas azul, amarela e vermelha usando MEV-EDS, mostrados nas Figuras 6.10, 6.11 e 6.12, observa-se a presença de $\mathrm{Al}, \mathrm{Fe}, \mathrm{C}, \mathrm{Mg}$ e $\mathrm{Ca}$. A quantidade de Al atômico encontrada no resíduo da tinta de cor azul foi de 9,1\%. Para $\mathrm{Mg}$, Fe, Ca e C as quantidades encontradas foram de $0,5 \% ; 0,4 \% ; 13,0 \%$ e 2,8\%, respectivamente. No residuo da tinta de cor amarela o valor de Al atômico é de 4,9\%, e para Fe, Ca e Ti é de 4,0\% ; $41,2 \%$ e $0,47 \%$, respectivamente e no residuo da tinta vermelha o valor de $\mathrm{Al}$ atômico é de $9,6 \%, \mathrm{Fe}, \mathrm{Ca}, \mathrm{Mg}$ e Si é de $2,3 \% ; 14,7 \%, 0,5 \%$ e 0,3 respectivamente. Este fato mostra que, com exceção do Alumínio, ocorreu digestão total dos elementos de interesse garantindo a eficiência na decomposição da amostra. A composição do residuo não foi determinada, mas é provável que sejam óxidos e fluoretos destes elementos. O primeiro pico do espectro não está identificado por não se tratar de linha espectral.

Se houver interesse em dissolver completamente a amostra, pode ser adicionado ácido bórico em uma segunda etapa no procedimento para facilitar a digestão dos fluoretos precipitados. Outra vantagem na adição deste ácido é para mascarar os ions fluoretos livres na solução caso não se possua tocha resistente a HF. 


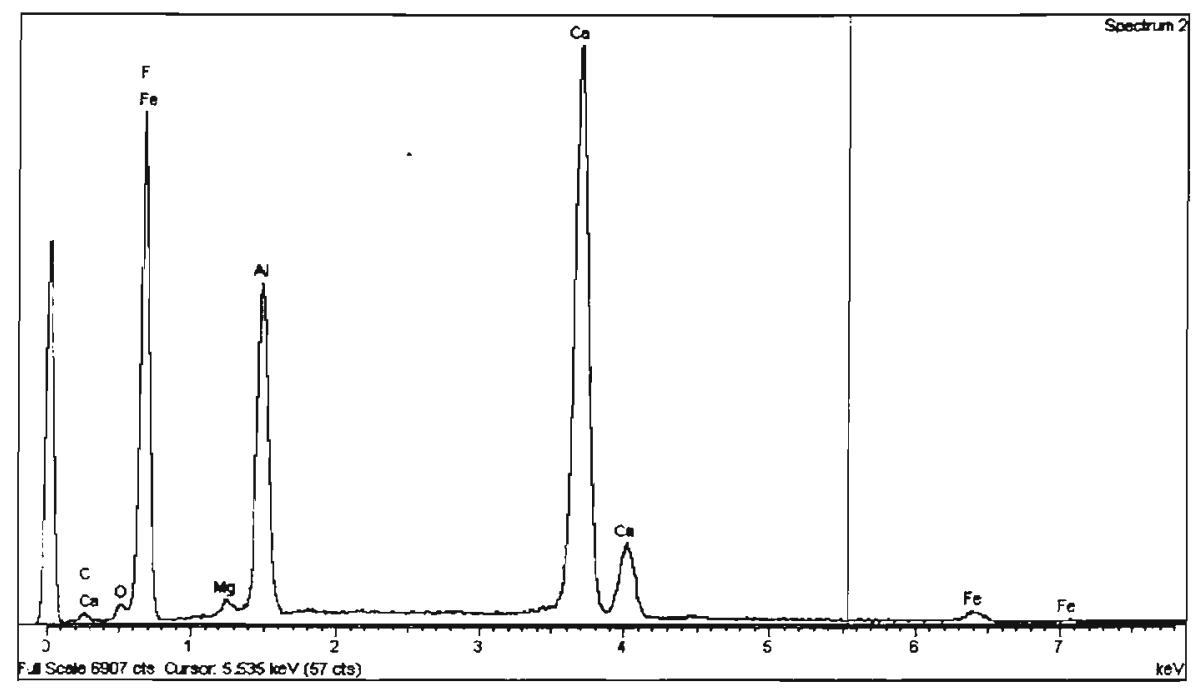

Figura 6.10. Espectro do resíduo da tinta azul, obtido por MEV-EDS

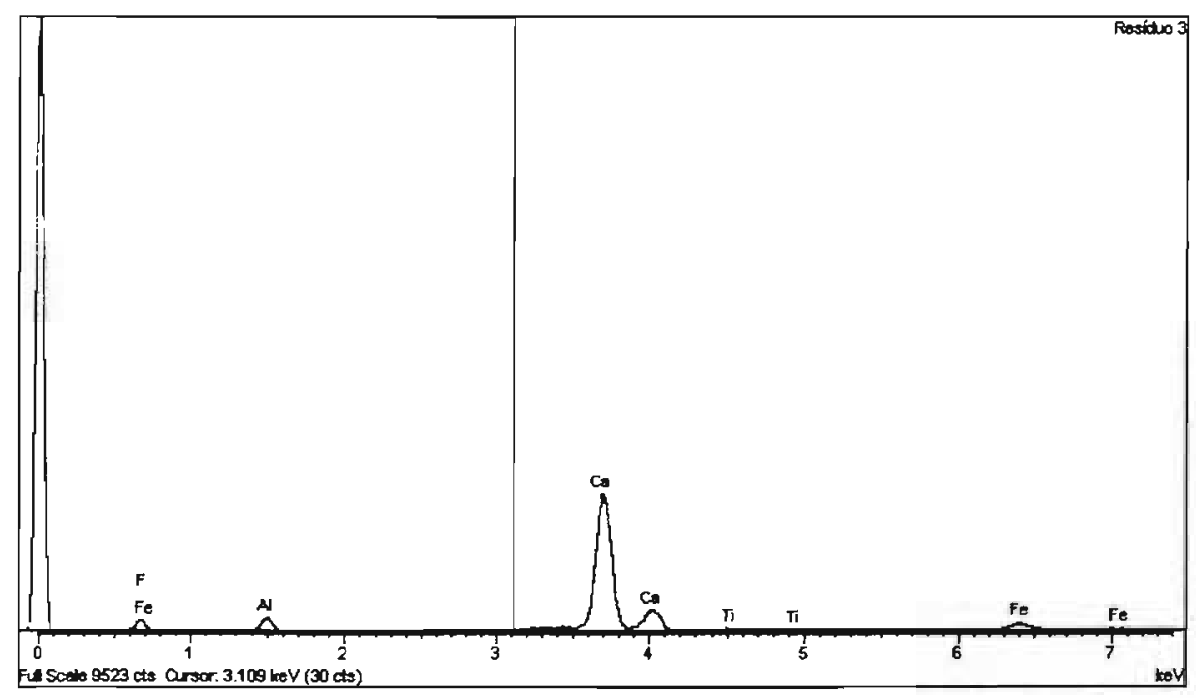

Figura 6.11. Espectro do resíduo da tinta amarela, obtido por MEV-EDS

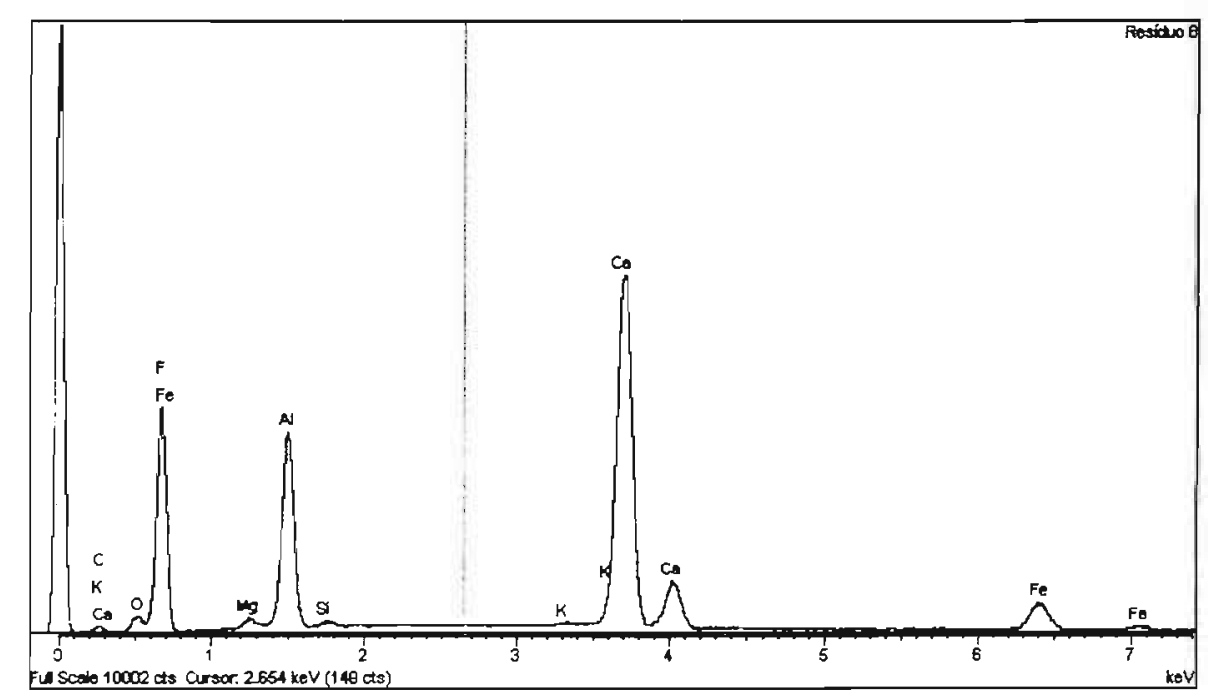

Figura 6.12. Espectro do resíduo da tinta vermelha, obtido por MEV-EDS 
Em função dos problemas encontrados na escolha da melhor linha de emissão no equipamento utilizado (Spectroflame Modula), fez-se a determinação de $\mathrm{Pb}$ por ICP-MS (Instituto de Física - USP) da tinta à base de água de cor vermelha. A digestão das amostras, usando aquecimento por microondas, foi a mesma utilizada no procedimento da Tabela 6.6. As concentrações de $\mathrm{Pb}$ utilizadas na obtenção da curva analítica foram: branco $-0,125-0,25-0,5-1,0-5,0-10,0 \mu \mathrm{g}$ $\mathrm{L}^{-1}$.

Os resultados estão apresentados nas Tabelas 6.11 e 6.12 .

Tabela 6.11. Quantidade encontrada em \% e desvios padrão de $\mathrm{Pb}$, em tinta à base de água de cor vermelha da marca $\mathrm{C}$.

\begin{tabular}{cc}
\hline Elemento & Vermelho cardinal $(n=3)(\%)$ \\
\hline $\mathrm{Pb}$ & $0,0051 \pm 0,0001$ \\
\hline
\end{tabular}

Tabela 6.12 Valores de concentração e recuperação de $\mathrm{Pb}$ adicionado e recuperado na tinta vermelha enriquecida.

\begin{tabular}{|c|c|c|c|c|}
\hline Eleniento & $\begin{array}{c}\text { Quantidade } \\
\text { adicionada (mg L-1) }\end{array}$ & $\begin{array}{l}\text { Quantidadie } \\
\text { esperada }\end{array}$ & $\begin{array}{c}\text { Quantidade } \\
\text { enconirada (mg L t) }\end{array}$ & $\begin{array}{c}\text { Recuperaçäo } \\
(\%)\end{array}$ \\
\hline $\mathrm{Pb}$ & 0,500 & 0,530 & $0,430 \pm 0,005$ & 80 \\
\hline
\end{tabular}

Este elemento deve ser avaliado com mais critério neste tipo de tinta devido ao baixo teor e pelas condições drásticas de digestão a que as amostras devem ser submetidas. Provavelmente deva ser necessária a adição de ácido bórico após a digestão, como sugerido acima.

Em função dos resultados mostrados acima, ficou claro que mesmo com a utilização do HF resta um resíduo, mas que este resíduo não comprometeu a determinação dos analitos de interesse. Um método alternativo foi testado para evitar o uso de HF, pois são poucos os equipamentos que possuem o sistema de 
nebulização resistente a esse ácido e . Os resultados obtidos são mostrados a seguir.

\subsubsection{Procedimento 3: $\mathrm{HNO}_{3} / \mathrm{HCl}$}

Foi empregada mistura ácida $\mathrm{HNO}_{3}$ e $\mathrm{HCl}$ a fim de fazer somente a lixiviação dos elementos de interesse. O objetivo foi o de verificar se, como no caso anterior, os analitos poderiam ser totalmente extraídos das amostras, deixando como resíduo somente material não tóxico. O procedimento é apresentado na Tabela 6.13.

Tabela 6.13. Procedimento empregado para a digestão das tintas à base de água utilizando forno de microondas com cavidade Ethos.

\begin{tabular}{cccccc}
\hline Etapas & Reagentes & Volume $(\mathrm{ml})$ & $\begin{array}{c}\text { Temperatura } \\
(\mathrm{C})\end{array}$ & $\begin{array}{c}\text { Rampa de } \\
\text { aquecinento (rin) }\end{array}$ & $\begin{array}{c}\text { Tempo } \\
\text { (rnin) }\end{array}$ \\
\hline 1 & $\mathrm{HNO}_{3}$ & 6 & 80 & 5 & 2 \\
2 & $\mathrm{HCl}$ & 2 & & & 2 \\
3 & & & 120 & 3 & 10 \\
4 & & & 200 & 10 & 30 \\
\hline
\end{tabular}

Após o resfriamento a solução foi transferida para um frasco volumétrico, o volume foi acertado com água desionizada em $30 \mathrm{~mL}$, homogeneizada, filtrada e os analitos foram determinados por ICP OES CIROS.

Na Tabela 6.14. são apresentados os valores das médias das concentrações dos elementos em \% e os desvios-padrão na determinação dos elementos $\mathrm{Al}, \mathrm{Cr}$, $\mathrm{Mn}, \mathrm{Co}, \mathrm{Ni}, \mathrm{Cu}, \mathrm{As}, \mathrm{Cd}$ e $\mathrm{Pb}$. 
Tabela 6.14. Quantidade encontrada e desvios padrão dos elementos $\mathrm{Al}, \mathrm{Cr}, \mathrm{Mn}$, $\mathrm{Co}, \mathrm{Ni}, \mathrm{Cu}, \mathrm{As}, \mathrm{Cd}$ e $\mathrm{Pb}$, em tinta à base de água da marca $\mathrm{C}$.

\begin{tabular}{cccc}
\hline Elementos & Azul profundo $(\%)$ & Amarelo canario $(\%)$ & Vemneho cardinal (\%) \\
\hline $\mathrm{Al}$ & $0,8 \pm 0,1$ & $1,5 \pm 0,4$ & $0,78 \pm 0,05$ \\
$\mathrm{Cr}$ & $0,00006 \pm 0,00002$ & $0,000476 \pm 0,00004$ & $0,00358 \pm 0,00003$ \\
$\mathrm{Mn}$ & $0,000422 \pm 0,000005$ & $0,000382 \pm 0,000005$ & $0,0016500 \pm 0,0000008$ \\
$\mathrm{Co}$ & $0,00004 \pm 0,00001$ & $0,000095 \pm 0,00004$ & $0,000070 \pm 0,000004$ \\
$\mathrm{Ni}$ & $<0,00001$ & $<0,00001$ & $<0,00001$ \\
$\mathrm{Cu}$ & $0,062 \pm 0,001$ & $0,000010 \pm 0,000003$ & $0,000040 \pm 0,000007$ \\
$\mathrm{As}$ & $<0,0001$ & $<0,0001$ & $<0,0001$ \\
$\mathrm{Cd}$ & $<0,00001$ & $<0,00001$ & $<0,00001$ \\
$\mathrm{~Pb}$ & $<0,00005$ & $<0,00005$ & $0,0019 \pm 0,0001$ \\
\hline
\end{tabular}

Estes resultados diferem consideravelmente dos obtidos após digestão com a mistura ácida de $\mathrm{HNO}_{3}$ com $\mathrm{HF}$. Este fato leva a crer que os elementos avaliados se encontram ocluídos no $\mathrm{TiO}_{2}$.

Fez-se teste de adição e recuperação de analito e os resultados estão apresentados nas Tabelas 6.15, 6.16 e 6.17 .

Tabela 6.15. Valores de concentração e recuperação dos elementos adicionados e recuperados da tinta azul enriquecida.

\begin{tabular}{|c|c|c|c|c|}
\hline $\begin{array}{l}\text { Elsmento } \\
\text { s }\end{array}$ & $\begin{array}{l}\text { Quantidade } \\
\text { adicionada (mg L }\end{array}$ & $\begin{array}{l}\text { Quantidado } \\
\text { esperada (mal L') }\end{array}$ & $\begin{array}{l}\text { Quantidade } \\
\text { encontrada (mg L }\end{array}$ & Recuperacäo (96) \\
\hline $\mathrm{Al}$ & 55 & 112 & $100 \pm 8$ & 90 \\
\hline $\mathrm{Cr}$ & 0,5 & 0,504 & $0,44 \pm 0,05$ & 87 \\
\hline $\mathrm{Mn}$ & 0,5 & 0,53 & $0,41 \pm 0,08$ & 77 \\
\hline Co & 0,5 & 0,503 & $0,43 \pm 0,05$ & 85 \\
\hline $\mathrm{Ni}$ & 0,5 & 0,5 & $0,40 \pm 0,07$ & 80 \\
\hline $\mathrm{Cu}$ & 5,5 & 9,7 & $9,1 \pm 0,4$ & 94 \\
\hline As & 0,5 & 0,5 & $0,39 \pm 0,08$ & 78 \\
\hline Cd & 0,5 & 0,5 & $0,43 \pm 0,05$ & 85 \\
\hline $\mathrm{Pb}$ & 0,5 & 0,5 & $0,45 \pm 0,04$ & 90 \\
\hline
\end{tabular}


Tabela 6.16. Valores de concentração e recuperação dos elementos adicionados e recuperados da tinta amarela enriquecida.

\begin{tabular}{|c|c|c|c|c|}
\hline Elementos & $\begin{array}{l}\text { Quantidade } \\
\text { adicionada (mg } L^{-1} \text { ) }\end{array}$ & $\begin{array}{l}\text { Quanfidade } \\
\text { esperada (mg L') }\end{array}$ & $\begin{array}{c}\text { Quantidade } \\
\text { encontrada (mg L ' ') }\end{array}$ & $\begin{array}{c}\text { Recuperaçảo } \\
(\%)\end{array}$ \\
\hline $\mathrm{Al}$ & 50 & 156 & $137 \pm 31$ & 88 \\
\hline $\mathrm{Cr}$ & 0,5 & 0,53 & $0,473 \pm 0,002$ & 89 \\
\hline $\mathrm{Mn}$ & 0,5 & 0,53 & $0,441 \pm 0,005$ & 84 \\
\hline Co & 1,5 & 1,51 & $1,3301 \pm 0,0009$ & 88 \\
\hline $\mathrm{Ni}$ & 0,5 & 0,5 & $0,38 \pm 0,009$ & 76 \\
\hline $\mathrm{Cu}$ & 0,5 & 0,51 & $0,491 \pm 0,001$ & 96 \\
\hline As & 0,5 & 0,50 & $0,293 \pm 0,004$ & 59 \\
\hline $\mathrm{Cd}$ & 0,5 & 0,50 & $0,4122 \pm 0,0009$ & 82 \\
\hline $\mathrm{Pb}$ & 0,5 & 0,50 & $0,41 \pm 0,01$ & 82 \\
\hline
\end{tabular}

Tabela 6.17. Valores de concentração e recuperação dos elementos adicionados e recuperados da tinta látex vermelha enriquecida.

\begin{tabular}{|c|c|c|c|c|}
\hline Elementos & $\begin{array}{l}\text { Quantidade } \\
\text { adicionada } \\
\left(m \mathrm{~L}^{-1}\right)\end{array}$ & $\begin{array}{l}\text { Quantidade } \\
\text { esperada } \\
\left.\text { (mg L } L^{-1}\right)\end{array}$ & $\begin{array}{l}\text { Quantidade } \\
\text { encontrada. } \\
\left(\mathrm{mg} \mathrm{L}^{\mathrm{t}} \text { ) }\right.\end{array}$ & Recuperacto $(\%)$ \\
\hline Al & 55 & 108 & $98 \pm 8$ & 91 \\
\hline $\mathrm{Cr}$ & 0,500 & 0,52 & $0,48 \pm 0,03$ & 92 \\
\hline$M n$ & 0,500 & 0,61 & $0,50 \pm 0,04$ & 81 \\
\hline Co & 0,500 & 0,505 & $0,44 \pm 0,04$ & 87 \\
\hline $\mathrm{Ni}$ & 0,500 & 0,50 & $0,40 \pm 0,07$ & 80 \\
\hline $\mathrm{Cu}$ & 0,500 & 0,503 & $0,457 \pm 0,004$ & 91 \\
\hline As & 0,500 & 0,50 & $0,41 \pm 0,04$ & 82 \\
\hline $\mathrm{Cd}$ & 0,500 & 0,50 & $0,44 \pm 0,07$ & 88 \\
\hline $\mathrm{Pb}$ & 0,500 & 0,63 & $0,64 \pm 0,06$ & 102 \\
\hline
\end{tabular}

Nas amostras de tinta de cor azul, Mn e As apresentaram valores de recuperação de 77 - $78 \%$, os demais apresentaram recuperação entre 85 e $90 \%$.

Nas amostras de tinta de cor amarela observaram-se porcentagens de recuperação entre 82 a $97 \%$ para $\mathrm{Al}, \mathrm{Cr}, \mathrm{Mn}, \mathrm{Co}, \mathrm{Cu}, \mathrm{Cd}$ e $\mathrm{Pb}$ e menor que $80 \%$ de recuperação para $\mathrm{Ni}(76 \%)$ e As $(59 \%)$. Nas amostras de tinta de cor vermelha ocorreram porcentagens de recuperação entre 81 a $102 \%$ para $\mathrm{Mn}, \mathrm{Co}, \mathrm{Ni}, \mathrm{Cu}, \mathrm{Cr}$, As, $\mathrm{Cd}$ e $\mathrm{Pb}$. 
Em função dos bons resultados de recuperação obtidos para a maioria dos elementos, elimina-se a possibilidade de efeito de matriz e perda destes elementos. A diferença entre os valores obtidos após digestão usando a mistura ácida de $\mathrm{HNO}_{3}$ com $\mathrm{HF}$ e a mistura de $\mathrm{HNO}_{3} \mathrm{com} \mathrm{HCl}$, parecem confirmar que estes elementos estão ocluídos no $\mathrm{TiO}_{2}$. Portanto, para tintas à base de água que apresentam em sua composição alta quantidade de $\mathrm{TiO}_{2}$ há a necessidade de digestão total, uma vez que nenhum dos analitos apresentou resultado concordante com o obtido com a digestão usando HF.

\subsection{Avaliação dos métodos de digestão de tinta à base de solvente orgânico}

Devido à complexidade da matriz pelo alto teor de matéria orgânica e presença de pigmentos, esta etapa de transformação da amostra sólida em líquida é extremamente crítica. Nesta fase estudaram-se procedimentos de decomposição para tintas à óleo e tintas esmalte nas cores azul, amarela e vermelha. Inicialmente utilizou-se uma tinta à óleo de cor azul para a avaliação do método a ser empregado em outras amostras.

Os procedimentos que foram adotados para a preparação das amostras foram: bombas de decomposição à pressão atmosférica, digestão assistida por microondas com radiação focalizada, sistema com cavidade, e método de cinzas.

\subsubsection{Utilização de sistema de bombas de decomposição}

A digestão da amostra por via úmida em sistemas abertos pode propiciar a perda de elementos voláteis e contaminações, e pode também acarretar a evolução de fumos ácidos que ocasionarão um problema de saúde ocupacional. Uma alternativa a esse método é a digestão em sistemas fechados, conhecidos como bombas de decomposição. As principais vantagens do sistema de bombas de decomposição são: não há perdas por volatilização; pode se trabalhar acima do ponto de ebulição do reagente; reduz-se a quantidade dos reagentes $e$ conseqüentes valores dos brancos; inibe-se o risco de contaminações por fontes externas[KRUG, 2004]. 
A digestão das amostras foi realizada num sistema de bombas de decomposição composto por um bloco de aço aquecido resistivamente, por frascos de digestão de PTFE que são colocados dentro de uma camisa de alumínio que, por sua vez, são colocadas dentro do bloco de aço, sendo aquecido por condução. Este sistema foi fabricado no Departamento de Engenharia de Materiais da FAENQUIL e está apresentado na Figura 6.13.

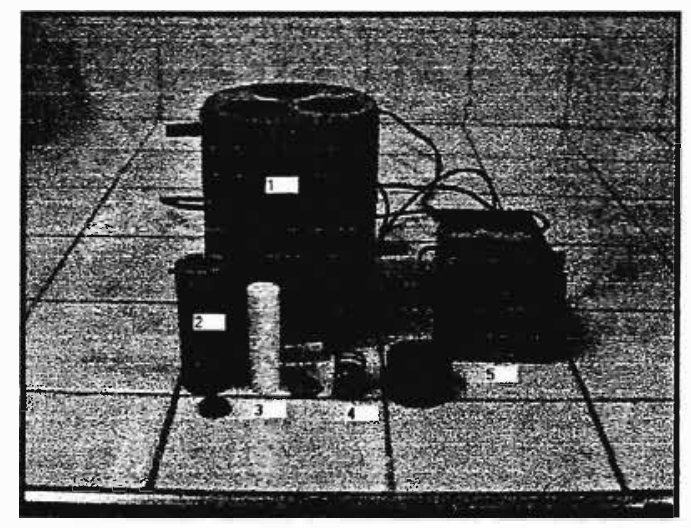

Figura 6.13. Sistema de Bombas de Decomposição (1- Bloco de aço inox; 2- camisa de alumínio; 3-cadinho de TEFLONQ; 4- mola; 5- termostato)

\subsubsection{Procedimento 1: $\mathrm{HNO}_{3} / \mathrm{HCl}(1: 3 \mathrm{v} / \mathrm{v})$}

Uma massa de $50 \mathrm{mg}$ de tinta a óleo de cor azul foram colocadas dentro do frasco digestor, adicionou-se $1 \mathrm{~mL}$ de $\mathrm{HNO}_{3}$ e $3 \mathrm{~mL}$ de $\mathrm{HCl}$ ambos, $20 \% \mathrm{v} / \mathrm{v}$. Os frascos foram colocados dentro do sistema de digestão a uma temperatura de $110^{\circ} \mathrm{C}$ por $3 \mathrm{~h}$. A amostra não solubilizou.

\subsubsection{Procedimento 2: $\mathrm{HNO}_{3} / \mathrm{HCl}(3: 1 \mathrm{v} / \mathrm{v})$}

Neste procedimento a massa, a temperatura e o tempo de reação foram mantidos iguais ao procedimento 1 . Variou-se a composição da mistura ácida. Neste caso, adicionou-se $3 \mathrm{~mL}$ de $\mathrm{HNO}_{3}$ e $1 \mathrm{~mL}$ de $\mathrm{HCl}$ ambos, $20 \% \mathrm{v} / \mathrm{v}$. A amostra não solubilizou. 


\subsubsection{Procedimento 3: $\mathrm{HNO}_{3} / \mathrm{H}_{2} \mathrm{O}_{2}(1: 3 \mathrm{v} / \mathrm{v})$}

Neste procedimento combinou-se o poder oxidante do $\mathrm{HNO}_{3}$ em conjunto com o $\mathrm{H}_{2} \mathrm{O}_{2} .50 \mathrm{mg}$ de tinta à óleo de cor azul foram colocadas no frasco digestor, adicionou-se $1 \mathrm{~mL}$ de $\mathrm{HNO}_{3}\left(20 \%\right.$; v/v ) e $3 \mathrm{~mL}$ de $\mathrm{H}_{2} \mathrm{O}_{2}(30 \% ; \mathrm{v} / \mathrm{v}) . \mathrm{O} \mathrm{H}_{2} \mathrm{O}_{2}$ geralmente é para oxidação de materiais orgânicos em presença de misturas ácidas facilitando a remoção final de produtos orgânicos coloridos que permaneçam em solução em alguns procedimentos [KRUG, 2004]. Não houve digestão da amostra.

Aumentando a temperatura de $110^{\circ} \mathrm{C}$ para $140^{\circ} \mathrm{C}$, foram testados os mesmos procedimentos anteriores $e$, nestes casos, houve vazamento inviabilizando o aumento da temperatura. Quando a mistura $\mathrm{HNO}_{3} / \mathrm{H}_{2} \mathrm{O}_{2}$ foi utilizada, os resíduos eram aparentemente melhores que os obtidos a temperatura de $110^{\circ} \mathrm{C}$. Porém, devido aos vazamentos causados pelo aumento da pressão, neste equipamento não foi possivel digerir as amostras de tinta óleo.

Os procedimentos acima foram testados para tinta esmalte de cor amarela e os resultados não foram satisfatórios. Portanto a utilização deste sistema para digestão de filmes de tinta à base de solvente orgânico não foi possível.

\subsubsection{Forno de microondas com radiação focalizada}

Forno de microondas com radiação focalizada a pressão atmosférica foi empregado em três métodos de decomposição das amostras em que se variou a composição do extrator, potência aplicada e tempo irradiação.

Após a homogeneização, as amostras de tintas líquidas foram pesadas por diferença de massa, ou seja, pesou-se uma quantidade de tinta em um copo descartável, transferiu-se diretamente para o vaso do forno de microondas inclinando-o levemente e pesou-se novamente o copo com a sobra da tinta. Para se manter aproximadamente a mesma massa para todas as digestões, verificou-se 0 equivalente a uma gota e colocou-se a mesma quantidade em gotas nos frascos Este procedimento foi necessário devido ao frasco utilizado ser grande. Nos casos em que os frascos de decomposição permitiam a colocação direta da tinta, esta foi colocada com auxílio de conta gotas descartáveis. 


\subsubsection{Procedimento 1: $\mathrm{HNO}_{3}$}

A 0,6 g de amostra adicionou-se $10 \mathrm{~mL}$ de $\mathrm{HNO}_{3}$ (65 \% v/v), aplicou-se uma potência de $30 \mathrm{~W}$ por $80 \mathrm{~min}$. O programa de aquecimento está apresentado na Tabela 6.18. Usando este procedimento a amostra não solubilizou.

Tabela 6.18. Procedimento empregado para a digestão de tinta azul a base de óleo da marca $A$ em forno de microondas com radiação focalizada.

\begin{tabular}{lllll}
\hline Etapas & Reagentes & Volume $(\mathrm{mL})$ & Potência $(\mathbf{l})$ & Tempo (min) \\
\hline 1 & $\mathrm{HNO}_{3}$ & 10 & 30 & 30 \\
2 & & 30 & 10 \\
3 & & 30 & 40 \\
\hline
\end{tabular}

\subsubsection{Procedimento 2: $\mathrm{HNO}_{3}$ e $\mathrm{H}_{2} \mathrm{O}_{2}$}

A $0,6 \mathrm{~g}$ de amostra adicionou-se $\mathrm{HNO}_{3}(65 \% \mathrm{v} / \mathrm{v})$ em duas etapas, totalizando $10 \mathrm{~mL}$ de ácido, aumentou-se a potência na primeira etapa e adicionou-se $\mathrm{H}_{2} \mathrm{O}_{2}$ na última. Apesar do aumento da potência e da atmosfera oxidante devido ao peróxido, restou amostra sem solubilizar. O programa de aquecimento e a solução extratora utilizada no forno de microondas focalizadas estão apresentados na Tabela 6.19.

Tabela 6.19. Procedimento empregado para a digestão de tinta azul a base de óleo da marca $A$ em forno de microondas com radiação focalizada.

\begin{tabular}{lllll}
\hline Etapas & Reagentes & Volume $(\mathrm{m})$ & Potencia $\mathrm{M}$ & Tempo (min) \\
\hline 1 & $\mathrm{HNO}_{3}$ & 2,5 & 60 & 10 \\
2 & $\mathrm{HNO}_{3}$ & 7,5 & 30 & 30 \\
3 & $\mathrm{H}_{2} \mathrm{O}_{2}$ & 2,0 & 30 & 5 \\
\hline
\end{tabular}




\subsubsection{Procedimento 3: $\mathrm{HNO}_{3} / \mathrm{HCl}$ e $\mathrm{H}_{2} \mathrm{O}_{2}$}

Neste procedimento aliou-se o poder oxidante da mistura $\mathrm{HNO}_{3} / \mathrm{H}_{2} \mathrm{O}_{2}$ com o poder complexante do $\mathrm{HCl}$ em $0,6 \mathrm{~g}$ de amostra [KRUG, 2004]. O procedimento está descrito na Tabela 6.20.

Tabela 6.20. Procedimento empregado para a digestão de tinta azul a base de óleo da marca $A$ em forno de microondas com radiação focalizada.

\begin{tabular}{lllll}
\hline Etapas & Reagentes & Volume $(\mathrm{mil})$ & Pótência (W) & Tempo $(\mathrm{min})$ \\
\hline 1 & $\mathrm{HNO}_{3}$ & 9 & 60 & 10 \\
& $\mathrm{HCl}$ & 3 & & \\
2 & & & 30 & 10 \\
3 & & 30 & 10 \\
4 & $\mathrm{H}_{2} \mathrm{O}_{2}$ & 2,0 & 30 & 5 \\
\hline
\end{tabular}

Nos três procedimentos descritos observou-re que a tinta á óleo não solubilizou completamente, restando uma pasta extremamente viscosa de cor acizentada.

A tinta esmalte foi avaliada na forma de filmes secos em forno de microondas com radiação focalizada e não sofreu alteração a não ser na cor da amostra. Portanto a utilização de forno de microondas focalizadas, usando os ácidos acima indicados não foi eficiente para a digestão de tintas à base de solvente orgânico.

\subsubsection{Método de cinzas - Forno mufla com radiação microondas}

O método de decomposição por via seca consiste em calcinar a amostra em temperaturas elevadas $\left(450-550^{\circ} \mathrm{C}\right)$, em atmosfera de $\mathrm{O}_{2}$. Estes testes foram feitos em forno mufla com microondas e, após a calcinação, as cinzas foram solubilizadas em ácido [WATSON, 1994]. O forno mufla com radiação microondas apresenta uma grande vantagem devido ao menor tempo de aquecimento, não difusão de calor e odores para o ambiente, circulação de ar, permitindo uma oxidação mais efetiva do 
carbono a $\mathrm{CO}_{2}$, menor contaminação, controle de tempo, potência e temperatura em cada etapa do programa.

$\mathrm{Na}$ aplicação deste método às amostras de tinta surgiu uma dificuldade adicional para a secagem do solvente, pois este inicialmente seca superficialmente, de modo que a camada líquida fica encapsulada por uma membrana fina do filme. Com o aquecimento, a camada líquida interior gera aumento de pressão, rompendo a película de forma explosiva e causando perda da amostra. Esse problema é particularmente sério nas amostras de tintas à base de solvente, de modo que vários testes foram feitos até chegar-se ao procedimento ideal, descrito a seguir. Pesou-se diretamente no do cadinho, cerca de $1 \mathrm{~g}$ de amostras de tintas à base d'água ou à base de solvente orgânico nas cores vermelha, amarela, azul e branca e levou-se à estufa a $100{ }^{\circ} \mathrm{C}$ por $24 \mathrm{~h}$. Esse procedimento foi suficiente para a secagem do solvente, de modo a evitar o problema de perda de amostras descrito anteriormente.

As amostras secas desta maneira foram levadas a mufla e levadas a cinzas utilizando o programa de aquecimento apresentado na Tabela 6.21. Após o resfriamento das amostras, as cinzas foram solubilizadas em $3 \mathrm{~mL}$ de ácido nítrico $14 \mathrm{~mol} \mathrm{~L}^{-1} \mathrm{e} 1 \mathrm{~mL}$ de ácido cloridrico $12 \mathrm{~mol} \mathrm{~L}^{-1}$. As amostras foram avolumadas a $25 \mathrm{~mL}$, homogeneizadas e diluídas quando necessário.

Fez-se teste de adição e recuperação para este método. A concentração adicionada de Co foi de $12 \mathrm{mg} \mathrm{L}^{-1}$, de $50 \mathrm{mg} \mathrm{L}^{-1}$ para o $\mathrm{Pb}$ e de $5 \mathrm{mg} \mathrm{L}^{-1}$ para os demais elementos. 
Tabela 6.21. Programa de aquecimento da mufla com radiação microondas para a decomposição de amostras de tinta a base de óleo, cor azul da marca A.

\begin{tabular}{cccc}
\hline Etapas & Potencia (W) & Temperatura (C) & Tempo (min) \\
\hline 1 & 250 & 80 & 90 \\
2 & 250 & 100 & 90 \\
3 & 250 & 200 & 90 \\
4 & 500 & 300 & 60 \\
5 & 500 & 400 & 90 \\
6 & 500 & 500 & 90 \\
7 & & & 30 \\
\hline
\end{tabular}

Na Tabela 6.22 são apresentados os resultados da análise de $\mathrm{Al}, \mathrm{Cr}, \mathrm{Mn}, \mathrm{Co}$, $\mathrm{Ni}, \mathrm{Cu}, \mathrm{As}$, Se, $\mathrm{Cd}$ e $\mathrm{Pb}$. Os elementos $\mathrm{Cr}$, Ni, As, Se e $\mathrm{Cd}$, não foram detectados nas condições experimentais utilizadas. Para As este resultado já era esperado, uma vez que este método é aplicável em amostras orgânicas para a determinação de vários elementos, com exceção do mercúrio e do arsênio, devido à volatilização destes elementos nestas condições [WATSON, 1994].

Tabela 6.22. Teores percentuais de $\mathrm{Al}, \mathrm{Cr}, \mathrm{Mn}, \mathrm{Co}, \mathrm{Ni}, \mathrm{Cu}, \mathrm{As}, \mathrm{Cd}$ e $\mathrm{Pb}$, em tinta azul da marca $\mathrm{A}$, após digestão das cinzas pela mistura $\mathrm{HNO}_{3} / \mathrm{HCl}$.

\begin{tabular}{cccc}
\hline Elementos & $\begin{array}{c}\text { Quantidade encontrada } \\
\end{array}$ & $\begin{array}{c}\text { Elementos } \\
\%(\mathrm{~m} / \mathrm{m})\end{array}$ & $\begin{array}{c}\text { Quantidade encontrada } \\
\%(\mathrm{~m} / \mathrm{m})\end{array}$ \\
\hline $\mathrm{Al}$ & $0,067 \pm 0,001$ & $\mathrm{Cu}$ & $0,232 \pm 0,008$ \\
$\mathrm{Cr}$ & $<0,00001$ & $\mathrm{As}$ & $<0,0001$ \\
$\mathrm{Mn}$ & $0,0042 \pm 0,0001$ & $\mathrm{Cd}$ & $<0,00001$ \\
$\mathrm{Co}$ & $0,019 \pm 0,001$ & $\mathrm{~Pb}$ & $0,64 \pm 0,01$ \\
$\mathrm{Ni}$ & $<0,00001$ & & \\
\hline
\end{tabular}

O mesmo procedimento foi empregado às soluções branco e solução "branco dopada" (branco contendo todos os elementos com quantidade conhecida). Ao doparmos a amostra nos deparamos com outro problema, a solubilidade entre a 
amostra (óleo) e a solução padrão (aquosa). Portanto, a amostra não foi misturada adequadamente aos padrões.

O resultado dos testes de recuperação para a digestão em mufla de microondas não foi diferente das avaliaçōes anteriores, ou seja, as recuperações para As foi abaixo de $80 \%$. Para os demais elementos a recuperação ficou entre 84 e $105 \%$ (Tabela 6.23).

Tabela 6.23. Resultado do teste de recuperação dos elementos $\mathrm{Al}, \mathrm{Cr}, \mathrm{Mn}, \mathrm{Co}, \mathrm{Ni}$, $\mathrm{Cu}, \mathrm{As}, \mathrm{Cd}$ e $\mathrm{Pb}$, em tinta azul da marca $\mathrm{A}$ após digestão das cinzas pela mistura $\mathrm{HNO}_{3} / \mathrm{HCl}$

\begin{tabular}{|c|c|c|c|c|}
\hline Elemento & $\begin{array}{l}\text { Concentraçáo } \\
\text { adicionada }\end{array}$ & $\begin{array}{c}\text { Concentraçáo } \\
\text { esperada }\end{array}$ & $\begin{array}{c}\text { Concentracáo } \\
\text { encontrada }\end{array}$ & Recuperacáo\% \\
\hline$\overline{A l}$ & 5,0 & 10,2 & 9,6 & 94 \\
\hline $\mathrm{Cr}$ & 5,0 & 7,9 & 7,7 & 97 \\
\hline $\mathrm{Mn}$ & 5,0 & 5,3 & 4,5 & 84 \\
\hline Co & 12,0 & 13,6 & 13 & 95 \\
\hline $\mathrm{Ni}$ & 5,0 & 5,0 & 4,5 & 89 \\
\hline $\mathrm{Cu}$ & 12,0 & 24,2 & 25,4 & 105 \\
\hline As & 5,0 & 5,0 & 3,4 & 68 \\
\hline $\mathrm{Cd}$ & 5,0 & 5,0 & 4,7 & 94 \\
\hline $\mathrm{Pb}$ & 50 & 103 & 108,2 & 105 \\
\hline
\end{tabular}

A avaliação em relação à solução contendo os extratores e elementos de interesse (branco dopado), mostra que mesmo o arsênio apresentou recuperação de $80 \%$ e a recuperação dos demais elementos se encontra na faixa de 91 a $107 \%$ (Tabela 6.24). 
Tabela 6.24. Resultado do teste de recuperação dos elementos $\mathrm{Al}, \mathrm{Cr}, \mathrm{Mn}, \mathrm{Co}, \mathrm{Ni}$, $\mathrm{Cu}, \mathrm{As}, \mathrm{Se}, \mathrm{Cd}$ e $\mathrm{Pb}$, em solução branco, contendo $\mathrm{HNO}_{3}$ e $\mathrm{HCl}$ e água desionizada, enriquecida com os elementos de interesse. Método Cinzas

\begin{tabular}{|c|c|c|c|}
\hline Elemento & $\begin{array}{c}\text { Quantidade adicionada } \\
\text { (mg L L-1) }\end{array}$ & $\begin{array}{c}\text { Quantidade encontrada } \\
\left(\mathrm{mg} \mathrm{L}^{-1}\right)\end{array}$ & \% recuperácáo \\
\hline Al & 5,00 & 4,63 & 93 \\
\hline $\mathrm{Cr}$ & 5,00 & 4,56 & 91 \\
\hline $\mathrm{Mn}$ & 5,00 & 4,62 & 93 \\
\hline Co & 12,00 & 11,74 & 98 \\
\hline $\mathrm{Ni}$ & 5,00 & 4,66 & 93 \\
\hline $\mathrm{Cu}$ & 5,00 & 5,34 & 107 \\
\hline As & 5,00 & 4,01 & 80 \\
\hline $\mathrm{Cd}$ & 5,00 & 4,90 & 98 \\
\hline $\mathrm{Pb}$ & 50,00 & 48,43 & 97 \\
\hline
\end{tabular}

Os resultados mostram que se obtiveram valores de recuperação analiticamente aceitáveis para todos os elementos, tanto nas amostras quanto para as soluções "branco dopadas". A única exceção foi para o As nas amostras, se obteve valores baixos de recuperação.

\subsubsection{Forno de microondas - Sistema com cavidade}

A digestão assistida por microondas em sistema fechado à pressão elevada foi empregada às tintas à base de solvente orgânico nas cores azul, vermelha e amarela.

A utilização do sistema fechado apresenta grande vantagem por favorecer o aumento do ponto de ebulição do extrator e evitar perdas de voláteis. A digestão usando sistema com cavidade apresenta a inconveniência de admitir somente 
massa reduzida de amostra, devido a riscos de vazamento e explosão resultantes da alta pressão dos gases produzidos pela oxidação da matéria orgânica. As reações envolvidas no processo de digestão são representadas pelas seguintes equações:

$$
\begin{gathered}
{ }^{*}\left(\mathrm{CH}_{2}\right) \mathrm{x}+2 \mathrm{HNO}_{3} \rightarrow \mathrm{CO}_{2(\mathrm{~g})}+2 \mathrm{NO}_{(\mathrm{g})}+2 \mathrm{H}_{2} \mathrm{O} \\
\mathrm{NO}_{(\mathrm{g})}+1 / 2 \mathrm{O}_{2(\mathrm{~g})} \rightarrow \mathrm{NO}_{2} \\
\mathrm{H}_{2} \mathrm{O}_{2} \rightarrow \mathrm{H}_{2} \mathrm{O}+1 / 2 \mathrm{O}_{2} \\
\mathrm{H}_{2} \mathrm{O}_{2}+{ }^{*}\left(\mathrm{CH}_{2}\right) \mathrm{x}+\mathrm{O}_{2(\mathrm{~g})} \rightarrow \mathrm{CO}_{2(\mathrm{~g})}+2 \mathrm{H}_{2} \mathrm{O}
\end{gathered}
$$

O mesmo programa de aquecimento do forno foi usado em todos os métodos empregados. O que difere nos métodos é a composição da mistura extratora e a forma em que se encontram as amostras, que podem ser líquidas ou secas (na forma de filmes).

Foram usados ácidos concentrados em todas as etapas de digestão e em todos os procedimentos.

Programa de Aquecimento - Fez-se uma rampa de aquecimento até se atingir a temperatura de $80{ }^{\circ} \mathrm{C}$, esta temperatura foi mantida por $2 \mathrm{~min}$ (isoterma) e novamente outra rampa até se atingir $120^{\circ} \mathrm{C}$. Manteve-se esta temperatura por 2 min e outra rampa mais demorada até atingirmos $200{ }^{\circ} \mathrm{C}$, que foi mantida por 10 min. O sistema foi resfriado por $30 \mathrm{~min}$. O gráfico apresentado na Figura 6.14 ilustra do programa.

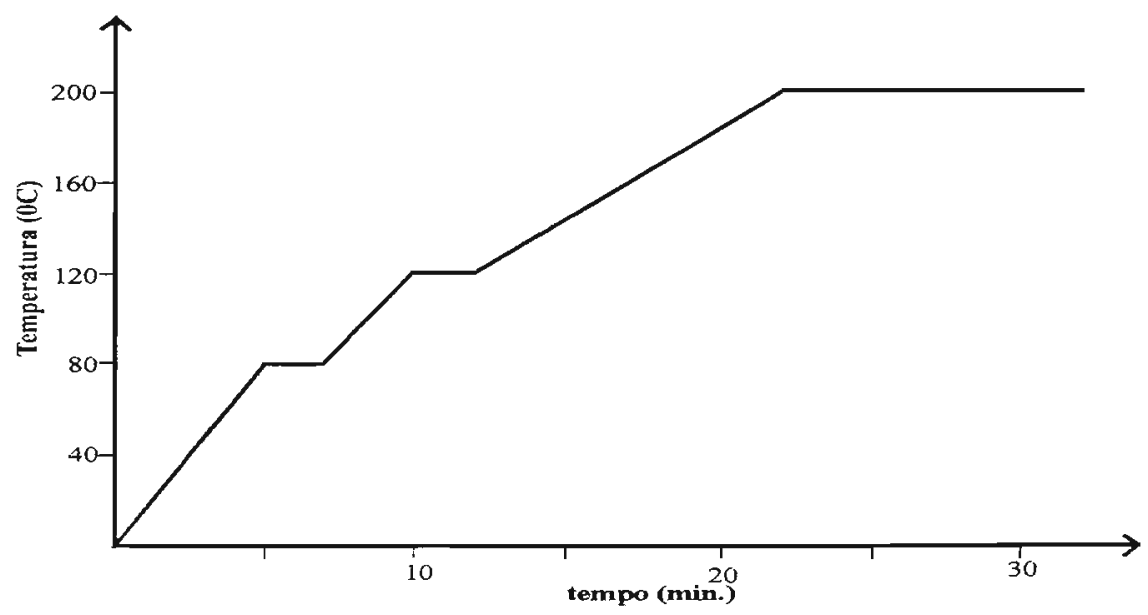

Figura 6.14. Representação gráfica do programa de aquecimento do forno de microondas com cavidade. 


\subsubsection{Procedimento 1: $\mathrm{HNO}_{3}$}

0,2 g de tinta a óleo de cor azul, na forma líquida, foi colocada no vaso de digestão com auxilio de conta-gotas descartável. Adicionou-se $8 \mathrm{~mL}$ de ácido nítrico e realizou-se a digestão de acordo com o programa de aquecimento apresentado na Tabela 6.25. Após a digestão as soluções foram transferidas para frascos volumétricos, seu volume completado a $25 \mathrm{~mL}$, agitadas (não foram filtradas) e os elementos de interesse determinados. Os resultados da determinação dos analitos estão apresentados na Tabela 6.26 .

As soluções resultantes apresentaram coloração levemente amarelada indicando que a oxidação da matéria orgânica foi completa. Embora a coloração de uma solução dê indícios da destruição da matéria orgânica, uma alternativa mais eficiente para a obtenção desta informação, é a determinação do teor de carbono residual, logo, este se toma um importante parâmetro na avaliação da eficiência dos procedimentos de decomposição de amostras [MATUSIEWICZ et al., 1989; SILVA et al., 2000].

Tabela 6.25. Procedimento empregado na digestão de tinta à óleo de cor azul

\begin{tabular}{llllll}
\hline Etapas & Reagentes & Volume $(\mathrm{ml})$ & $\begin{array}{c}\text { Temperatura } \\
\text { (G) }\end{array}$ & $\begin{array}{c}\text { Rampa } \\
\text { aquecimente (min) }\end{array}$ \\
\hline 1 & $\mathrm{HNO}_{3}$ & 8 & 80 & 5 & 2 \\
2 & & 120 & 3 & 2 \\
3 & & 200 & 10 & 10 \\
4 & & 0 & & 30 \\
\hline
\end{tabular}

\subsubsection{Procedimento 2: $\mathrm{HNO}_{3} / \mathrm{H}_{2} \mathrm{O}_{2}$}

Neste procedimento, empregou-se o mesmo método usado na Tabela 6.25 acrescentando, junto ao ácido nítrico, o peróxido de hidrogênio. Após a digestão as soluções foram transferidas para frascos volumétricos, seu volume completado a 25 $\mathrm{mL}$, agitadas (não foram filtradas) e os elementos de interesse foram determinados e seus resultados apresentados na Tabela 6.26. 
As soluções resultantes apresentaram coloração levemente amarelada indicando que a oxidação da matéria orgânica foi completa.

\subsubsection{Procedimento 3: $\mathrm{HNO}_{3} / \mathrm{HCl}$}

Neste procedimento usou-se $0,2 \mathrm{~g}$ de tinta à óleo na cor azul, na forma líquida, adicionou-se $6 \mathrm{~mL}$ de ácido nítrico juntamente com $2 \mathrm{~mL}$ de ácido clorídrico e utilizou-se o procedimento de aquecimento apresentado na Tabela 6.25.

Após a digestão as soluções foram transferidas para frascos volumétricos, seu volume completado a $25 \mathrm{~mL}$, agitadas (não foram filtradas) e os elementos de interesse determinados.

As soluções apresentaram coloração levemente amarelada indicando a oxidação da matéria orgânica que foi comprovada pela determinação, por ICP OES, de $0,3 \%$, de carbono residual, sendo que o teor de carbono total da amostra era de $73 \%$. Portanto, o baixo valor de carbono residual indicou a eficiência do método de digestão em relação à destruição da matéria orgânica.

Os resultados da determinação dos elementos de interesse são apresentados na Tabela 6.26.

As soluções usadas nos testes de recuperação foram feitas a partir das soluções analiticas de referência.

Após cada procedimento de digestão fez-se a limpeza dos frascos e as soluções resultantes foram avaliadas. A quantidade encontrada dos elementos de interesse foi a mesma encontrada na solução branco, garantindo que não houve perda de amostra por aderência nas paredes dos frascos. 
Tabela 6.26. Teores percentuais em \% dos elementos $\mathrm{Al}, \mathrm{Cr}, \mathrm{Mn}, \mathrm{Co}, \mathrm{Ni}, \mathrm{Cu}, \mathrm{As}, \mathrm{Cd}$ e $\mathrm{Pb}$, em tinta azul da marca $\mathrm{A}$ após digestão pela mistura $\mathrm{HNO}_{3}$ e $\mathrm{HCl}$ utilizando forno de microondas de alta pressão - ETHOS.

\begin{tabular}{cccc}
\hline Elementos & $\begin{array}{c}\text { Procedimento 1 } \\
\mathrm{HNO}_{3}\end{array}$ & $\begin{array}{c}\text { Procedimento 2 } \\
\mathrm{HNO}_{3} / \mathrm{H}_{2} \mathrm{O}_{2}\end{array}$ & $\begin{array}{c}\text { Procedimento 3 } \\
\mathrm{HNO}\end{array}$ \\
\hline $\mathrm{Al}$ & $0,081 \pm 0,005$ & $0,077 \pm 0,003$ & $0,072 \pm 0,002$ \\
$\mathrm{Cr}$ & $0,050 \pm 0,003$ & $0,043 \pm 0,001$ & $0,042 \pm 0,001$ \\
$\mathrm{Mn}$ & $0,0043 \pm 0,0004$ & $0,0052 \pm 0,0003$ & $0,0050 \pm 0,0001$ \\
$\mathrm{Co}$ & $0,021 \pm 0,001$ & $0,0201 \pm 0,0004$ & $0,0211 \pm 0,0001$ \\
$\mathrm{Ni}$ & $<0,00001$ & $<0,00001$ & $<0,00001$ \\
$\mathrm{Cu}$ & $0,24 \pm 0,08$ & $0,278 \pm 0,008$ & $0,271 \pm 0,008$ \\
$\mathrm{As}$ & $<0,0001$ & $<0,0001$ & $<0,0001$ \\
$\mathrm{Cd}$ & $<0,00001$ & $<0,00001$ & $<0,00001$ \\
$\mathrm{~Pb}$ & $0,59 \pm 0,03$ & $0,618 \pm 0,009$ & $0,610 \pm 0,023$ \\
\hline
\end{tabular}

Aplicando-se 0 teste $t$ pareado entre os resultados obtidos com os três procedimentos avaliados, não houve diferença significativa em um nível de confiança de $95 \%$ para os elementos avaliados. O mesmo procedimerto foi adotado em relação ao emprego do método de cinzas e utilização de forno de microondas e não houve diferença significativa em um nível de confiança de $95 \%$.

Devido ao fato de não possuirmos amostras certificadas de tinta à base de solvente, realizou-se estudo para comprovar a exatidão do método tanto de preparo da amostra e quanto da determinação dos analitos por ICP OES. O teste de adição e recuperação de analito é uma alternativa comumente utilizada para a avaliação da eficiência do método em matrizes ricas em matéria orgânica, além da avaliação do carbono residual. Neste estudo, as amostras reais foram enriquecidas sinteticamente com quantidades conhecidas dos elementos de interesse e passaram pelo mesmo procedimento de digestão da amostra e determinação dos analitos. Os resultados são comparados com os resultados das amostras que não foram enriquecidas. Os resultados estão apresentados na Tabela 6.27 e foram calculados com base nos valores de concentrações esperados e efetivamente encontrados nas soluções de análise $\left(\mathrm{mg} \mathrm{L}^{-1}\right)$. 
Tabela 6.27. Resultado do teste de recuperação dos elementos $\mathrm{Al}, \mathrm{Cr}, \mathrm{Mn}, \mathrm{Co}, \mathrm{Ni}$, $\mathrm{Cu}, \mathrm{As}, \mathrm{Cd}$ e $\mathrm{Pb}$, da tinta a óleo azul após digestão pela mistura de $\mathrm{HNO}_{3}$ e $\mathrm{HCl}$.

\begin{tabular}{ccccc}
\hline Elemento & $\begin{array}{c}\text { Quantidade } \\
\text { adicionada }\left(\mathrm{mg} \mathrm{L}^{-1}\right)\end{array}$ & $\begin{array}{c}\text { Quantidade } \\
\text { esperada }\left(\mathrm{mg} \mathrm{L} \mathrm{L}^{-1}\right)\end{array}$ & $\begin{array}{c}\text { Cuantidade } \\
\text { encontrada }\left(\mathrm{mg} \mathrm{L}^{-1}\right)\end{array}$ & $\begin{array}{c}\text { Recuperaço } \\
\%\end{array}$ \\
\hline $\mathrm{Al}$ & 5,0 & $11,0 \pm 0,2$ & $12,5 \pm 0,3$ & 113 \\
$\mathrm{Cr}$ & 5,0 & $8,4 \pm 0,1$ & $8,2 \pm 0,2$ & 97 \\
$\mathrm{Mn}$ & 5,0 & $5,37 \pm 0,01$ & $4,89 \pm 0,08$ & 91 \\
$\mathrm{Co}$ & 12,0 & $13,7 \pm 0,3$ & $13,5 \pm 0,2$ & 98 \\
$\mathrm{Ni}$ & 5,0 & $5,0 \pm 0,1$ & $4,67 \pm 0,08$ & 93 \\
$\mathrm{Cu}$ & 10,0 & $32,2 \pm 0,1$ & $31,2 \pm 0,7$ & 97 \\
$\mathrm{As}$ & 5,0 & $5,0 \pm 0,6$ & $3,32 \pm 0,06$ & 66 \\
$\mathrm{Cd}$ & 5,0 & 5,00 & $4,83 \pm 0,09$ & 97 \\
$\mathrm{~Pb}$ & 50 & 100 & $101 \pm 2$ & 101 \\
\hline
\end{tabular}

Com exceção do As, que recuperou somente $66 \%$ da quantidade adicionada, os demais elementos apresentaram recuperação entre 91 e 113\%. Estes valores indicam que aparentemente não ocorreram efeitos de matriz nas determinações por ICP OES. A perda de As pode ter ocorrido juntamente com pequena quantidade de gás que foi liberado na abertura dos frascos. Em alguns frascos observou-se perda de gás, mesmo após a espera de tempo suficiente para o resfriamento do sistema.

Os testes de adição e recuperação dos analitos foram feitos em soluções em branco. As quantidades adicionadas e recuperadas estão apresentadas na Tabela 6.28. Todos os valores dos elementos avaliados se encontram dentro da faixa de 80 a 108\%. Observa-se que a recuperação de As é inferior aos demais elementos o que sugere que realmente pode ter ocorrido perda por volatilização ao abrir o frasco. Porém, para os demais elementos verifica-se que não houve perda por aderência no frasco ou por volatilização.

Embora as soluções resultantes apresentarem-se claras, com baixo carbono residual e os resultados dos testes de recuperação fossem satisfatórios, percebeuse em alguns casos que as paredes dos frascos estavam levemente oleosas. Este fato mostra que a quantidade de matéria orgânica que restou sem digerir é maior do 
que a encontrada pela determinação com o ICP OES. Isso, entretanto, não interferiu na determinação dos analitos, pois após transferência quantitativa das soluções fezse o procedimento de limpeza do frasco usando a mistura ácida e os procedimentos de aquecimento citados. Fez-se a determinação dos analitos de interesse na solução de limpeza e, com exceção do alumínio, os demais elementos não apresentaram sinal analítico, eliminando-se a possibilidade de perda destes elementos por aderência ou reação paralela com a fase orgânica.

Tabela 6.28. Resultado do teste de recuperação dos elementos $\mathrm{Al}, \mathrm{Cr}, \mathrm{Mn}, \mathrm{Co}, \mathrm{Ni}$, $\mathrm{Cu}, \mathrm{As}, \mathrm{Cd}$ e $\mathrm{Pb}$, na solução branco composta por $\mathrm{HNO}_{3}$ e $\mathrm{HCl}$.

\begin{tabular}{cccc}
\hline Elemento & $\begin{array}{c}\text { Quantidade adicionada } \\
\left(\mathrm{mg} \mathrm{L}^{-1}\right)\end{array}$ & $\begin{array}{c}\text { Quantidade } \\
\text { enconirada (mg L - })\end{array}$ & $\begin{array}{c}\text { Recuperaçá } \\
\%\end{array}$ \\
\hline $\mathrm{Al}$ & 5,00 & 4,65 & 93 \\
$\mathrm{Cr}$ & 5,00 & 4,56 & 91 \\
$\mathrm{Mn}$ & 5,00 & 4,62 & 92 \\
$\mathrm{Co}$ & 12,00 & 11,74 & 98 \\
$\mathrm{Ni}$ & 5,00 & 4,66 & 93 \\
$\mathrm{Cu}$ & 5,00 & 5,4 & 108 \\
$\mathrm{As}$ & 5,00 & 4,01 & 80 \\
$\mathrm{Cd}$ & 5,00 & 4,90 & 98 \\
$\mathrm{~Pb}$ & 50,0 & 48,4 & 97 \\
\hline
\end{tabular}

\subsubsection{Procedimento 4: $\mathrm{HNO}_{3} / \mathrm{HCl}$ - Empregando filmes secos de tinta}

Neste procedimento usou-se $0,2 \mathrm{~g}$ de tinta à óleo na cor azul, na forma de filme seco, adicionou-se $6 \mathrm{~mL}$ de ácido nítrico e $2 \mathrm{~mL}$ de ácido clorídrico conforme o procedimento apresentado na Tabela 6.29. 
Tabela 6.29. Procedimento empregado na digestão de tinta à óleo de cor azul

\begin{tabular}{llllll}
\hline Etapas & Reagentes & Volume $(\mathrm{mL})$ & $\begin{array}{l}\text { Temperatura } \\
\text { (C) }\end{array}$ & $\begin{array}{l}\text { Rampa } \\
\text { aquecimento (min) }\end{array}$ & $\begin{array}{c}\text { de Tin) } \\
\text { (min }\end{array}$ \\
\hline 1 & $\mathrm{HNO}_{3}$ & 6 & 80 & 5 & 2 \\
& $\mathrm{HCl}$ & 2 & & & 2 \\
2 & & & 120 & 3 & 10 \\
3 & & & 200 & 10 & 30 \\
4 & & & 0 & & 2 \\
\hline
\end{tabular}

Após a digestão as soluções foram transferidas para frascos volumétricos, seu volume completado a $25 \mathrm{~mL}$, agitadas, filtradas e os elementos de interesse determinados.

As soluções apresentaram coloração levemente amarelada indicando a oxidação da matéria orgânica. O problema de oleosidade nas paredes dos frascos foi resolvido com a evaporação dos solventes orgânicos (COV - Compostos Voláteis Orgânicos) durante a secagem dos filmes.

Este procedimento, embora tenha a mesma mistura ácida e programa de aquecimento do procedimento 3 , foi novamente apresentado para facilitar a compreensão do leitor em relação as análises posteriores em que este método será constantemente citado, uma vez que em todas as análise que seguem, a tinta foi usada na forma seca. Os resultados da análise estão apresentados na Tabela 6.30. 
Tabela 6.30. Teores percentuais dos elementos $\mathrm{Al}, \mathrm{Cr}, \mathrm{Mn}, \mathrm{Co}, \mathrm{Ni}, \mathrm{Cu}, \mathrm{As}, \mathrm{Cd}$ e $\mathrm{Pb}$, em tinta azul da marca $\mathrm{A}$ após digestão pela mistura $\mathrm{HNO}_{3}$ e $\mathrm{HCl}$. Utilização de forno de microondas de alta pressão-ETHOS.

\begin{tabular}{cccc}
\hline Elementos & $\begin{array}{c}\text { Concentraçá } \\
\%\end{array}$ & Elementos & $\begin{array}{c}\text { Concentraçäo } \\
\%\end{array}$ \\
\hline $\mathrm{Al}$ & $0,162 \pm 0,006$ & $\mathrm{Cu}$ & $0,49 \pm 0,06$ \\
$\mathrm{Cr}$ & $0,074 \pm 0,005$ & $\mathrm{As}$ & $<0,0001$ \\
$\mathrm{Mn}$ & $0,007 \pm 0,000$ & $\mathrm{Cd}$ & $<0,00001$ \\
$\mathrm{Co}$ & $0,033 \pm 0,001$ & $\mathrm{~Pb}$ & $1,16 \pm 0,05$ \\
$\mathrm{Ni}$ & $<0,00001$ & & \\
\hline
\end{tabular}

$\mathrm{Na}$ obtenção dos filmes secos de tinta, a perda de massa dos COVs da tinta utilizada foi de $48,3 \% \pm 0,3, n=5$. Portanto, ao compararmos os valores obtidos utilizando a tinta líquida com a tinta seca, verifica-se que não apresentam diferença significativa para a maioria dos elementos, permitindo a utilização de ambos métodos.

No espectro do resíduo obtido após a digestão da tinta azul usando MEV-EDS (Figura 6.15), observa-se que houve digestão total dos elementos de interesse garantindo a eficiência na decomposição da amostra. A única exceção é um sinal muito baixo mostrando uma pequena quantidade de $\mathrm{Al}$, que pode ser devido à presença de alumina na tinta ou à sua formação durante o processo de oxidação da amostra.

Uma vez estabelecidos os métodos, optou-se pela mistura $\mathrm{HNO}_{3} / \mathrm{HCl}$, (procedimento 4) aliando-se o poder oxidante do ácido rítrico com o complexante do ácido clorídrico, para a avaliação das outras cores de tinta, cujos resultados estão apresentados na Tabela 6.31. 


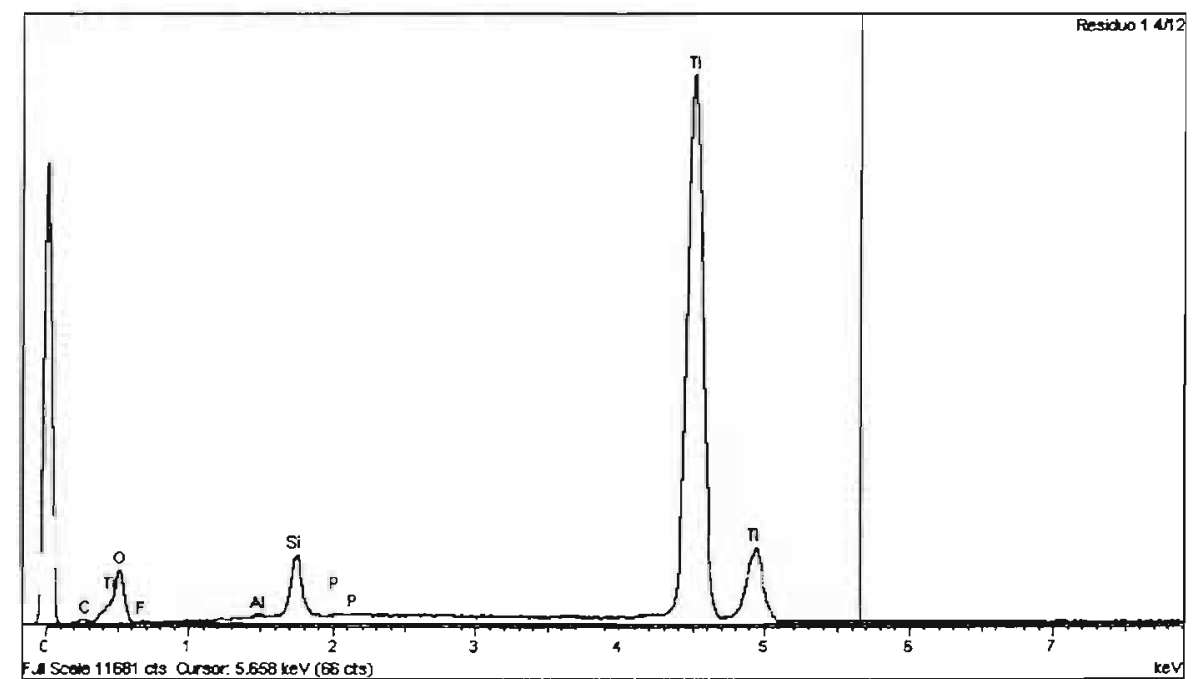

Figura 6.15. Espectro do resíduo da tinta esmalte azul, obtido por MEV-EDS. 


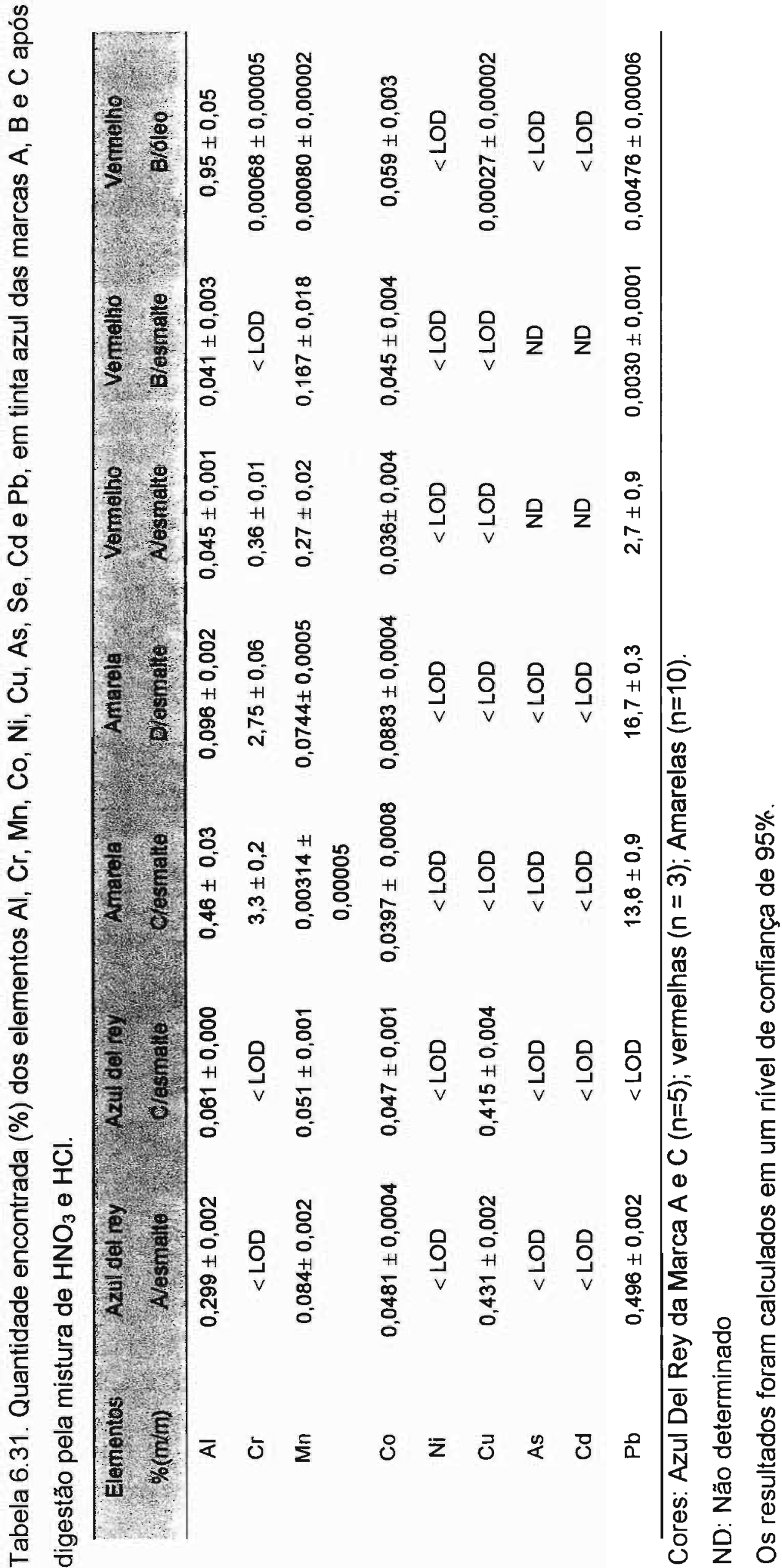


Novos testes de adição e recuperação de analito foram realizados nas amostras de tinta amarela, por estas apresentarem valores extremamente altos de chumbo e também na tinta vermelha a óleo, por apresentar valores baixos. Os resultados destes testes estão apresentados nas Tabelas $6.32,6.33$ e 6.34 .

Tabela 6.32. Valores de concentração e recuperação dos elementos adicionados e recuperados da tinta esmalte amarela, marca $C$ enriquecida.

\begin{tabular}{|c|c|c|c|c|}
\hline \multirow[t]{3}{*}{ Elemento } & Quantidade & Quantidade & Quantidade & Recuperação \\
\hline & adicionada (mg Lt) & esperada ( $\mathrm{mg} \mathrm{L}^{-1}$ ) & encontrada & (\%) \\
\hline & & & & \\
\hline Al & 15 & 33,5 & $35,9 \pm 0,9$ & 107 \\
\hline $\mathrm{Cr}$ & 100 & 234 & $246 \pm 6$ & 105 \\
\hline $\mathrm{Mn}$ & 0,5 & 0,627 & $0,6205 \pm 0,0002$ & 99 \\
\hline Co & 1,5 & 3,11 & $2,31 \pm 0,03$ & 74 \\
\hline $\mathrm{Ni}$ & 0,5 & 0,50 & $0,395 \pm 0,003$ & 79 \\
\hline $\mathrm{Cu}$ & 0,5 & 0,500 & $0,556 \pm 0,004$ & 111 \\
\hline As & 0,5 & 0,5 & $0,425 \pm 0,004$ & 85 \\
\hline $\mathrm{Cd}$ & 0,5 & 0,500 & $0,474 \pm 0,006$ & 95 \\
\hline $\mathrm{Pb}$ & 100 & 651 & $681 \pm 15$ & 105 \\
\hline
\end{tabular}

Tabela 6.33. Valores de concentração e recuperação dos elementos adicionados e recuperados da tinta esmalte amarela marca $D$ enriquecida.

\begin{tabular}{ccccc}
\hline Elemento & $\begin{array}{c}\text { Quantidade } \\
\text { acicionada }\left(\mathrm{mg}^{-1} \text { ) }\right.\end{array}$ & $\begin{array}{c}\text { Quantidade } \\
\text { esperada }\left(\text { nq L L }^{3}\right)\end{array}$ & $\begin{array}{c}\text { Quantidade } \\
\text { encontrada } \\
\text { (mg L } \text { ) }\end{array}$ & $\begin{array}{c}\text { Recuperacáo } \\
(\%)\end{array}$ \\
\hline $\mathrm{Al}$ & 4,0 & 7,84 & $8,5 \pm 0,1$ & 117 \\
$\mathrm{Cr}$ & 100,0 & 210 & $219 \pm 2$ & 110 \\
$\mathrm{Mn}$ & 3,0 & 5,975 & $6,195 \pm 0,1$ & 103 \\
$\mathrm{Co}$ & 3,0 & 6,53 & $6,8 \pm 0,1$ & 104 \\
$\mathrm{Ni}$ & 0,5 & 0,5 & $0,525 \pm 0,005$ & 105 \\
$\mathrm{Cu}$ & 0,5 & 0,5 & $0,5767 \pm 0,0006$ & 115 \\
$\mathrm{As}$ & 0,5 & 0,5 & $0,515 \pm 0,002$ & 103 \\
$\mathrm{Cd}$ & 0,5 & 0,5 & $0,511 \pm 0,002$ & 102 \\
$\mathrm{~Pb}$ & 100 & 766 & $760 \pm 14$ & 99 \\
\hline
\end{tabular}

$n=4$ 
Tabela 6.34. Valores de concentração e recuperação dos elementos adicionados e recuperados da tinta óleo vermelha marca $B$ enriquecida.

\begin{tabular}{|c|c|c|c|c|}
\hline Elemento & $\begin{array}{c}\text { Quantidade } \\
\text { adicionada ( } \mathrm{mg} L^{-} \text {) }\end{array}$ & $\begin{array}{c}\text { Quantidade } \\
\text { esperada (mg L') }\end{array}$ & $\begin{array}{l}\text { Quantidade } \\
\text { encontrada (mg L-1) }\end{array}$ & $\begin{array}{c}\text { Recuperacáo } \\
(\%)\end{array}$ \\
\hline $\mathrm{Al}$ & 50 & 113 & $108 \pm 1$ & 95 \\
\hline $\mathrm{Cr}$ & 0,5 & 0,546 & $0,534 \pm 0,002$ & 98 \\
\hline $\mathrm{Mn}$ & 0,5 & 0,554 & $0,527 \pm 0,008$ & 95 \\
\hline Co & 1,5 & 5,5 & $5,2 \pm 0,2$ & 95 \\
\hline $\mathrm{Ni}$ & 0,5 & 0,5 & $0,468 \pm 0,02$ & 94 \\
\hline $\mathrm{Cu}$ & 0,5 & 0,52 & $0,54 \pm 0,01$ & 105 \\
\hline As & 0,5 & 0,5 & $0,487 \pm 0,005$ & 97 \\
\hline $\mathrm{Cd}$ & 0,5 & 0,5 & $0,476 \pm 0,01$ & 95 \\
\hline $\mathrm{Pb}$ & 0,5 & 0,82 & $0,78 \pm 0,01$ & 95 \\
\hline
\end{tabular}

\subsection{Determinação de mercúrio}

Mercúrio pode estar presente nas tintas como agente bactericida e fungicida.

A técnica de análise mais freqüentemente utilizada para a determinação de $\mathrm{Hg}$ é a Espectrometria de Absorção Atômica por geração de vapor frio. Neste caso é necessário o preparo da amostra, além da rotina analítica exigida pela técnica de determinação do analito. Esse procedimento geralmente demanda longo tempo de análise, elevado consumo de reagentes, geração de resíduos e risco de contaminação. Quando se trata de métodos de tratamento de amostra e descarte, é importante ressaltar 0 fato de que a minimização, o reuso e a reciclagem de compostos de mercúrio estão sendo cada vez mais enfatizados, seja por razões legais, econômicas ou ecológicas [MIRACONI et al.,2000]. A utilização do analisador direto de mercúrio possibilitou análise rápida, em 5 min após a introdução da amostra e menor geração de resíduos. Os resultados obtidos estão apresentados nas Tabelas 6.35 e 6.36 . 
Tabela 6.35. Concentração de mercúrio em tintas à base de água, média e desvio padrão $(n=3)$.

\begin{tabular}{cc}
\hline Tinta & Concentraça $\left(\mu \mathrm{kg}^{-}\right)$ \\
\hline Branco neve (C) & $63,5 \pm 0,8$ \\
Marfim látex (B) & $43,0 \pm 4,5$ \\
Azul profundo (C) & $188 \pm 9$ \\
Vermelho cardinal (A) & $98 \pm 14$ \\
Vermelho Japão (A) & $63 \pm 4$ \\
\hline
\end{tabular}

Tabela 6.36. Concentração de mercúrio em tintas à base de solvente, média e desvio padrão $(n=3)$.

\begin{tabular}{cc}
\hline Tinta & Concentração $\left.(\mu \mathrm{g} \mathrm{kg})^{-7}\right)$ \\
\hline Oleo - Marfin (B) & $43 \pm 4$ \\
Esmalte - Azul Del Rey (A) & $33,2 \pm 0,8$ \\
Esmalte - Azul Del Rey (B) & $42,5 \pm 0,6$ \\
Esmalte - Amarelo ouro (C) & $218 \pm 1$ \\
Esmalte - amarelo (D) & $13,0 \pm 0,6$ \\
Esmalte - vermelho (C) & $144 \pm 7$ \\
Oleo - vermelho (C) & $161 \pm 5$ \\
\hline
\end{tabular}

Embora na literatura encontra-se que $\circ \mathrm{Hg}$ pode estar presente nas tintas como agente bactericida e fungicida, a sua utilização em tintas látex para pintura de interiores foi banida em 1990 e uso exterior em 1991 pelo EPA norte americano. Conseqüentemente sua utilização foi reduzida consideravelmente. Porém alguns trabalhos na literatura ainda mostram que tintas são fontes de contaminação de mercúrio. Geralmente este tipo de contaminação se deve às tintas fabricadas antes da proibição [EPA, http://www.epa.gov, 2005; CHERRY et al., 2002].

No Brasil não existe legislação própria restringindo a utilização de mercúrio em tintas, porém a Norma NBR 10004 (1987), que trata da classificação de residuos sólidos, estabelece que se o mercúrio ou seus compostos excederem a $100 \mathrm{mg} \mathrm{kg}^{-1}$ do resíduo, este deve ser disposto em instalações adequadas. Os resultados mostram que nas tintas avaliadas a quantidade encontrada é cerca de 1000 vezes menor do que esse limite. 


\subsection{Estudo da migração de elementos potencialmente tóxicos em tintas}

\subsubsection{Intemperismo acelerado}

Neste estudo foi avaliada a alteração morfológica do filme seco de tinta após sua exposição a raios ultravioleta em câmara de intemperismo acelerado do tipo WO ("Weather-Ometer") e conseqüente liberação dos elementos de interesse ao ambiente.

Após o processo de exposição dos filmes de acordo com o procedimento descrito no item 4.6.1.2. (Ensaio de degradação), foram verificadas alterações na estrutura do filme que estão associadas à redução do brilho, cor e morfologia [BIGGS et al., 2001]. A perda do brilho e o esmaecimento da cor podem ser observados na Figura 6.16, que mostra fotografias de placas pintadas que foram submetidas ao intemperismo acelerado. A região "a" das fotos apresenta uma parte que foi protegida da exposição durante os testes de intemperismo e, neste caso, observou-se o brilho e cor original da tinta, enquanto a região (b) apresenta a parte que foi exposta aos raios UV e, neste caso, observou-se que a tinta apresentou-se sem brilho e cor esmaecida. Isso se deve à presença de partículas finas semelhantes a um pó esbranquiçado sobre a superfície pintada, conseqüência da degradação da resina pelos raios ultravioleta causando o esmaecimento da cor (calcinação).
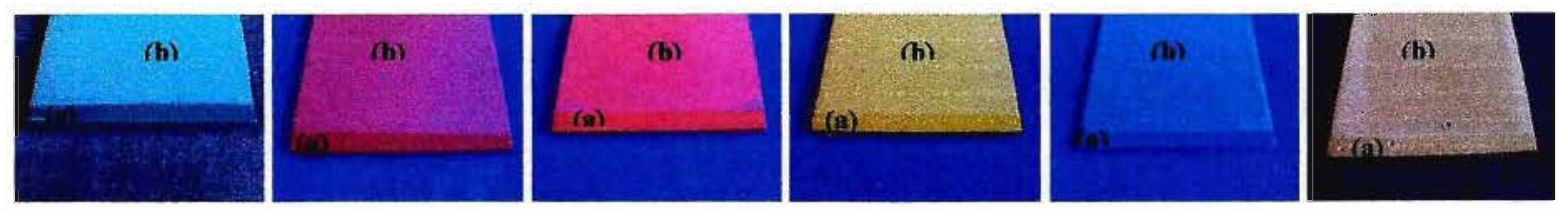

Figura 6.16. Fotografias de parte de placas de Polietileno cobertas com tinta, comparando a regiöes protegidas durante os testes de intemperismo (a) com as regiões expostas (b).

Os filmes de tinta esmalte de cor amarela e tinta à base de água de cor vermelha foram analisadas por MEV e ICP OES antes e após, ao teste de intemperismo, e os resultados são discutidos a seguir. 


\subsubsection{Análise por Microscopia Eletrónica de Varredura}

A utilização desta técrica forneceu importantes parâmetros, como homogeneidade da amostra, uniformidade do filme e análise semiquantitativa dos analitos de interesse.

Na Figura 6.17 é apresentada uma micrografia do filme da tinta esmalte amarela que não foi submetida ao envelhecimento. Nesta micrografia pode ser observada a homogeneidade da amostra e, também a uniformidade na aplicação do filme. As Figuras 6.18 (a) e (b) mostram as micrografias da tinta que foi submetida ao intemperismo acelerado conforme procedimento apresentado no item 5.5.1.2.

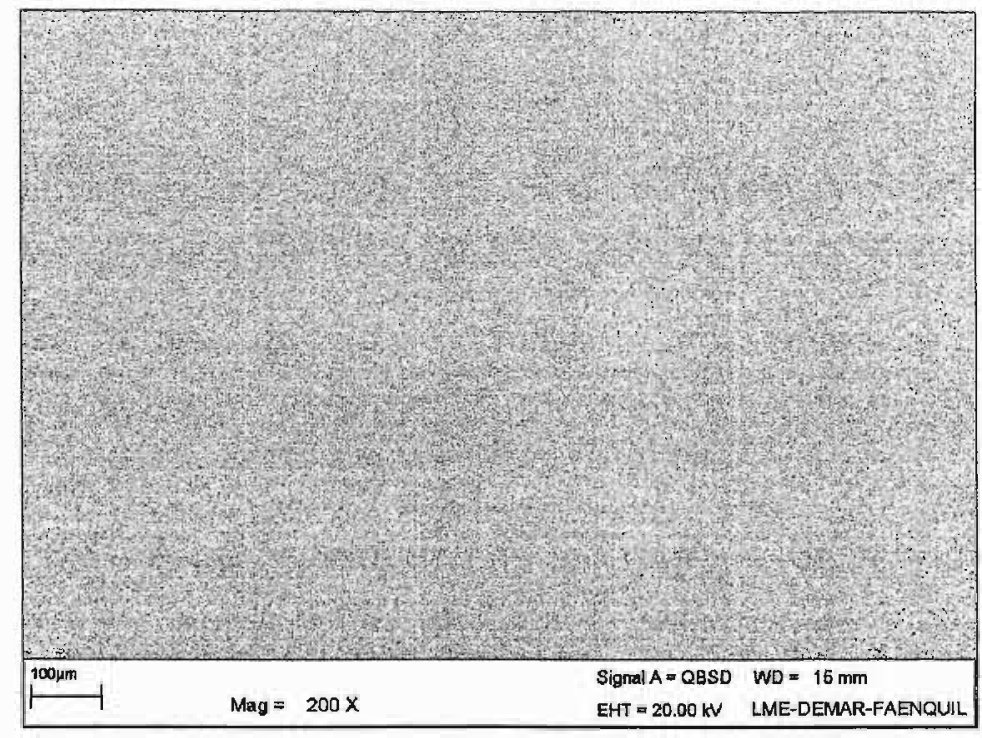

Figura 6.17. Micrografia do filme da tinta esmalte amarela antes da exposição aos raios ultravioleta $(200 \mathrm{x})$.

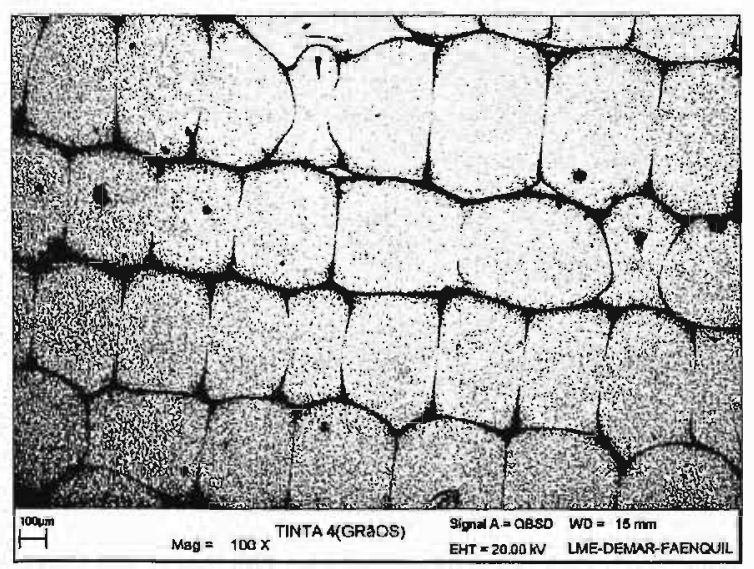

(a)

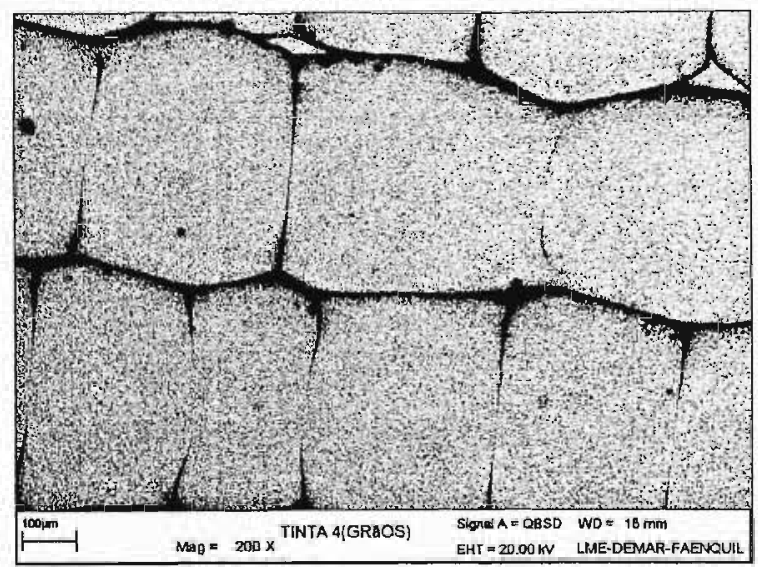

(b)

Figura 6.18. Micrografia aumentada: (a) 100x e (b) 200x. 
Na micrografia apresentada na Figura 6.18, observa-se alteração no filme de tinta esmalte. Ocorreu a formação de pequenas "células" de degradação. Segundo Maia e Paoli (2000) a degradação ocorre preferencialmente na superfície do revestimento, sendo resultado das reações de foto-degradação, intensificadas pelo elevado nível de radiação UV, umidade e presença de oxigênio. A formação das "células" deixa vazios no filme que podem levar à entrada de agentes agressivos. Dependendo da resina, estes filmes podem sofrer trincas.

Além da avaliação visual fez-se também análise semiquantitativa das tintas antes e após o envelhecimento acelerado. Estes resultados estão apresentados na Tabela 6.37.

Tabela 6.37. Valores médios do teor dos elementos estudados por Microscopia Eletrônica de Varredura e EDS em tinta esmalte de cor amarela da marca D antes e após a degradaçăo.

\begin{tabular}{ccc}
\hline Elemento & $\begin{array}{c}\text { Tinta sem envehecimento } \\
(\% \mathrm{~m} / \mathrm{m})\end{array}$ & $\begin{array}{c}\text { Tinta apos envelhecimento em } \\
\text { camara (\% m/m) }\end{array}$ \\
\hline $\mathrm{C}$ & $57,7 \pm 3,1$ & $\langle 1,5 \pm 5,5$ \\
$\mathrm{O}$ & $19,8 \pm 1,7$ & $21,2 \pm 3,7$ \\
$\mathrm{Na}$ & $0,03 \pm 0,01$ & $0,05 \pm 0,01$ \\
$\mathrm{Al}$ & $0,13 \pm 0,01$ & $0,16 \pm 0,05$ \\
$\mathrm{Si}$ & $1,5 \pm 0,5$ & $2,2 \pm 1,2$ \\
$\mathrm{Cr}$ & $3,1 \pm 0,2$ & $4,9 \pm 0,3$ \\
$\mathrm{Mn}$ & $0,09 \pm 0,03$ & $0,10 \pm 0,01$ \\
$\mathrm{Sb}$ & $0,96 \pm 0,06$ & $1,34 \pm 0,10$ \\
$\mathrm{Ba}$ & $1,2 \pm 0,2$ & $1,34 \pm 0,09$ \\
$\mathrm{~Pb}$ & $16,0 \pm 0,8$ & $24,3 \pm 0,4$ \\
\hline
\end{tabular}

$n=3$

Os resultados da microanálise obtidos por espectroscopia de energia dispersiva (EDS), realizadas nas amostras antes e após envelhecimento em câmara tipo "Weather-Ometer", indicaram que ocorreu perda de carbono. O resultado é relativo, ou seja, neste método à soma de todos os elementos determinados é atribuído valor de $100 \%$ da massa e a quantidade de cada elemento determinado é expressa como uma porcentagem desta massa total. Deste modo, se houver perda 
de carbono a quantidade relativa dos outros elementos aumenta de modo a manter a somatória em $100 \%$.

Na Figura 6.19 (a) e (b) estão apresentadas as micrografias do filme de tinta à base de água de cor vermelha. A micrografia (a) mostra o filme seco de tinta antes da exposição aos raios ultravioleta e a (b) mostra o filme seco após a exposição aos raios ultravioleta. A região mais clara representa os elementos de peso atômico maiores. Portanto observa-se para esta tinta diferença significativa entre os dois filmes, o que significa que ocorre a degradação do polímero e perda de alguns elementos ao ambiente.

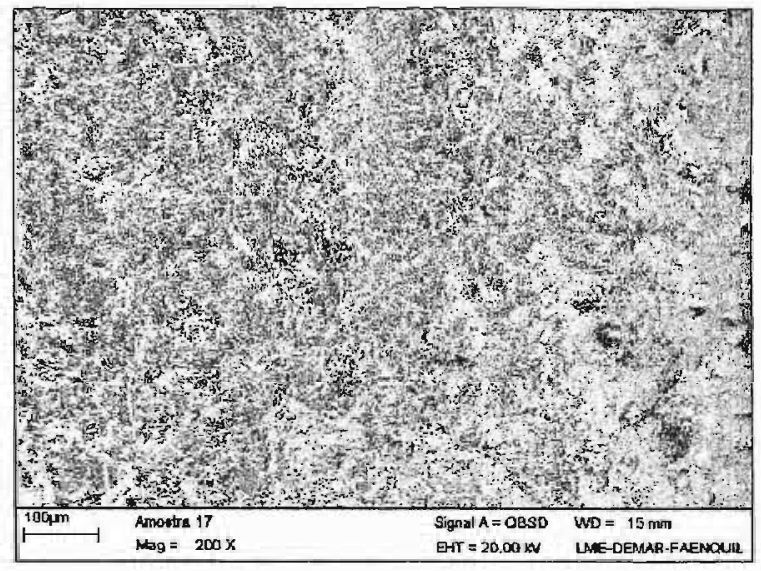

(a)

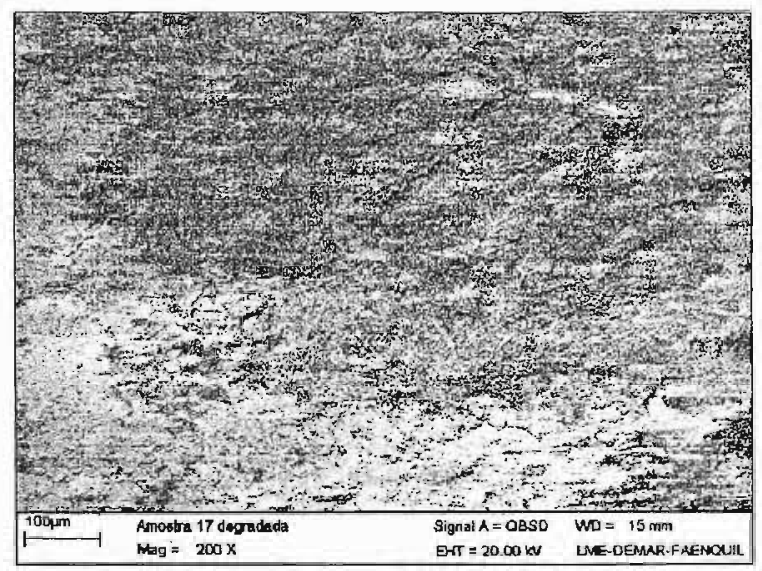

(b)

Figura 6.19. Micrografias de um filme de tinta à base de água: (a) antes do envelhecimento e (b) após envelhecimento (200x).

\subsubsection{Análise do filme envelhecido por Espectrometria de Emissão Óptica (ICP OES)}

Fez-se a análise da tinta esmalte de cor amarela por Espectrometria de Emissão Ótica dos filmes antes e após a exposição aos raios ultravioleta. Para este estudo os filmes foram destacados com auxilio de espátula de plástico e aproximadamente $200 \mathrm{mg}$ de amostra das tintas foram dissolvidas em forno de microondas de acordo com o procedimento 4 descrito na página 67 . Os resultados estão apresentados na Tabela 6.38. 
Tabela 6.38. Teores médios e desvios padrão radiação e determinação por ICP OES de tinta esmalte da marca $C$ antes e após envelhecimento.

\begin{tabular}{ccc}
\hline Elementos & Tinta antes do envelhecimento & Tinta após o ervelnecinento \\
$(\%)$ & $(\%)$ \\
\hline $\mathrm{Al}$ & $0,105 \pm 0,001$ & $0,107 \pm 0,005$ \\
$\mathrm{Cr}$ & $2,42 \pm 0,06$ & $2,48 \pm 0,12$ \\
$\mathrm{Mn}$ & $0,077 \pm 0,001$ & $0,076 \pm 0,004$ \\
$\mathrm{Co}$ & $0,081 \pm 0,001$ & $0,082 \pm 0,004$ \\
$\mathrm{Ni}$ & $<0,00001$ & $<0,00001$ \\
$\mathrm{Cu}$ & $\mathrm{ND}$ & $\mathrm{ND}$ \\
$\mathrm{As}$ & $<0,0001$ & $<0,0001$ \\
$\mathrm{Cd}$ & $<0,00001$ & $<0,00001$ \\
$\mathrm{~Pb}$ & $12,8 \pm 0,2$ & $13,2 \pm 0,6$ \\
\hline antes do envelhecimento); $\mathrm{n}=3$ (após o envelhecimento) \\
Não determinado & &
\end{tabular}

A análise destes filmes por ICP OES após digestão por mistura ácida em forno de microondas mostra que não há diferença significativa entre os valores encontrados nos filmes antes e após o envelhecimento acelerado. Isso pode ser devido à pequena fração degradada em relação à não degradada, uma vez que é feita a digestão total da amostra.

Em função destes resultados e da complexidade na preparação das amostras para as determinações por ICP OES, além da dificuldade de acesso a uma câmara de intempéries, propõe-se um método analítico para a avaliação da mobilidade dos metais nas tintas baseada na lixiviação de amostras de tinta em ambiente controlado. 


\subsubsection{Exposição à ação de soluções extratoras - Testes de lixiviação}

Os testes de lixiviação foram realizados por meio de um procedimento elaborado a partir de uma adaptação das normas NBR 10006 (1987) e 10005 (1987), que utilizam água e solução de pH 5 (ácido acético), respectivamente, como extratores. Nos testes de lixiviação não foram usadas as amostras fragmentadas ou massa úmida como sugere a norma. Em vez disso optou-se por aplicar um filme da tinta em uma superfície adequada na qual ocorreu o processo de lixiviação, de modo a obter-se uma situação mais próxima da utilização real do produto. Além dos extratores citados nas normas foram feitos testes também com soluções simulando $\mathrm{pH}$ de chuva ácida e solução salina de modo a simular as condições encontradas em grandes centros urbanos e cidades litorâneas, respectivamente.

Nestes testes, os corpos de provas foram preparados conforme descrito no 5.5.2.1. Os filmes secos de tinta látex vermelha da marca $C$ e esmalte amarela da marca $C$ ficaram em contato direto com soluções extratoras com o objetivo de verificar a possivel migração dos elementos de interesse para estas soluções, de modo a se obter dados para avaliação da contaminação do ambiente.

Os testes foram feitos em duplicata e a determinação dos analitos foi feita por ICP OES (CIROS). Os testes foram divididos em dois conjuntos como seguem:

\section{Conjunto 1:}

As soluções foram colocadas nos frascos e avaliadas após o período de 7 dias. Após a análise estas soluções foram substituídas por novas (usando os mesmos frascos) e deixadas por mais 7 dias em repouso, agitadas e os analitos determinados. Este procedimento foi refeito a cada 7 dias até completar 28 dias. Os resultados dos elementos cuja extração foi acima do LOD do equipamento estão apresentados nas Tabelas 6.39 à 6.46 .

\section{Conjunto 2:}

Paralelamente. outros conjuntos de frascos contendo as soluções extratoras, em duplicatas, foram agitados por 5 min e deixados em repouso por 14 (quatorze), 21 (vinte e um) e 28 (vinte e oito) dias. 
As médias dos resultados referentes aos períodos de 1, 2, 3 e 4 semanas, estão apresentadas nas Tabelas 6.47 à 6.56. Para melhor visualização estes dados também estão apresentados na forma de gráfico nas Figuras 6.21 à 6.25 (tinta esmalte) e 6.31 à 6.33 (tinta látex).

Os elementos $\mathrm{Ni}, \mathrm{Cu}, \mathrm{As}, \mathrm{Cd}$ tiveram seus valores abaixo do limite de detecção em ambas as tintas para os quatros extratores. Este fato já era esperado uma vez que $\mathrm{Ni}$, As e $\mathrm{Cd}$ não foram detectados nas amostras.

Tabela 6.39. Quantidade encontrada em $\mathrm{mg} \mathrm{L}^{-1}$ de aluminio na tinta esmalte após lixiviação com água desionizada, solução de $\mathrm{NaCl} 5 \%(\mathrm{~m} / \mathrm{v})$, solução sulfonítrica de $\mathrm{pH}=4$ e $\mathrm{HAc}$ de $\mathrm{pH}=5$, após troca de extrator a cada 7 dias.

\begin{tabular}{ccccc}
\hline & \multicolumn{3}{c}{ Tempo de exposiçáa (días) } & 7 \\
Extratores & 7 & 7 & 7 & 0,004 \\
\hline $\mathrm{H}_{2} \mathrm{O}$ & 0,020 & 0,009 & 0,081 & 0,010 \\
$\mathrm{NaCl}$ & 0,075 & 0,022 & 0,094 & 0,008 \\
Chuva ácida & 0,377 & 0,033 & 0,312 & 0,005 \\
$\mathrm{HAc}$ & 0,026 & 0,011 & 0,048 & \\
\hline
\end{tabular}

Tabela 6.40. Quantidade encontrada em mg $\mathrm{L}^{-1}$ de crômio na tinta esmalte após lixiviação com água desionizada, solução de $\mathrm{NaCl} 5 \%(\mathrm{~m} / \mathrm{v})$, solução sulfonítrica de $\mathrm{pH}=4$ e HAc de $\mathrm{pH}=5$, após troca de extrator a cada 7 dias.

\begin{tabular}{ccccc}
\hline & & Tempo de exposifáo (dias) & \\
Extratores & 7 & 7 & 7 & $\mathbf{T}$ \\
\hline $\mathrm{H}_{2} \mathrm{O}$ & 0,116 & 0,080 & 0,134 & 0,061 \\
$\mathrm{NaCl}$ & 0,988 & 0,121 & 1,006 & 0,018 \\
Chuva ácida & 0,786 & 0,713 & 0,802 & 0,325 \\
$\mathrm{HAC}$ & 0,134 & 0,087 & 0,140 & 0,065 \\
\hline
\end{tabular}


Tabela 6.41. Quantidade encontrada em $\mathrm{mg} \mathrm{L}^{-1}$ de manganês na tinta esmalte após lixiviação com água desionizada, solução de $\mathrm{NaCl} 5 \%(\mathrm{~m} / \mathrm{v})$, solução sulfonitrica de $\mathrm{pH}=4$ e HAc de $\mathrm{pH}=5$, após troca de extrator a cada 7 dias.

\begin{tabular}{ccccc}
\hline & \multicolumn{4}{c}{ Tempo de exposiçáo (dias) } \\
Extratores & $\mathbf{7}$ & $\mathbf{7}$ & $\mathbf{7}$ & $\mathbf{7}$ \\
\hline $\mathrm{H}_{2} \mathrm{O}$ & 0,004 & 0,002 & 0,007 & 0,001 \\
$\mathrm{NaCl}$ & 0,003 & 0,003 & 0,005 & 0,001 \\
Chuva ácida & 0,009 & 0,003 & 0,010 & 0,001 \\
$\mathrm{HAC}$ & 0,005 & 0,002 & 0,008 & 0,001 \\
\hline
\end{tabular}

Tabela 6.42. Quantidade encontrada em $\mathrm{mg} \mathrm{L}^{-1}$ de cobalto na tinta esmalte após lixiviação com água desionizada, solução de $\mathrm{NaCl} 5 \%(\mathrm{~m} / \mathrm{v})$, solução sulfonítrica de $\mathrm{pH}=4$ e $\mathrm{HAc}$ de $\mathrm{pH}=5$, após troca de extrator a cada 7 dias.

\begin{tabular}{ccccc}
\hline & & Tempo de exposiçán (dias) & \\
Extratores & 7 & 7 & 7 & 7 \\
\hline $\mathrm{H}_{2} \mathrm{O}$ & 0,080 & 0,028 & 0,121 & 0,014 \\
$\mathrm{NaCl}$ & 0,047 & 0,018 & 0,067 & 0,008 \\
Chuva ácida & 0,136 & 0,039 & 0,146 & 0,010 \\
$\mathrm{HAc}$ & 0,092 & 0,029 & 0,126 & 0,015 \\
\hline
\end{tabular}

Tabela 6.43. Quantidade encontrada em $\mathrm{mg} \mathrm{L}^{-1}$ de chumbo na tinta esmalte após lixiviação com água desionizada, solução de $\mathrm{NaCl} 5 \%(\mathrm{~m} / \mathrm{v})$, solução sulfonítrica de $\mathrm{pH}=4$ e $\mathrm{HAc}$ de $\mathrm{pH}=5$, após troca de extrator a cada 7 dias.

\begin{tabular}{ccccc}
\hline & \multicolumn{4}{c}{ Tempo de exposicäo (dias) } \\
Extratores & 7 & 7 & 7 & 7 \\
\hline $\mathrm{H}_{2} \mathrm{O}$ & 0,765 & 0,410 & 1,156 & 0,257 \\
$\mathrm{NaCl}$ & 4,678 & 0,593 & 4,721 & 0,141 \\
Chuva ácida & 4,150 & 3,315 & 4,012 & 1,413 \\
$\mathrm{HAC}$ & 0,984 & 0,459 & 1,258 & 0,234 \\
\hline
\end{tabular}


Tabela 6.44. Quantidade encontrada em $\mathrm{mg} \mathrm{L}^{-1}$ de alumínio na tinta látex após lixiviação com água desionizada, solução de $\mathrm{NaCl} 5 \%(\mathrm{~m} / \mathrm{v})$, solução sulfonítrica de $\mathrm{pH}=4$ e HAc de $\mathrm{pH}=5$, após troca de extrator a cada 7 dias.

\begin{tabular}{ccccc}
\hline & \multicolumn{4}{c}{ Tempo de exposiçáo (dias) } \\
Extratores & $\boldsymbol{T}$ & $\boldsymbol{T}$ & $\boldsymbol{7}$ & $\mathbf{7}$ \\
\hline $\mathrm{H}_{2} \mathrm{O}$ & 0,660 & 0,868 & 0,412 & 0,969 \\
$\mathrm{NaCl}$ & 0,502 & 0,517 & 0,511 & 0,392 \\
Chuva ácida & 0,076 & 0,051 & 0,035 & 0,054 \\
$\mathrm{HAc}$ & 0,614 & 0,569 & 0,362 & 0,801 \\
\hline
\end{tabular}

Tabela 6.45. Quantidade encontrada em $\mathrm{mg} \mathrm{L}^{-1}$ de manganês na tinta látex após lixiviação com água desionizada, solução de $\mathrm{NaCl} 5 \%(\mathrm{~m} / \mathrm{v})$, solução sulfonítrica de $\mathrm{pH}=4$ e HAc de $\mathrm{pH}=5$, após troca de extrator a cada 7 dias.

\begin{tabular}{ccccc} 
& \multicolumn{4}{c}{ Tempo de exposiçăo (dias) } \\
Extratores & 7 & 7 & 7 & 7 \\
\hline $\mathrm{H}_{2} \mathrm{O}$ & $<0,00001$ & $<0,00001$ & $<0,00001$ & $<0,00001$ \\
$\mathrm{NaCl}$ & $<0,00001$ & $<0,00001$ & $<0,00001$ & $<0,00001$ \\
Chuva ácida & 0,0128 & 0,0106 & 0,017 & 0,008 \\
$\mathrm{HAc}$ & 0,002 & 0,001 & 0,002 & $<0,00001$ \\
\hline
\end{tabular}

Tabela 6.46. Quantidade encontrada em $\mathrm{mg} \mathrm{L}^{-1}$ de chumbo na tinta látex após lixiviação com água desionizada, solução de $\mathrm{NaCl} 5 \%(\mathrm{~m} / \mathrm{v})$, solução sulfonítrica de $\mathrm{pH}=4$ e HAc de $\mathrm{pH}=5$, após troca de extrator a cada 7 dias.

\begin{tabular}{ccccc}
\hline & \multicolumn{4}{c}{ Tempo de exposiçäo (dias) } \\
Extratores & 7 & 7 & 7 & 7 \\
\hline $\mathrm{H}_{2} \mathrm{O}$ & 0,030 & $<0,00005$ & 0,034 & $<0,00005$ \\
$\mathrm{NaCl}$ & 0,017 & $<0,00005$ & $<0,00005$ & $<0,00005$ \\
Chuva ácida & 0,048 & $<0,00005$ & 0,036 & 0,015 \\
$\mathrm{HAC}$ & 0,033 & $<0,00005$ & 0,016 & $<0,00005$ \\
\hline
\end{tabular}


Observou-se que para a maioria dos elementos e extratores houve decréscimo na migração dos elementos à medida que as soluções foram trocadas. Este fato pode estar relacionado à perda superficial do pigmento e, uma vez que ocorra perda de material polimérico do revestimento, as partículas de pigmento podem ficar expostas na superficie do filme e a extração voltar a ocorrer. A erosão do pigmento pode ser observada na Figura 6.20 [BATISTA, 2004].

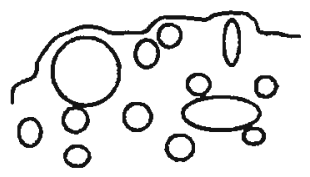

(a)

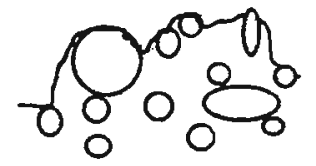

(b)

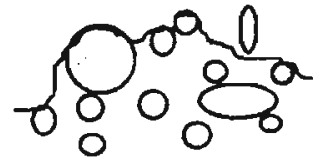

(c)

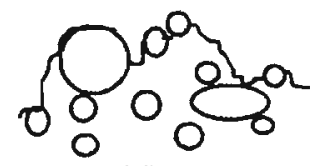

(d)

Figura. 6.20. Representação esquemática do processo de degradação da superfície do revestimento. a) sem exposição; b) pouco tempo de exposição, perda de resina; c) perda de partículas de pigmento; d) perda do revestimento de resina, exposição e perda de pigmento.

As Tabelas seguintes apresentam os resultados relativos ao período d 7,14 , 21 e 28 dias de exposição às soluções extratoras.

Tabela 6.47. Quantidade encontrada em $\mathrm{mg} \mathrm{L}^{-1}$ de alumínio na tinta esmalte após lixiviação com água desionizada, solução de $\mathrm{NaCl} 5 \%(\mathrm{~m} / \mathrm{v})$, solução sulfonítrica de $\mathrm{pH}=4$ e $\mathrm{HAc}$ de $\mathrm{pH}=5$.

\begin{tabular}{ccccc}
\hline & & Tempo de exposicso (dias) & \\
Extratores & 7 & 14 & 21 & 28 \\
\hline $\mathrm{H}_{2} \mathrm{O}$ & $0,020 \pm 0,001$ & $0,043 \pm 0,01$ & $0,011 \pm 0,001$ & $0,084 \pm 0,004$ \\
$\mathrm{NaCl}$ & $0,075 \pm 0,003$ & $0,013 \pm 0,001$ & $0,011 \pm 0,0009$ & $0,1180 \pm 0,0003$ \\
Chuva ácida & $0,377 \pm 0,003$ & $0,05 \pm 0,01$ & $0,033 \pm 0,007$ & $0,3660 \pm 0,0009$ \\
$\mathrm{HAc}$ & $0,026 \pm 0,006$ & $0,04 \pm 0,01$ & $0,010 \pm 0,001$ & $0,1030 \pm 0,0002$ \\
\hline
\end{tabular}


Tabela 6.48. Quantidade encontrada em $\mathrm{mg} \mathrm{L}^{-1}$ de crômio na tinta esmalte após lixiviação com água desionizada, solução de $\mathrm{NaCl} 5 \%(\mathrm{~m} / \mathrm{v})$, solução sulfonítrica de $\mathrm{pH}=4$ e $\mathrm{HAc}$ de $\mathrm{pH}=5$.

\begin{tabular}{ccccc}
\hline & \multicolumn{4}{c}{ Tempo de exposiçä (dias) } \\
Extratores & $\mathbf{7}$ & $\mathbf{1 4}$ & $\mathbf{2 1}$ & $\mathbf{2 8}$ \\
\hline $\mathrm{H}_{2} \mathrm{O}$ & $0,116 \pm 0,002$ & $0,0710 \pm 0,0008$ & $0,064 \pm 0,002$ & $0,173 \pm 0,003$ \\
$\mathrm{NaCl}$ & $0,988 \pm 0,02$ & $0,08 \pm 0,01$ & $0,025 \pm 0,002$ & $1,2370 \pm 0,0033$ \\
Chuva ácida & $0,79 \pm 0,01$ & $0,6510 \pm 0,0005$ & $0,672 \pm 0,002$ & $0,946 \pm 0,008$ \\
$\mathrm{HAC}$ & $0,134 \pm 0,007$ & $0,0740 \pm 0,0003$ & $0,0520 \pm 0,0009$ & $0,200 \pm 0,004$ \\
\hline
\end{tabular}

Tabela 6.49. Quantidade encontrada em $\mathrm{mg} \mathrm{L}^{-1}$ de manganês na tinta esmalte após lixiviação com água desionizada, solução de $\mathrm{NaCl} 5 \%(\mathrm{~m} / \mathrm{v})$, solução sulfonítrica de $\mathrm{pH}=4$ e $\mathrm{HAc}$ de $\mathrm{pH}=5$.

\begin{tabular}{ccccc}
\hline & & \multicolumn{4}{c}{ Tempo de exposicá (dias) } & 28 \\
\hline Extratores & 7 & 14 & 21 & 28 \\
\hline $\mathrm{H}_{2} \mathrm{O}$ & $0,004 \pm 0,0001$ & $0,001 \pm 0,00015$ & $0,001 \pm 0,00025$ & $0,011 \pm 0,0004$ \\
$\mathrm{NaCl}$ & $0,003 \pm 0,0001$ & $0,002 \pm 0,00015$ & $0,002 \pm 0,00001$ & $0,007 \pm 0,00001$ \\
Chuva ácida & $0,00885 \pm 0,00001$ & $0,00125 \pm 0,00005$ & $0,00135 \pm 0,00005$ & $0,0138 \pm 0,0002$ \\
$\mathrm{HAc}$ & $0,005 \pm 0,00035$ & $0,0011 \pm 0,0002$ & $0,001 \pm 0,00001$ & $0,0105 \pm 0,0001$ \\
\hline
\end{tabular}

Tabela 6.50. Quantidade encontrada em $\mathrm{mg} \mathrm{L}^{-1}$ de cobalto na tinta esmalte após lixiviação com água desionizada, solução de $\mathrm{NaCl} 5 \%(\mathrm{~m} / \mathrm{v})$, solução sulfonítrica de $\mathrm{pH}=4$ e $\mathrm{HAc}$ de $\mathrm{pH}=5$.

\begin{tabular}{ccccc}
\hline & \multicolumn{4}{c}{ Tempo de exposiçáo (dias) } \\
Extratores & 7 & 14 & 21 & 28 \\
\hline $\mathrm{H}_{2} \mathrm{O}$ & $0,080 \pm 0,0026$ & $0,016 \pm 0,0002$ & $0,011 \pm 0,0004$ & $0,174 \pm 0,0006$ \\
$\mathrm{NaCl}$ & $0,047 \pm 0,00355$ & $0,011 \pm 0,00085$ & $0,010 \pm 0,00025$ & $0,095 \pm 0,0007$ \\
Chuva ácida & $0,136 \pm 0,0016$ & $0,019 \pm 0,00045$ & $0,013 \pm 0,0003$ & $0,202 \pm 0,00405$ \\
$\mathrm{HAC}$ & $0,092 \pm 0,0089$ & $0,016 \pm 0,00045$ & $0,010 \pm 0,0002$ & $0,1801 \pm 0,0001$ \\
\hline
\end{tabular}


Tabela 6.51. Quantidade encontrada em $\mathrm{mg} \mathrm{L}^{-1}$ de chumbo na tinta esmalte após lixiviação com água desionizada, solução de $\mathrm{NaCl} 5 \%(\mathrm{~m} / \mathrm{v})$, solução sulfonítrica de $\mathrm{pH}=4$ e $\mathrm{HAc}$ de $\mathrm{pH}=5$.

\begin{tabular}{ccccc}
\hline & & Tempo de exposiçáo (dias) & \\
Extratores & 7 & 14 & 21 & 28 \\
\hline $\mathrm{H}_{2} \mathrm{O}$ & $0,77 \pm 0,01$ & $0,40 \pm 0,01$ & $0,33 \pm 0,02$ & $1,68 \pm 0,05$ \\
$\mathrm{NaCl}$ & $4,7 \pm 0,1$ & $0,41 \pm 0,06$ & $0,17 \pm 0,01$ & $5,89 \pm 0,05$ \\
Chuva ácida & $4,15 \pm 0,08$ & $2,86 \pm 0,007$ & $3,05 \pm 0,002$ & $5,09 \pm 0,03$ \\
$\mathrm{HAC}$ & $1,0 \pm 0,1$ & $0,4 \pm 0,2$ & $0,18 \pm 0,06$ & $1,86 \pm 0,05$ \\
\hline
\end{tabular}

Tabela 6.52. Quantidade encontrada em $\mathrm{mg} \mathrm{L}^{-1} \mathrm{de} \mathrm{Ni}, \mathrm{Cu}$, As e $\mathrm{Cd}$ na tinta esmalte após lixiviação com água desionizada, solução de $\mathrm{NaCl} 5 \%(\mathrm{~m} / \mathrm{v})$, solução sulfonítrica de $\mathrm{pH}=4$ e HAc de $\mathrm{pH}=5$ após a troca do extrator em $7,14,21$ e 28 dias).

\begin{tabular}{ccccc}
\hline & \multicolumn{4}{c}{ Extratores } \\
Elementos & $\mathrm{H}_{2} \mathrm{O}$ & $\mathrm{NaGl}$ & Chuva acida & HAc \\
\hline $\mathrm{Ni}$ & $<0,00001$ & $<0,00001$ & $<0,00001$ & $<0,00001$ \\
$\mathrm{Cu}$ & $<0,0001$ & $<0,0001$ & $<0,0001$ & $<0,0001$ \\
$\mathrm{As}$ & $<0,0001$ & $<0,0001$ & $<0,0001$ & $<0,0001$ \\
$\mathrm{Cd}$ & $<0,00001$ & $<0,00001$ & $<0,00001$ & $<0,00001$ \\
\hline
\end{tabular}

Tabela 6.53. Quantidade encontrada em $\mathrm{mg} \mathrm{L}^{-1}$ de alumínio na tinta látex após lixiviação com água desionizada, solução de $\mathrm{NaCl} 5 \%(\mathrm{~m} / \mathrm{v})$, solução sulfonitrica de $\mathrm{pH}=4$ e $\mathrm{HAc}$ de $\mathrm{pH}=5$.

\begin{tabular}{ccccc}
\hline & \multicolumn{4}{c}{ Tempo de exposiçö (dias) } \\
Extratores & 7 & $\mathbf{1 4}$ & $\mathbf{2 1}$ & $\mathbf{2 8}$ \\
\hline $\mathrm{H}_{2} \mathrm{O}$ & $0,660 \pm 0,003$ & $0,813 \pm 0,03$ & $0,772 \pm 0,01$ & $0,338 \pm 0,07$ \\
$\mathrm{NaCl}$ & $0,502 \pm 0,03$ & $0,434 \pm 0,007$ & $0,516 \pm 0,04$ & $0,417 \pm 0,08$ \\
Chuva ácida & $0,076 \pm 0,02$ & $0,023 \pm 0,001$ & $0,051 \pm 0,005$ & $0,0253 \pm 0,002$ \\
$\mathrm{HAC}$ & $0,614 \pm 0,09$ & $0,738 \pm 0,02$ & $0,763 \pm 0,009$ & $0,218 \pm 0,006$ \\
\hline
\end{tabular}


Tabela 6.54. Quantidade encontrada em $\mathrm{mg} \mathrm{L}^{-1}$ de manganês na tinta látex após lixiviação com água desionizada, solução de $\mathrm{NaCl} 5 \%(\mathrm{~m} / \mathrm{v})$, solução sulfonítrica de $\mathrm{pH}=4$ e $\mathrm{HAc}$ de $\mathrm{pH}=5$.

\begin{tabular}{ccccc}
\hline & \multicolumn{4}{c}{ Tempo de exposiçăo (dias) } \\
Extratores & $\mathbf{7}$ & $\mathbf{1 4}$ & $\mathbf{2 1}$ & $\mathbf{2 8}$ \\
\hline $\mathrm{H}_{2} \mathrm{O}$ & $<0,00001$ & $<0,00001$ & $<0,00001$ & $0,0015 \pm 0,0002$ \\
$\mathrm{NaCl}$ & $<0,00001$ & $<0,00001$ & $<0,00001$ & $0,0013 \pm 0,0001$ \\
Chuva ácida & $0,0128 \pm 0,0002$ & $0,00945 \pm 0,00003$ & $0,00625 \pm 0,00001$ & $0,02545 \pm 0,00001$ \\
$\mathrm{HAc}$ & $0,0015 \pm 0,0007$ & $<0,00001$ & $<0,00001$ & $0,0077 \pm 0,0005$ \\
\hline
\end{tabular}

Tabela 6.55. Quantidade encontrada em $\mathrm{mg} \mathrm{L}^{-1}$ de chumbo na tinta látex após lixiviação com água desionizada, solução de $\mathrm{NaCl} 5 \%(\mathrm{~m} / \mathrm{v})$, solução sulfonítrica de $\mathrm{pH}=4$ e HAc de $\mathrm{pH}=5$.

\begin{tabular}{ccccc}
\hline & \multicolumn{4}{c}{ Tempo de exposicăo (dias) } \\
Extratores & 7 & 14 & 21 & 28 \\
\hline $\mathrm{H}_{2} \mathrm{O}$ & $0,030 \pm 0,001$ & $0,014 \pm 0,0007$ & $0,019 \pm 0,003$ & $0,047 \pm 0,0065$ \\
$\mathrm{NaCl}$ & $0,017 \pm 0,0043$ & $<0,00005$ & $<0,00005$ & $0,025 \pm 0,0063$ \\
Chuva ácida & $0,048 \pm 0,007$ & $0,017 \pm 0,004$ & $0,019 \pm 0,003$ & $0,077 \pm 0,02$ \\
$\mathrm{HAC}$ & $0,03 \pm 0,01$ & $<0,00005$ & $0,0001 \pm 0,002$ & $0,048 \pm 0,003$ \\
\hline
\end{tabular}

Tabela 6.56. Quantidade encontrada em $\mathrm{mg} \mathrm{L}^{-1}$ de $\mathrm{Cr}$, $\mathrm{Co}, \mathrm{Ni}, \mathrm{Cu}$, As e $\mathrm{Cd}$ na tinta látex após lixiviação com água desionizada, solução de $\mathrm{NaCl} 5 \%(\mathrm{~m} / \mathrm{v})$, solução sulfonítrica de $\mathrm{pH}=4$ e HAc de $\mathrm{pH}=5$ após a troca do extrator em $7,14,21$ e 28 dias).

\begin{tabular}{ccccc}
\hline & \multicolumn{4}{c}{ Extrabres } \\
Elementos & $\mathrm{H}_{2} \mathrm{O}$ & $\mathrm{NaCl}$ & Chuva ácida & HAc \\
\hline $\mathrm{Cr}$ & $<0,00001$ & $<0,00001$ & $<0,00001$ & $<0,00001$ \\
$\mathrm{Co}$ & $<0,00001$ & $<0,00001$ & $<0,00001$ & $<0,00001$ \\
$\mathrm{Ni}$ & $<0,00001$ & $<0,00001$ & $<0,00001$ & $<0,00001$ \\
$\mathrm{Cu}$ & $<0,0001$ & $<0,0001$ & $<0,0001$ & $<0,0001$ \\
$\mathrm{As}$ & $<0,0001$ & $<0,0001$ & $<0,0001$ & $<0,0001$ \\
$\mathrm{Cd}$ & $<0,00001$ & $<0,00001$ & $<0,00001$ & $<0,00001$ \\
\hline
\end{tabular}


Neste conjunto, em que se compara tempo de exposição e quantidade extraída, observou-se que a maior extração ocorreu após 28 dias, mas que após 14 e 21 dias houve diminuição da migração em relação à primeira medição. Este comportamento é inesperado e requer uma melhor avaliação. Por outro lado, somando-se os resultados das quatro semanas do primeiro conjunto (28 dias trocando o extrator a cada 7 dias) e comparando-se o resultado em relação aos 28 dias do segundo conjunto (sem trocar o extrator), pode-se verificar que a troca do extrator favorece a extração, uma vez que o resultado da somatória é na maioria dos casos superior ao resultado da extração obtida por 28 dias consecutivos. Estes dados podem ser observados nas Tabelas 6.26 à 6.30 (tinta esmalte) e 6.34 à 6.36 (tinta látex).

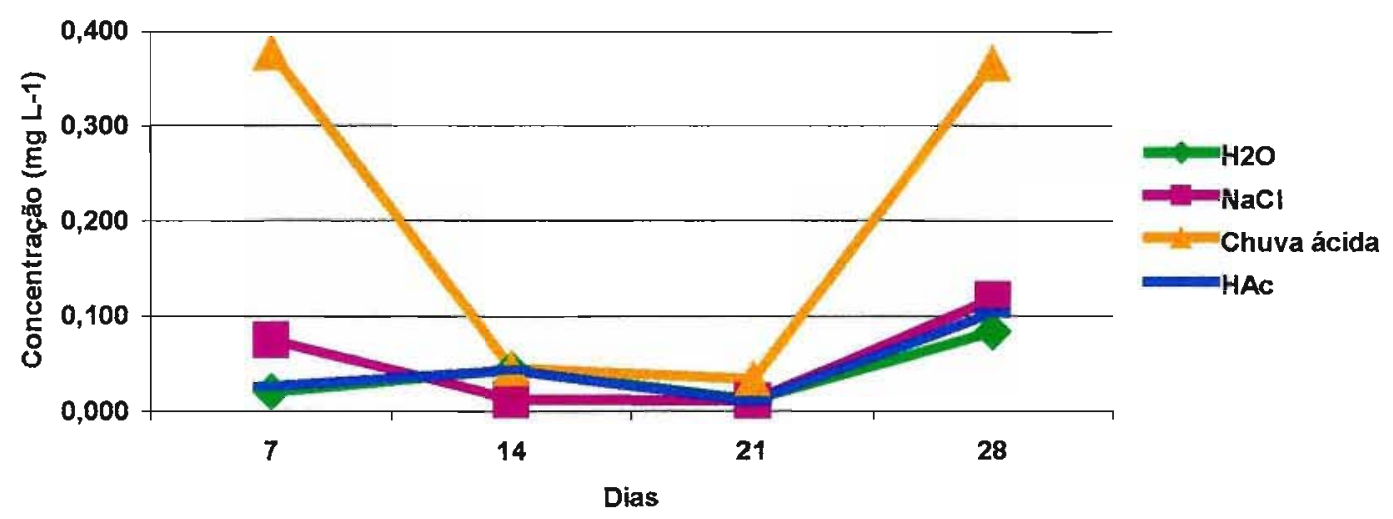

Figura 6.21. Concentração de Al em função do tempo de exposição das soluções extratoras em tinta esmalte.

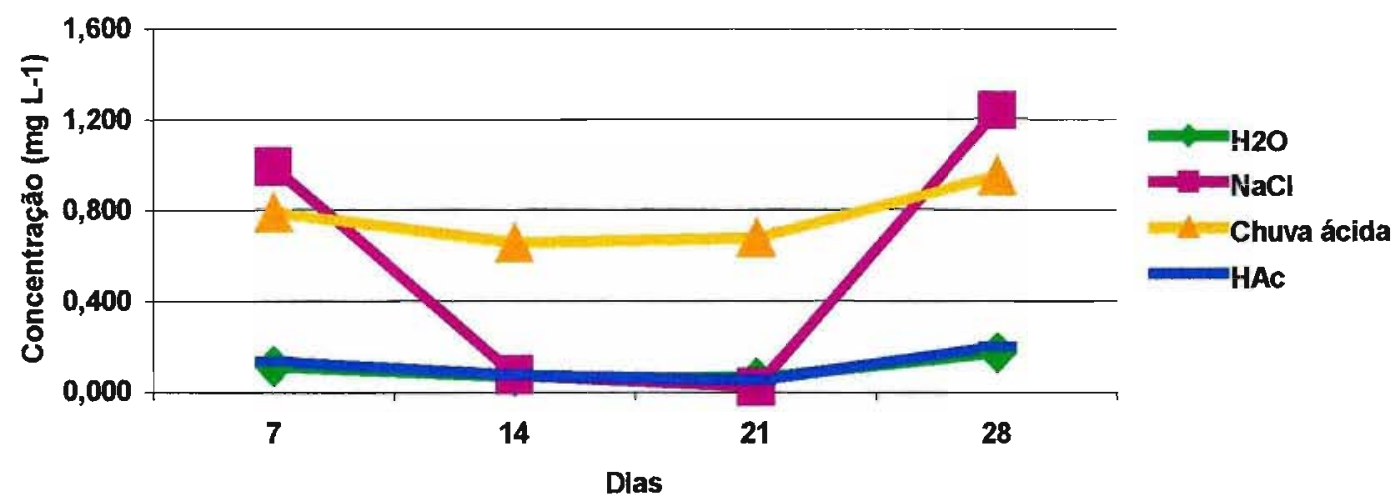

Figura 6.22. Concentração de $\mathrm{Cr}$ em função do tempo de exposição das soluções extratoras em tinta esmalte. 


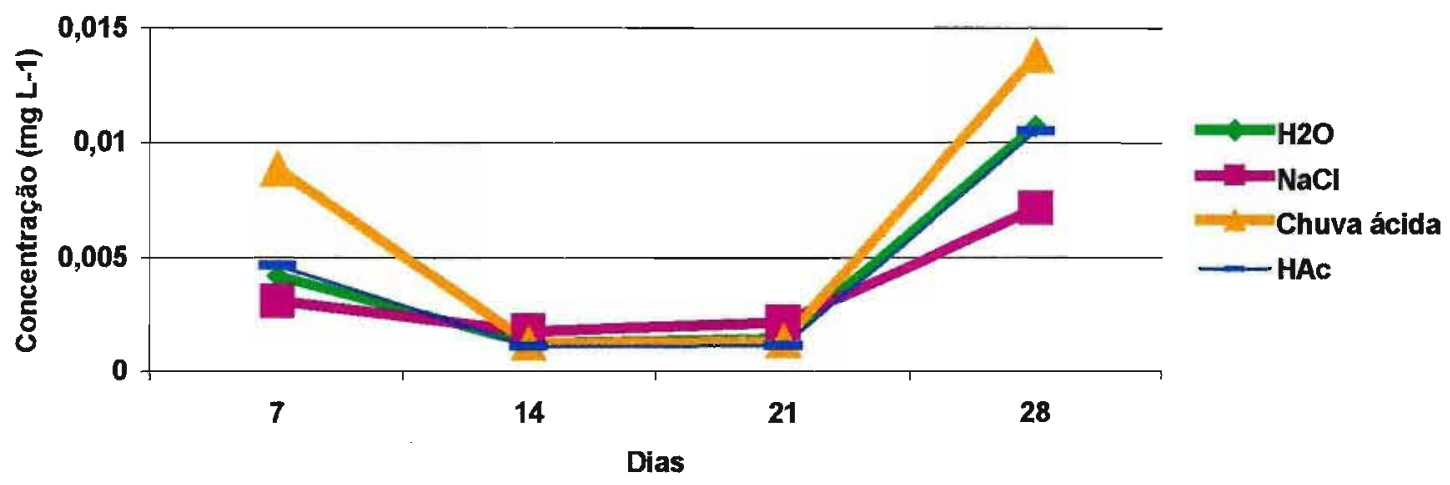

Figura 6.23. Concentração de $\mathrm{Mn}$ em função do tempo de exposição das soluções extratoras em tinta esmalte.

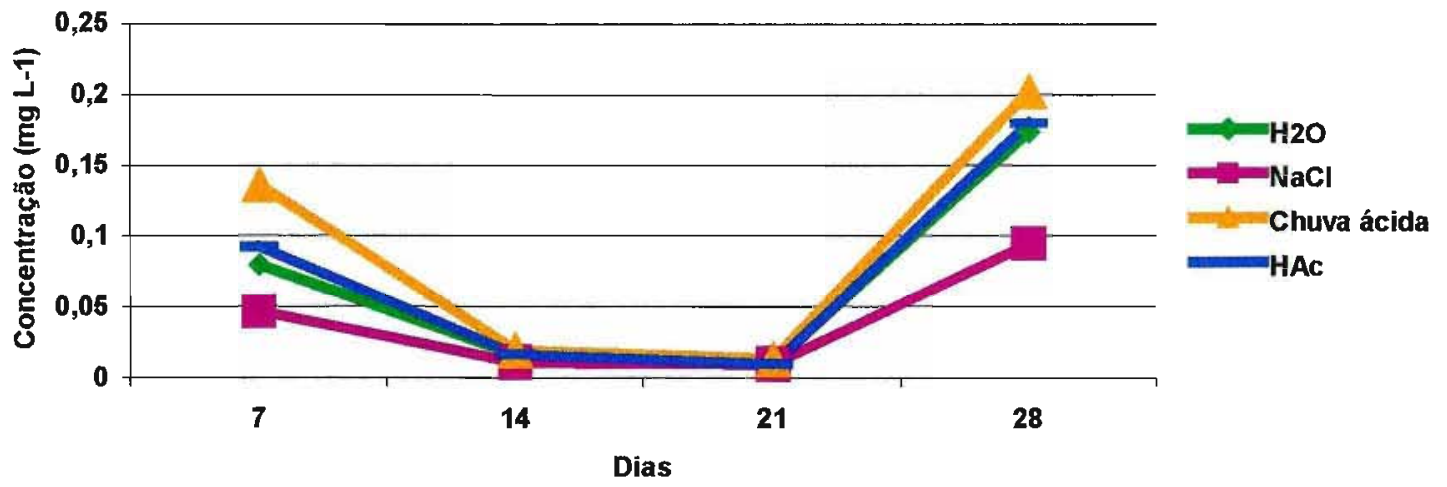

Figura 6.24. Concentração de Co em função do tempo de exposição das soluçães extratoras em tinta esmalte.

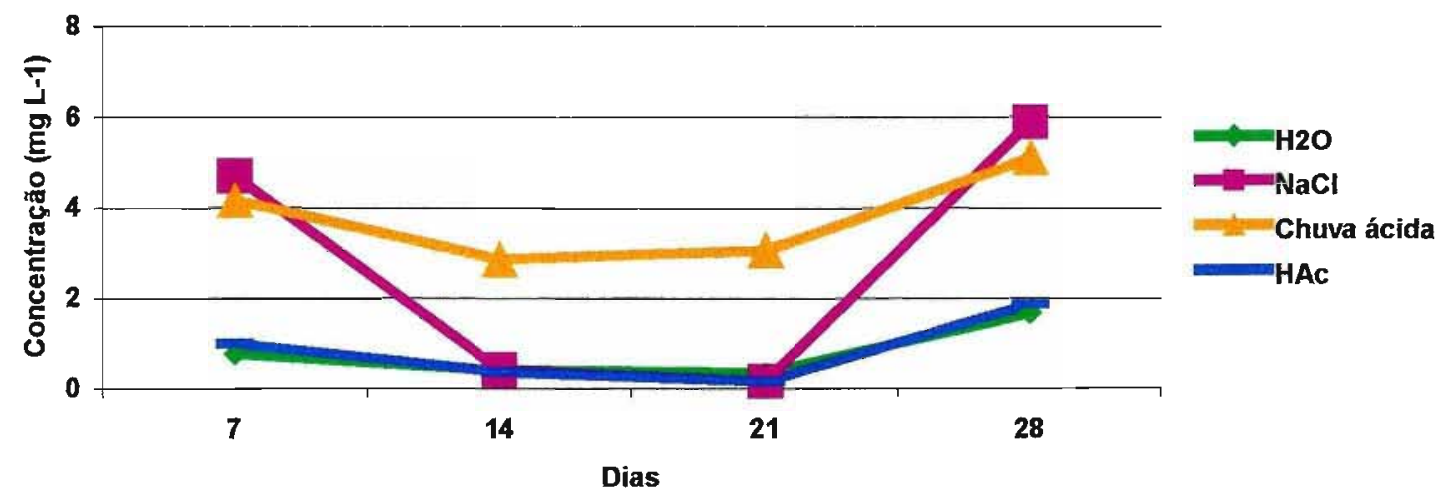

Figura 6.25. Concentração de $\mathrm{Pb}$ em função do tempo de exposição das soluções extratoras em tinta esmalte. 


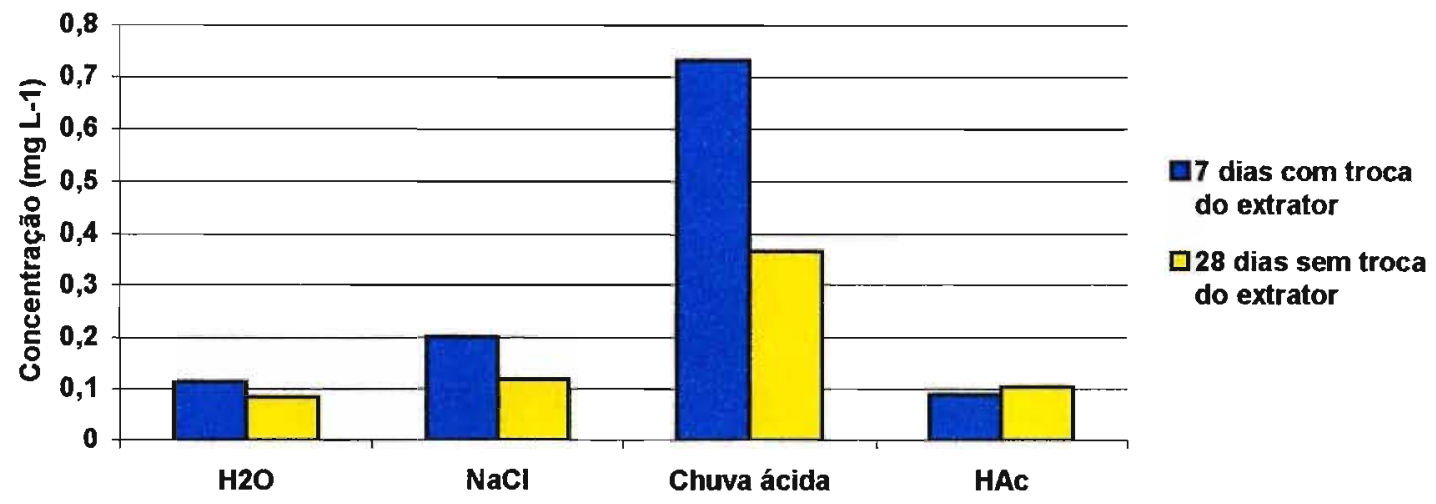

Figura 6.26. Variação da concentração de Al nos diferentes extratores em tinta esmalte após 28 dias com troca de extrator a cada 7 em comparação a 28 dias ininterruptos.

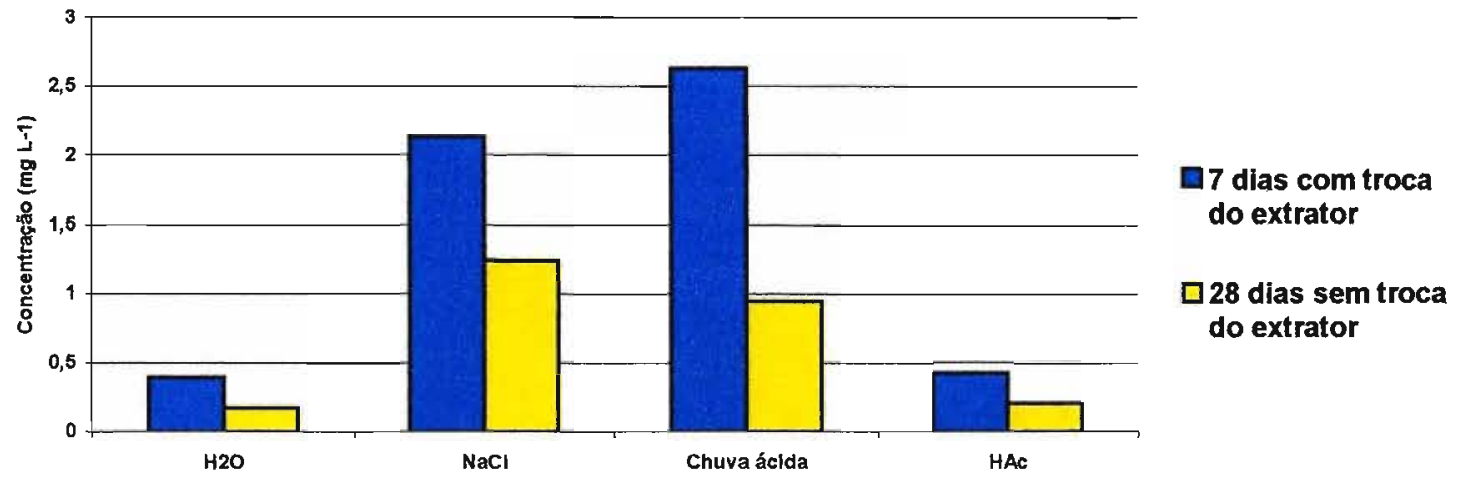

Figura 6.27. Avaliação do equilíbrio da extração de $\mathrm{Cr}$ nos diferentes extratores em tinta esmalte.

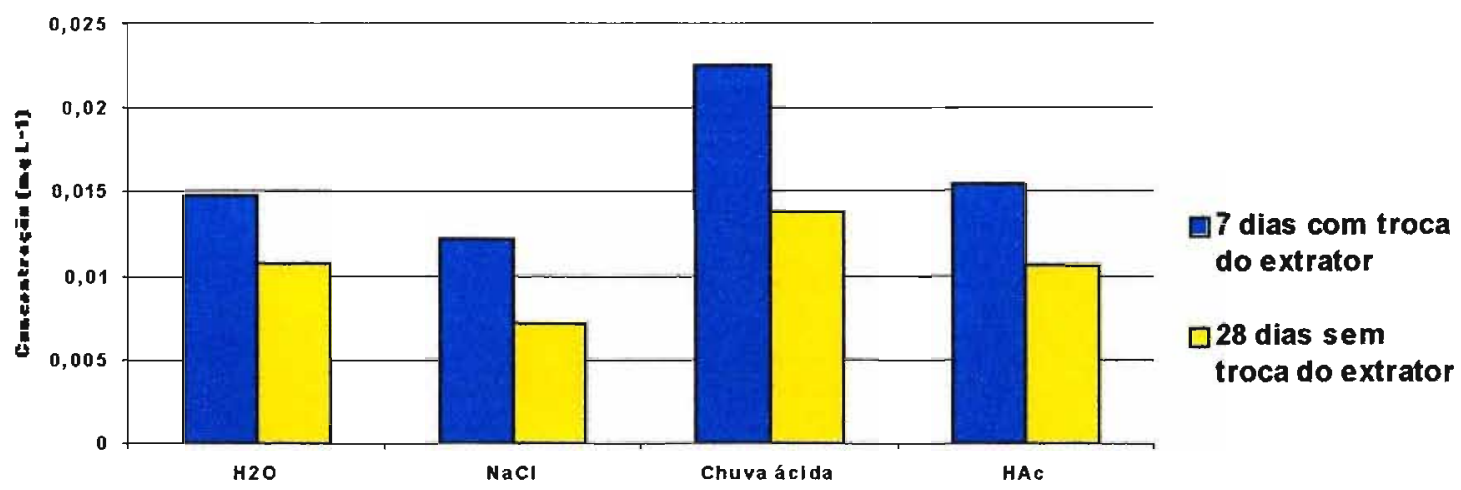

Figura 6.28. Avaliação do equilíbrio da extração de Mn nos diferentes extratores em tinta esmalte. 


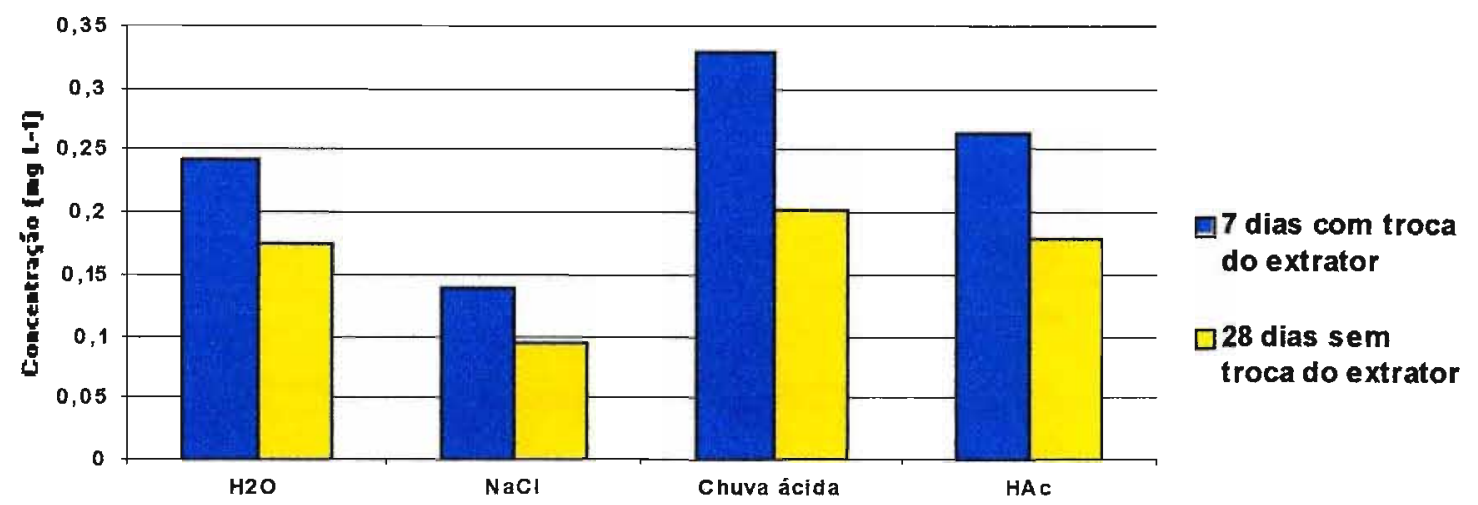

Figura 6.29. Avaliação do equilíbrio da extração de Co nos diferentes extratores em tinta esmalte.

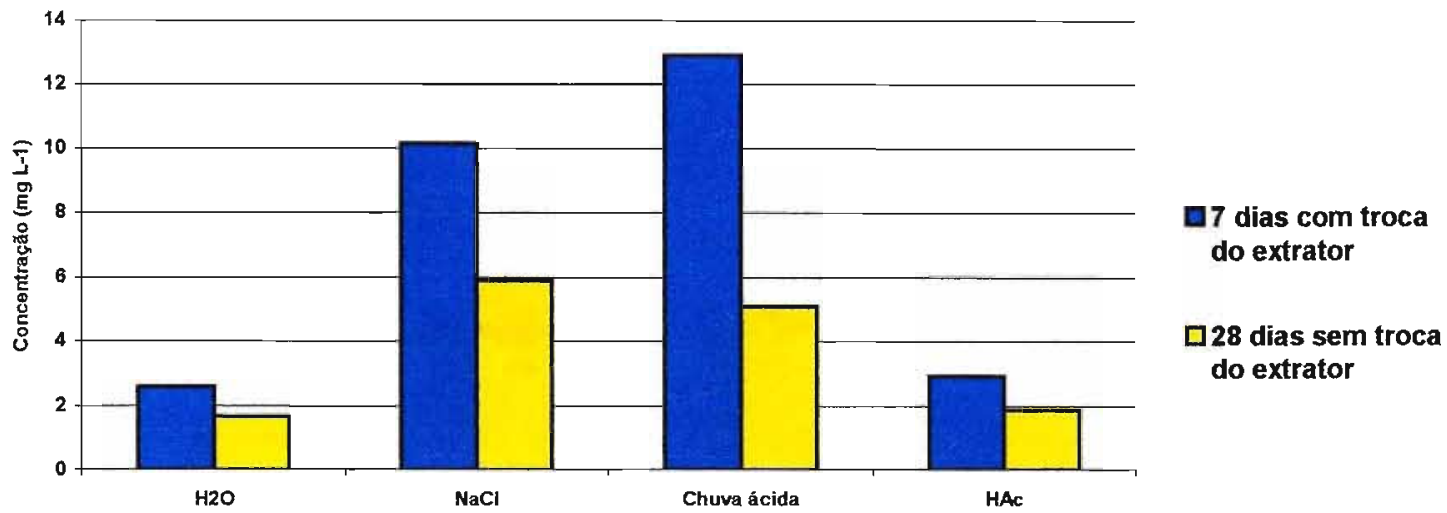

Figura 6.30. Avaliação do equilíbrio da extração de $\mathrm{Pb}$ nos diferentes extratores em tinta esmalte. 


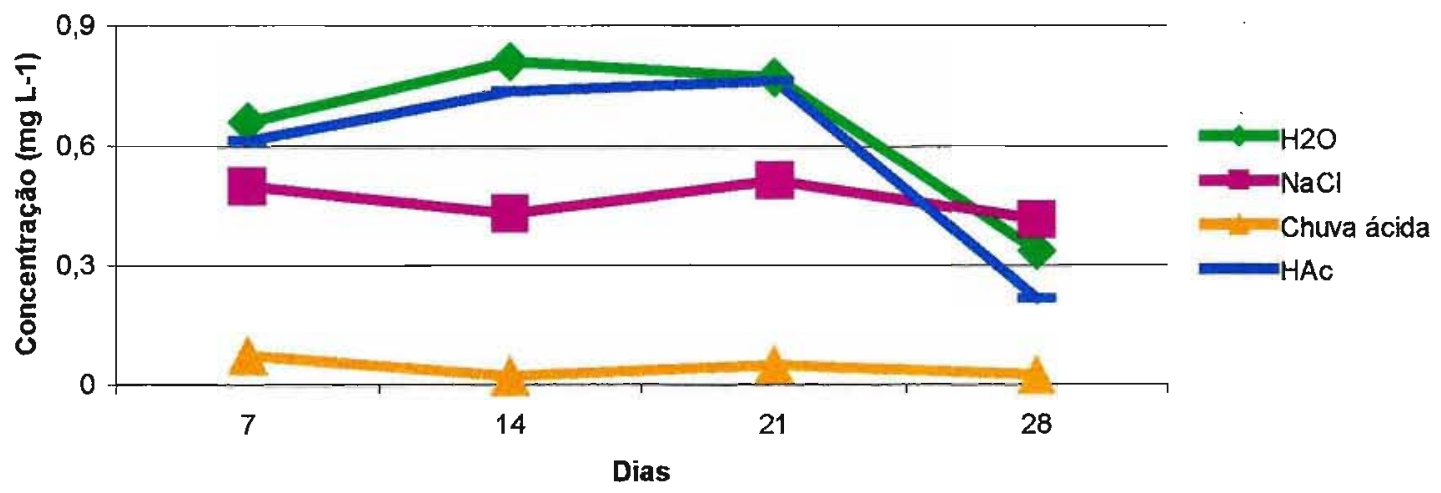

Figura 6.31. Concentração de Al em função do tempo de exposição das soluções extratoras em tinta látex.

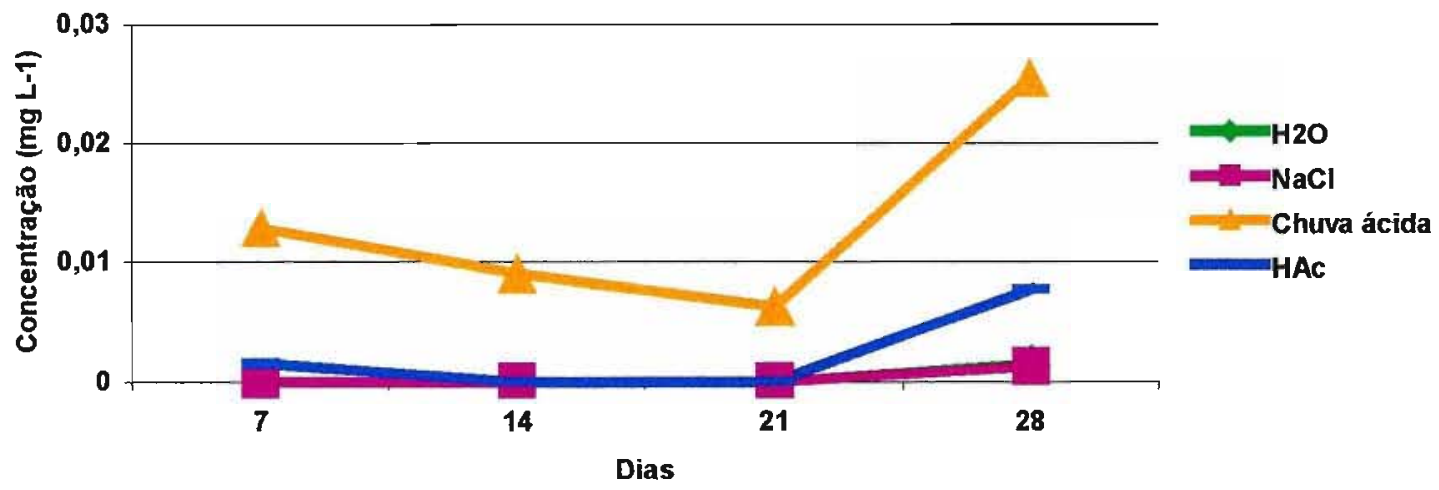

Figura 6.32. Concentração de Mn em função do tempo de exposição das soluções extratoras em tinta látex.

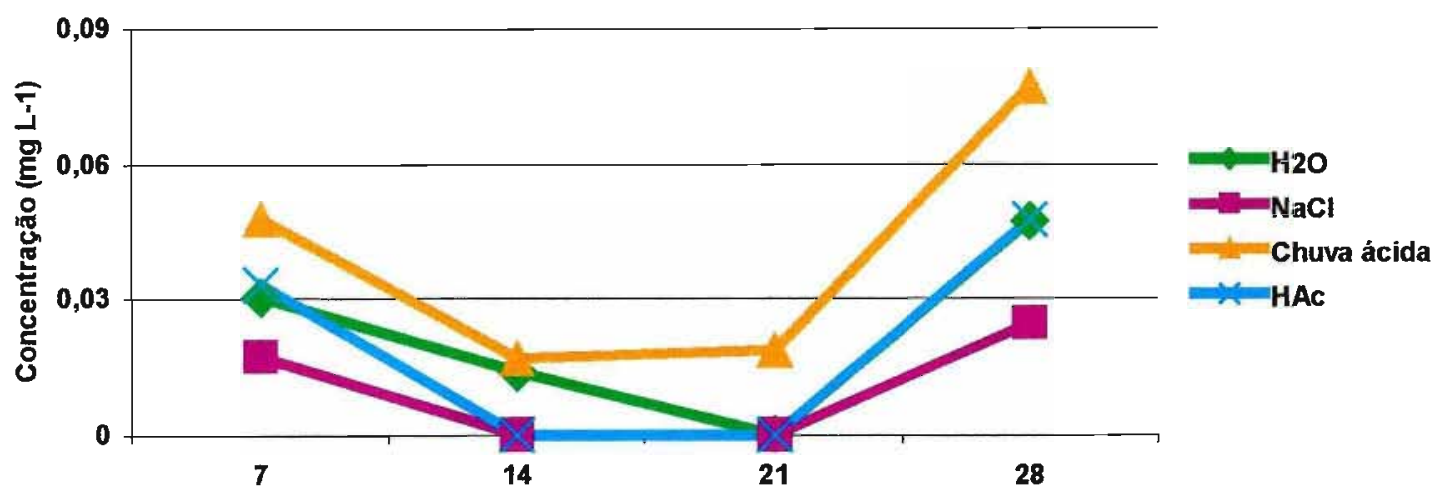

Figura 6.33. Concentração de $\mathrm{Pb}$ em função do tempo de exposição das soluções extratoras em tinta látex. 


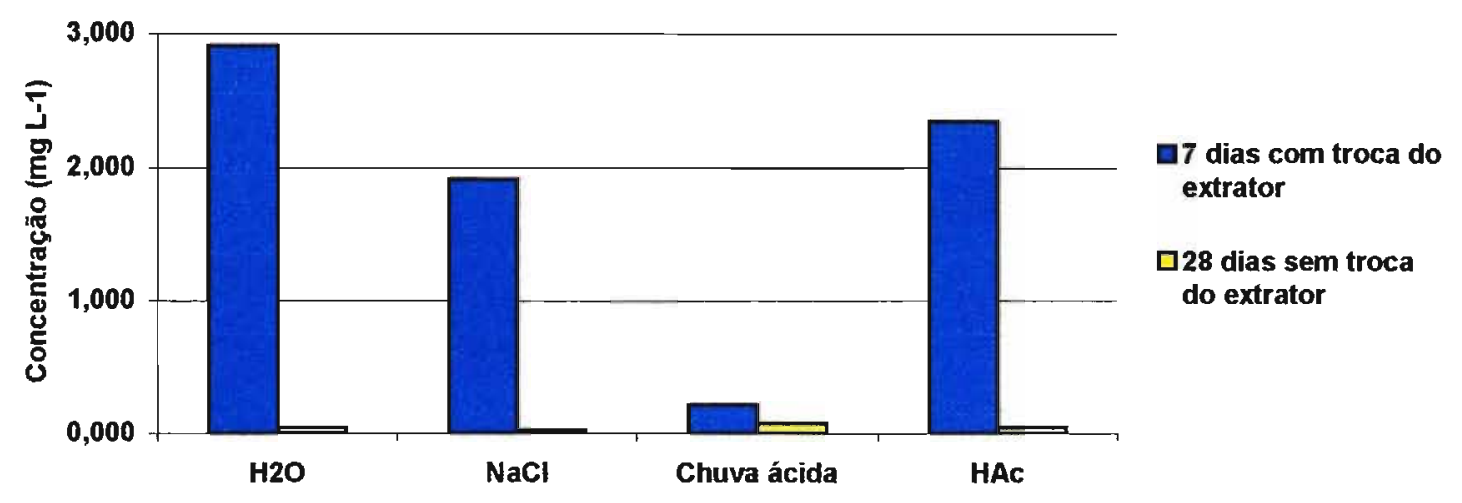

Figura 6.34. Concentração de Al em função do tempo de exposição das soluções extratoras em tinta látex.

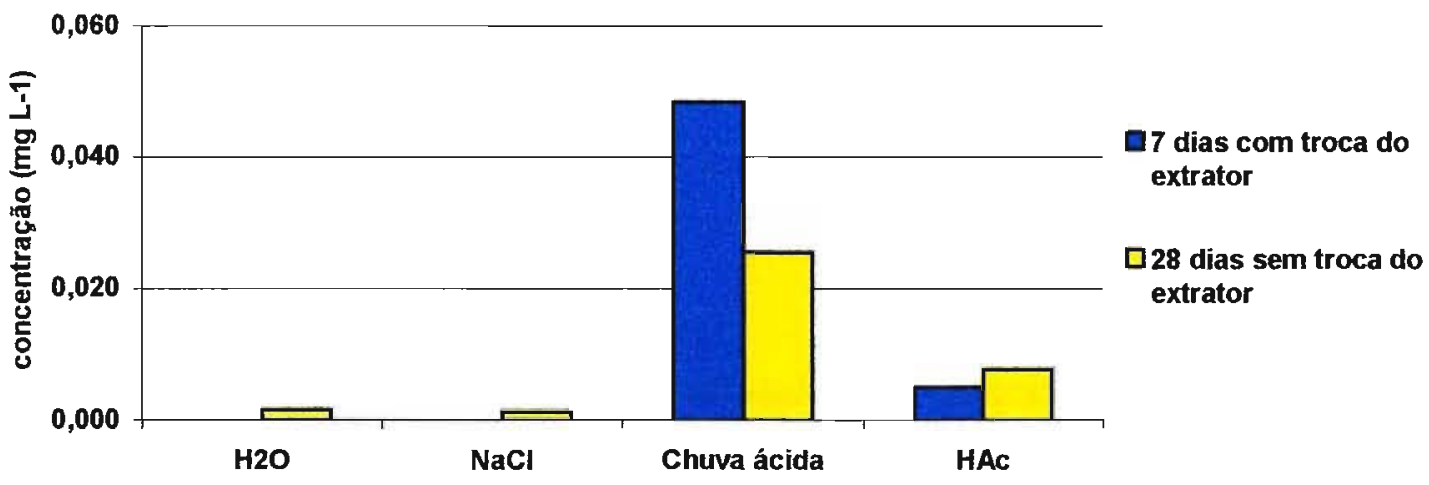

Figura 6.35. Concentração de $\mathrm{Mn}$ em função do tempo de exposição das soluções extratoras em tinta látex.

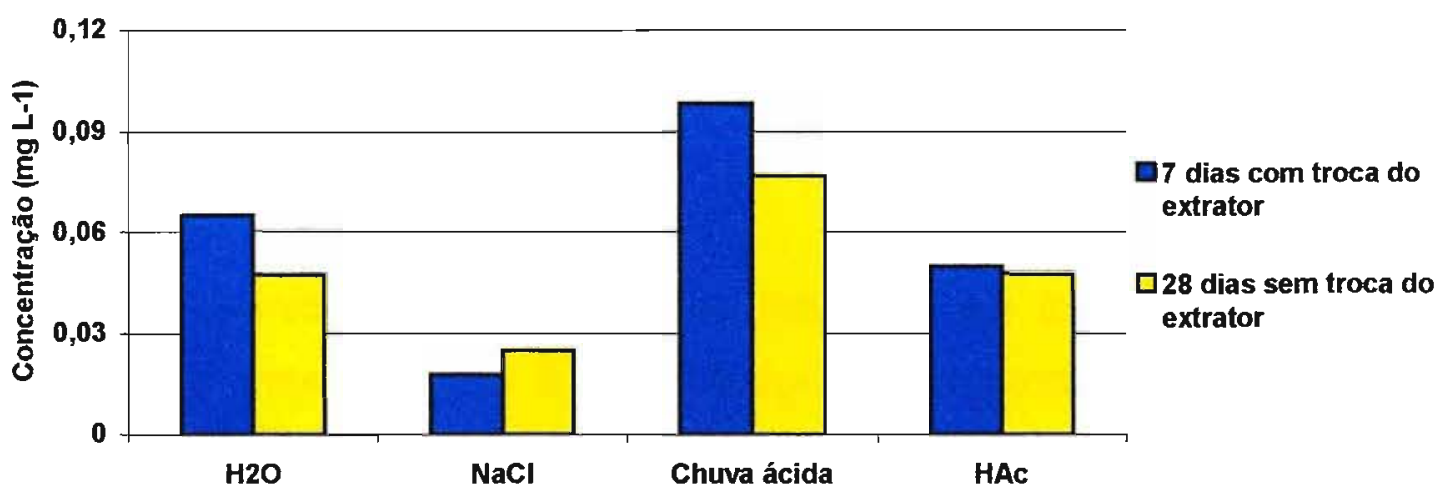

Figura 6.36. Concentração de $\mathrm{Pb}$ em função do tempo de exposição das soluções extratoras em tinta látex. 
A repetibilidade do método foi avaliada preparando-se 10 frascos com a tinta esmalte e chuva ácida como solução extratora. Os frascos ficaram 23 dias em repouso. Os resultados estão apresentados na Tabela 6.57. O teste $t$ (Student) foi aplicado aos resultados e mostrou que este método é reprodutivel em um nivel de confiança de $95 \%$.

Tabela 6.57. Avaliação da reprodutibilidade na tinta esmalte após lixiviação com solução sulfonítrica de $\mathrm{pH}=4$ (chuva ácida).

\begin{tabular}{|c|c|c|c|}
\hline Elementos & $\begin{array}{c}\text { Tinta Esmalte amarela } \\
\text { (mg L }\end{array}$ & Elementos & $\begin{array}{c}\text { Tinta Esmalte amarela } \\
\left(\mathrm{mgL}^{-1}\right)\end{array}$ \\
\hline $\mathrm{Al}$ & $0,43 \pm 0,01$ & $\mathrm{Cu}$ & $<0,0001$ \\
\hline $\mathrm{Cr}$ & $0,77 \pm 0,02$ & As & $<0,0001$ \\
\hline $\mathrm{Mn}$ & $0,0140 \pm 0,0003$ & $\mathrm{Cd}$ & $<0,00001$ \\
\hline Co & $0,146 \pm 0,005$ & $\mathrm{~Pb}$ & $3,9 \pm 0,1$ \\
\hline $\mathrm{Ni}$ & $<0,00001$ & & \\
\hline
\end{tabular}

De uma maneira geral, os resultados mostraram que todos os elementos presentes na tinta à base de solvente, exceto cobre, foram lixiviados em maior ou menor grau dependendo do extrator e do tempo de lixiviação. Nas tintas à base de água, somente $\mathrm{Al}, \mathrm{Mn}$ e $\mathrm{Pb}$ foram lixiviados nas condições do teste.

Dos elementos avaliados, $\mathrm{Pb}$ apresentou lixiviação em todas as amostras investigadas. A extração deste elemento em tinta esmalte foi maior do que na tinta à base de água. Entretanto, cabe lembrar que a tinta esmalte apresenta alto teor deste elemento em sua composição, o que indica que apesar da massa de chumbo lixiviada ser maior nas amostras deste tipo de tinta, proporcionalmente a extração é mais efetiva nas tintas à base de água.

O alumínio também apresentou lixiviação em todas as amostras, mas a migração foi maior na tinta à base de água, provavelmente devido à quantidade maior deste elemento neste tipo de tinta.

Novos estudos serão necessários para se estabelecer os mecanismos de extração para cada um dos analitos, que provavelmente dependerá da natureza do elemento e do extrator, da cinética da reação e da forma como estes elementos estão ligados aos componentes da tinta. 
O emprego deste método apresentou as seguintes vantagens: as amostras são colocadas individualmente em sistema fechado, portanto livre de contaminação, aumentando a confiabilidade dos resultados analíticos; se evita procedimentos drásticos de digestão das amostras, geralmente a etapa mais lenta, trabalhosa e sujeita a erros experimentais, porém necessária nos métodos convencionais de determinação por Espectrometria de Emissão Ótica com Plasma Indutivamente Acoplado (ICP OES); as soluções não precisam ser filtradas; as soluções resultantes são menos complexas que as obtidas pelo método de decomposição das amostras por forno de microondas; em função da menor complexidade da matriz, facilita-se a determinação por ICP OES, onde são esperados menos problemas de interferências e conseqüentemente limites de detecção mais baixos.

Deve-se salientar que, apesar das soluções lixiviadas apresentarem concentrações baixas dos analitos, a simples obtenção do sinal analítico nas condições estudadas revela a potencialidade do método para fornecer subsídios a uma legislação nacional em termos de qualidade das tintas. Por exemplo, ocorreu migração de $\mathrm{Pb}$ para as soluções extratoras, resultando em concentrações de 0,017 $\mathrm{mg} \mathrm{L}^{-1}$ a $5,89 \mathrm{mg} \mathrm{L}^{-1}$, para uma área pintada de somente $57 \mathrm{~mm}^{2}$. Isso, cabe ressaltar, são valores obtidos em um método em desenvolvimento, mas que sem dúvida fornece vantagens claras em termos de tratamento e preparação de amostras quando comparada aos outros métodos de análise por ICP OES. Além disso, as soluçōes finais apresentam matrizes menos complexas e mais fáceis de determinar. Uma outra possibilidade é a redução do tempo de lixiviação para agilizar a análise, associada ao uso de técnicas analiticas mais sensiveis, como ICP MS, por exemplo. Também neste caso, as vantagens de se obter matrizes menos complicadas com menos manipulação são óbvias. 


\subsection{Conclusões}

Em relação ao método de digestão de tinta à base de água, a utilização do forno de microondas em sistema fechado, empregando mistura ácida com $\mathrm{HNO}_{3}(2$ $\mathrm{mL})$ e $\mathrm{HF}(6 \mathrm{~mL})$, permitiu uma digestão rápida e eficiente das amostras em tempo inferior a $35 \mathrm{~min}$, mas exige a neutralização do $\mathrm{HF}$ ou a disponibilidade de equipamento resistente a esse ácido para a determinação dos analitos.

As misturas contendo $\mathrm{HNO}_{3}$ e $\mathrm{HCl}$ não se mostraram eficientes, devido à grande quantidade de Ti presente nas amostras.

Para as tintas à base de solvente, nenhuma digestão ácida em sistemas de baixa pressão foi totalmente eficiente, mesmo com a utilização de sistema de bombas de decomposição ou forno de microondas aberto.

O método de digestão utilizando cinzas permitiu a digestão das tintas à base de solvente (amostras líquidas) e teve sua eficiência comprovada para a maioria dos analitos. Porém o tempo empregado é excessivamente demorado, totalizando $9 \mathrm{~h}$.

Os métodos de digestão de tinta à base de solvente, utilizando forno de microondas com sistema fechado, permitiram uma digestão rápida e eficiente das amostras em tempo inferior a $35 \mathrm{~min}$. Os métodos foram comprovados por meio de valores aceitáveis dos testes de recuperação e adição, para a maioria dos analitos. O resíduo avaliado não apresentou os elementos de interesse, comprovando a eficiência do método.

O procedimento usado para a avaliação dos filmes secos que foram submetidos ao envelhecimento acelerado, usando câmara do tipo "Weather-Ometer" apresentou fortes indícios de que a degradação do material facilita a disponibilidade dos analitos para o ambiente.

Os procedimentos analíticos utilizados não confirmaram a disponibilidade dos analitos causada pelo envelhecimento, provavelmente por causa da pequena quantidade de material degradado em relação à massa total da amostra.

A utilização de MEV tornou possivel a verificação da homogeneidade das amostras bem como a uniformidade na aplicação do filme. Verificou-se também que houve mudança na morfologia do polímero que foi submetido ao intemperismo acelerado. 
O método de lixiviação demonstra que ocorre a migração de alguns elementos para as soluções estudadas e que, dos extratores avaliados, a chuva ácida apresentou maior potencial de lixiviação.

O emprego deste método apresentou as seguintes vantagens:

As amostras são colocadas individualmente em sistema fechados, portanto livres de contaminação, aumentando a confiabilidade dos resultados analíticos;

Procedimentos drásticos e trabalhosos de digestão de amostras são evitados e as soluções resultantes não precisam ser filtradas;

As soluções resultantes são menos complexas que as obtidas pelo método de decomposição das amostras por Microondas, facilitando a determinação por métodos espectroscópicos de análise;

$\mathrm{O}$ método proposta mostrou, por exemplo, que ocorreu migração de $\mathrm{Pb}$ para as soluções extratoras, cuja concentração variou de $0,017 \mathrm{mg} \mathrm{L}^{-1}$ a $5,89 \mathrm{mg} \mathrm{L}^{-1}$, para uma área pintada de $57 \mathrm{~mm}^{2}$.

Este novo método apresenta potencialidade para o desenvolvimento de procedimentos de análises de rotina simples e eficientes para a qualificação de tintas disponíveis no mercado por métodos espectroscópicos de análise. Para isso novos estudos serão necessários de modo a otimizar a relação entre tempo de análise e sensibilidade analítica.

Como resultado deste trabalho, métodos adequados para determinação de elementos potencialmente tóxicos em tintas à base de água e de solvente orgânico foram estabelecidas. Estes métodos poderão servir de referência para o desenvolvimento e otimização da nova proposta de procedimento de análise por lixiviação. 


\subsection{Trabalhos futuros}

Como proposta de trabalhos futuros pode-se citar:

- estabelecimento de métodos de análise de rotina para o controle de qualidade das tintas, que poderão ser usados tanto pelas indústrias quanto por órgãos de fiscalização;

- desenvolvimento de método analítico baseada na lixiviação, de modo a obter procedimentos mais rápidos, que possam ser associados a métodos de análise mais sensiveis, tais como ICP MS ou Forno de Grafite. 


\subsection{Referências Bibliográficas}

1. ABNT, NBR 5839, coleta de amostras de tintas e vernizes, 1984.

2. AFSHARI, S., NAGARKAR, V., SUILLANTE, M., R., Quantitative measurement of lead in paint by XRF analysis without manual substrate correction. Appl. Radiat. Isot. V. $48,910-! 2)$, p. 1425-1431, 1997

3. AGAZZI, A.; PIROLA, C. Fundamental, methods and future trends of environmental microwave sample preparation. Microchem. Journal. 67, p. 337341, 2000.

4. AHMED, N. J. S.; ALAM, H. M. Levels and sources of heavy metals in house dust. Journal of Radioanalytical and Nuclear Chemistry; v. 247(1), p. 145-149, 2001.

5. ARRUDA, M. A Z; SANTELLI,R. E. Mecanização no preparo de amostras por microonda: "O estado da arte". Quim. Nova, v. 20(6): p. 638-643, 1997.

6. ASTM D 1014. Test Method for Conducting Exterior Exposure Tests of Paints on Steel, 1995.

7. BAIRD, C., Química Ambiental, Bookman, EUA, 2a ed., 2002.

8. BATISTA, M. A.J., Síntese de poliéster e caracterização de revestimentos poliéster/melamina após degradação em intemperismo acelerado, Dissertação de Mestrado. Apresentada no Departamento de Engenharia de materiais, FAENQUIL, 2004.

9. BIGGS, S.; LUKEY, C. A.; SPINKS, G. M.; YAU, S., An Atomic Force Microscopy Study of Wheathering of Polyester/Melamine Paint Surfaces. Progress in Organic Coatings, v. 42, p. 49-58, 2001. 
10. BOUMANS, P. W. J. Line Coincidence Tables for Inductively Coupled Plasma Atomic Emission Spectrometry. v. 1 e 2, 2a ed., Pergamon Press, 1984.

11.BRAUN, C.V; LINDERN, I.H.V.; KHRISTOFOROVA, N.K.; KACHUR, A.H.; YELPATYEVSKY, V. P.; ELÁTYEVSKAYA, V.P.; SPALINGER, S. M. Environmental Lead Contamination in the Rudnaya Pristan Dalnegorsk Mining and Smelter District, Russian Far East. Environmental Research Section A 88, p. 164-173, 2002.

12. BUENO, M. I.M.S., CASTRO, M. T.P.O, SOUZA, M.A., OLIVEIRA, E.B.S., TEIXEIRA, A.P., X-ray scattering processes and chemometrics for differentiating complex samples using conventional EDXRF equipment. Chemometrics and intelligent laboratory systems, 78, p. 96-102, 2005.

13. BURGUERA, M., BURGUERA, J. L., Microwave-assisted sample decomposition in flow analysis. Anal. Chem. Acta, v. 366, p. 63-80, 1998

14. CARRÉ, M.; EXCOFFIER, S.; MERMET, J.M. A study of the relation between the limit of detection and the limit of quantification in inductively coupled plasma spectrochemistry. Spectrochim. Acta Part B 52, p. 2043-2049,1997.

15. CECHÁK; T.; GERNDT, J.; KOPECKÁ I.; MUSÍLEK, L. X-ray fluorescence in research on Czeh cultural monuments. I Nucl. Instr. And Meth. In Phys. Res. B 213 , p. $735-740,2004$.

16. CETESB, Relatório de Qualidade das Águas Interiores do Estado de São Paulo, São Paulo,1996.

17. CHERRY, D.; LOWRY, L.; VELEZ, L.; COTRELL, C.; KEYES, D. C., Elemental Mercury Poisoning in a Family of Seven, Family \& Community Health, v. 24(4), 18. 2002. 
18. CHIRENJE, T.; MA, L., Q.; CHEN, M.; ZILLIOUX, E., J., Comparison between background concentrations of arsenic in urban and non-urban areas of Florida, Advances in Environmental Research, v. 8, p. 137-146, 2003.

19.DAVIS, Allen P.; BURNS, M. Evaluation of lead concentration in Runoff from painted structures. Wat. Res. Vol.33, no. 13, p. 2949-2958, 1999.

20. EPA / 600/R-04/012, Milestone Inc.'s Direct Mercury Analyzer (DMA)-80, 2004.

21.EPA, http://www.epa.gov/grtlakes/bnsdocs/mercsrce/index.html, data de acesso em 09/11/2005.

22. FAZENDA, J. M. R. Tintas e Vernizes - Ciência e Tecnologia, $2^{a}$ ed., Ed. Abrafati, São Paulo, 1995.

23. GULMINE, J. V;; JANISSEK, P. R.; HEISE, H. M.; AKCELRUD, L., Degradation Profile of Polyethylene After Artificial Accelerated, Weathering. Polymer Degradation and Stability, v.79, p. 385-397, 2003.

24. HALL, G.S.;TINKLENBERG, J. Determination of $T i, \mathrm{Zn}$, and $\mathrm{Pb}$ in lead-based house paints by EDXRF. J. Anal. At. Spectrom., 18, P. 775-778, 2003.

25. HEE, S. Q.; BOYLE, J.R. Simultaneous multielemental analysis of some environmental and biological samples by Inductively Coupled Plasma Atomic Emission Spectrometry. Anal. Chem. v. 60, p.1033-1042, 1988.

26. JABEEN, N, AHMED, S., HASSAN, S.T., ALAM, N. M., Lead and sources of heavy metals in house dust. J. of Radioanalytical and Nuclear Chemistry. V. 247 (1), p. 145-149, 2001.

27. JOHN, V. M. Meio Ambiente-Construção e desenvolvimento sustentável. In: Qualidade na Construção. Sinduscon-SP São Paulo, v. 29 no23, p.34-44. Ano III 2000. 
28. JORDÃO, C.; SILVA A. C.; PEREIRA, J. L. BRUNE. Contaminação por crômio de águas de rios proveniente de curtumes em Minas Gerais. Quim. Nova, Vol. 22, (1), p. $47-52,1999$.

29. KENNETH K. K. LAM AND W. T. CHAN, Novel Laser Sampling Technique for Inductively Coupled Plasma Atomic Emission Spectrometry Journal of Analytical Atomic Spectrometry, January 1997, Vol. 12 (7-12).

30. KINGSTON, H. M; Jassie, L. B. Introduction to Microwave Sample Preparation. Washington: ACS, 1988.

31. KINGSTON, H.M. WALTER, P, J., EPA Method 3052, Microwave Assisted Acid Digestion of Siliceous and Organically Based Matrices. IN: Test Methods for Evaluating Solid Waste, 3rd.ed., 3rdupdate, U.S. Enviromental Protection Agency, Washington, DC, 1995.

32. KORN, M, G,A.; FERREIRA,A. C. F.; COSTA, A. C. S.; NOBREGA, J. A., SILVA, C. R. Companison of decomposition procedures for analyses of titanium dioxide using inductively coupled plasma optical emission spectrometry. Microchem. J. 71, p. $41-48,2002$.

33. KRUG, F. J. Métodos de Decomposição de Amostras. V'Workshop Sobre Preparo de Amostras São Paulo. SP 18 a 22 de outubro de 2004.

34. LAMBOURNE, R. Paint and Surface Coatings - Theory and Practice, ED. Ellis Horwood Limited, Ney York, 1987.

35. LEAL, L. H. M. Fundamentos de Microscopia. Ed UERJ. Rio de Janeiro. 2000.

36. LEE, J. D. Química inorgânica não tão concisa. São Paulo, Ed. Edgard Blücher. p. $298,1996$.

37. LEITE, F. Validação em Análise Química. Ed. Átomo, Campinas, p. 64, 1996. 
38. MAIA. D. R. J.; PAOLI, M. A. D. Embranquecimento do Polipropileno isotático Injetado Contendo $\mathrm{TiO}_{2}$ como pigmento. Polímeros, v.10 n.4, p. 209-217, 2000.

39. MARTIN, J.E; RESPALDIZAB, M.A.; TENORIO, R.G.; BOLIVAR, J.P.; CAMACHOB, J. G.; SILVA, M.F. Anthropogenic contamination of an estuarine system evaluated by PIXE. Nuclear Instruments and Methods in Physics Research B 109/110, p.506-510, 1996.

40. MATUSIEWICZ, H.; STURGEON, R.E.; BERMAN, S.S. Trace Element Analysis of Biological Material Following Pressure Digestion with Nitric Acid - Hydrogen Peroxide and Microwave Heating. Joumal of Analytical Atomic Spectrometry, v.4, p.323-327, 1989

41. MEIER, M.A; GEE, P.; SCHALATTER, J. P. Lead Replacement in Industrial Paints. $6^{\circ}$ Congresso Internacional de Tinta. ABRAFATI, 1999.

42. MICARONI, R., C., C.; BUENO, M., I., M., S.; JARDIN, W., F., Quim. Nova, v. 23 (4) p. $494,2000$.

43. MIELKE, H.W.; POWELL, E.T.; GONZALES, C.R.; MIELKE, P.W. Multiple Metal Contamination from House Paints: Consequences of Power Sanding and Paint Scraping in New Orteans. Environmental Health Perspectives, v. 109 (9), p.973978, 2001.

44. MOORE, J. W.; RAMAMOORTHY, S. Heavy metals in material waters applied monitorinand impact assessment. New York, Springer Verlag, p. 268, 1984.

45. MOREIRA, F. R.; MOREIRA, J.C. A cinética do chumbo no organismo humano e sua importância para a saúde. ciência \& Saúde Coletiva, v. 9(1):167-181, 2004.

46. MOREIRA, F. R.; MOREIRA, J.C. A importância da análise de especiação do chumbo em plasma para a avaliação dos riscos à saúde. Quim. Nova, Vol. 27, No. 2, p.251-260. 2004 
47. NASCIMENTO, O. L. DO; MANSUR, A. A. P.; MANSUR, H. S., Estudo de tintas acrílicas para pintura de piso. XVI Congresso Brasileiro de Engenharia e Ciência dos materiais (CD). Porto Alegre, RS, 2004.

48. NBR 10.004, ABNT - Classificação de Resíduos Sólidos, 1987.

49. NBR 10.005, ABNT, Lixiviação de resíduos, 1987].

50. NBR 10.006, ABNT. Digestão de resíduos, 1987].

51. NBR 3, EB 1813, Tinta de acabamento Epóxi-Vinílica, poliamina- Semibrilhante. Nov, 1987.

52. NBR 5839 - Coleta de amostras de tintas e vernizes, 1984.

53. News Link Environmental, http://www.caprep.com, data de acesso 05/08/05.

54. ORGANIZAÇÃO MUNDIAL DE SAÚDE. Elementos traço na Nutrição e saúde Humanas. Tradução Andréa Favano, São Paulo, Roca, 1998.

55.PAUDYN, A.M.; SMITH, R.G. Determination of elements in paints and paint scrapings by inductively coupled plasma atomic emission spectrometry using microwave assisted digestion. Fresenius J. Anal. Chem. 345 p.695-700, 1993.

56. PEDRO, N., A., R., Determinação de nutrientes minerais em alguns alimentos por ICP AES, Dissertação de Mestrado, USP, 1998.

57. PIMENTA, A., S.; VITAL, B.R. Contaminação de pintores profissionais por metais pesados provenientes de tintas e vernizes. Quím. Nova; 17 (4), p.277-280, 1994.

58. SALDÍVAR, E.; Ibarra, S.; Munguia, Nadia. Book of Abstracts. Seventh Rio Symposiym on Atomic Spectrometry. Santa Catarina, Brazil. p. 96.2002. 
59. SILVA, A.R.;VERONEZI, A.M.; MANTOVANI, R.A.; ZORL, H.E.; RIBEIRO.,C.A.; CRESPI, M. S. Identificação e Quantificação de Resinas, Cargas e Pigmentos em Tintas Látex Branca. Eclet. Quim. v.25. São Paulo. 2000.

60. SUTTON P. M., ATHANASOULIS M., FLESSEL P., GURIGUIS G., HAAN M., SCHLAG R. and Goldman L. R. Lead levels in the household environment of children in three high-risk communities in California. Environmental Research 68, p. $45-57,1995$.

61. TEIXEIRA, V.G.;COUTINHO, F.M.B. Resinas poliméricas para separação e préconcentração de chumbo, Quim. Nova, v. 27(5), p. 754-762, 2004.

62. TEVES, M.L.U., Lixo urbano, contaminação por resíduos de tintas e vernizes. Fundacentro, 2001.

63. The Merck Index, 9a edição, Merck \& CO., Inc., EUA, 1976.

64.TONG, S.T.Y.U; LAMB, K.C.; Home sweet home? A case study of household dust contamination in Hong Kong. The Science of the Total Environment 256, p. 115-123, 2000.

65.TRAVERSO, S. D.; LORETTI, A. P.; DOMINI, M. A. \& DRIEMEIER, D. Lead poisoning cattle in southern Brazil. Arq. Bras. Med. Vet. Zootec., v.56(3), p.418421, 2004.

66. VALET, A. Light Stabilizers of Paint, Ed. Vincentz, Hannover, 1997.

67. VANZ A.; MIRLEAN, N.; BAISCH, P. Avaliação de poluição do ar por chumbo particulado: uma abordagem geoquímica. Quim. Nova,v. 26(1), p.25-29, 2003.

68. WATSON, C.A. Official and Standardized Methods of Analysis 3rd Edition. The Royal Society of Chemistry, p 461, 749. 1994. 
69. WERNSTAHL, K. M. Service Life Prediction of Automotive Coatings, Correlating Infrared Measurements and Gloss Retention. Polymer Degradation and Stability, v. 54, p. $57-65,1996$.

70.WICKS, Z, W.; JONES, F. N.; PAPPAS, S. P. Educational Series -Exterior Durability. Journal of Coatings Technology, v.71(891), p. 31-36, 1999.

71.WONG, A. Toxicologia de tintas em relação ao usuário final. $6^{\circ}$ Congresso internacional de tinta. ABRAFAT, 1999.

72. WONG, K. L., Determination of Trace Amounts of Ceriun in Paint by Inductively Coupled Plasma Atomic Emission Spectrometry, Anal.Chem. 53, p.: 2148-2149, 1981.

73. YABE, M. J. S., Determinação de Metais Pesados em Águas Superficiais por ICP-AES Objetivando Caracterização e Recuperação de Bacias Hidrográficas, Tese de doutorado apresentada ao Instituto de Química da USP, São Paulo (1995).

74. YANG, X. F.; TALLMAN, D. E.; BIERWAGEN, G. P.; CROLL, S. G.; ROHLIK, S. Blistering and degradation of polyurethane coatings under different accelerated weathering tests, v.77, p. 103-109, 2002.

75. YANG, X. F.; VANG, C.; CROLL, S. G.; TALLMAN, D. E.; BIERWAGEN, G. P.; ROHLIK, S. Weathering degradation of a Polyurethane Coating. Polymer Degradation and Stability, v.74, p. 341-351, 2001.

76. YANG, X.F.; LI, J.; CROLL, S. G.; TALLMAN, D. E.; BIERWAGEN, G. P. Degradation of Low Gloss Polyurethane Aircraft Coatings Under UV, and Prohesion Alternating Exposures. Polymer Degradation and, Stability, v.80, p. 5158, 2003. 
77. EDGE, M.; HAYES, M.; MOHAMMADIAN, M.; ALLEN, N. S.; JEWITT, T. S. Aspects of Poly(ethylene terephthalate) Degradation for Archival Life and Environmental Degradation. Polymer Degradation and Stability, v.32, p. 131-153, 1991.

78. NGUYEN, T.; MARTIN, J.; BYRD, E.; EMBREE, N. Relating Laboratory and Outdoor Exposure of Coatings III. Effect of Relative Humidity on MoistureEnchanced Photolysis of Acrylic-Melamine Coatings. Polymer Degradation and Stability, v.77, p. 1-16, 2002.

79. NBR 9944, Tintas - Determinação do teor de pigmentos. Ago, 1987.

30. FUNASA, Nota Técnica $n^{\circ}$ 10/2001, Projeto de Lei $n^{\circ}$ 4509/01, que proíbe a utilização de chumbo na fabricação de tintas de parede, Documento: Processo 25000.053445/2001-11.

31. ABRAFATI, http//www.abrafati.com.br data de acesso 21/10/05. 